\title{
The continued development of reticulated vitreous carbon as a versatile electrode material: structure, properties and applications
}

\author{
F.C. Walsh, ${ }^{\mathrm{a}, \mathrm{b},}$, L.F. Arenas, ${ }^{\mathrm{a}}$ C. Ponce de León, ${ }^{\mathrm{a}}$ G.W. Reade, ${ }^{\mathrm{c}}$ I. Whyte, ${ }^{\mathrm{d}}$ \\ B.G. Mellor ${ }^{\text {b }}$ \\ ${ }^{a}$ Electrochemical Engineering Laboratory, Energy Technology Research Group, Faculty \\ of Engineering and the Environment, University of Southampton SO17 1BJ, UK. \\ ${ }^{\mathrm{b}}$ Materials Engineering Group, Engineering Sciences, Faculty of Engineering and the \\ Environment, University of Southampton SO17 1BJ, UK. \\ ${ }^{\mathrm{c}}$ Ceres Power, Viking House, Foundry Lane, Horsham RH13 5PX, UK. \\ ${ }^{\mathrm{d}}$ Potential Reactions Ltd, Bedford, MK43 8AS, UK. \\ * Author for correspondence; F.C. Walsh; f.c.walsh@soton.ac.uk.
}

\begin{abstract}
The limitations of 2-dimensional electrodes can be overcome by using threedimensional materials having sufficient porosity and active area while offering moderate mass transport rates and a relatively low pressure drop at controlled electrolyte flow rate. In concept, a wide variety of metal, ceramic and composite materials are possible but restrictions are imposed by the need to avoid materials degradation, while maintaining adequate electrical conductivity, sufficient robustness and the possibility of facile scale-up. Despite its fragility, one of the traditional electrode materials used as a porous, 3-dimensional electrode is carbon foam, particularly in the $97 \%$ vol. porous form of reticulated vitreous carbon, RVC. A timeline indicates that the history of this material dates back over 50 years to the mid1960s, when it was primarily used as an uncoated material in small-scale, laboratory electroanalysis. Surface modification and diverse coatings have considerably extended the use of RVC. Recent applications are found in sensors and monitors, electrosynthesis, environmental processing and energy conversion. This review highlights the fundamental structure and summarises the physicochemical properties of RVC. Fluid flow through various porosity grades of the material, their active electrochemical area and rates of mass transport are quantified. The diverse applications of RVC in energy conversion, environmental treatment and electrosynthesis are illustrated by selected examples from the authors' laboratories and others over the last 30 years. Recent research on coated RVC, energy conversion environmental remediation and sensors is highlighted. Critical areas deserving further research and development are proposed.
\end{abstract}

Keywords: area, energy, foam, mass transport, porosity, structure, three-dimensional.

(Approx. 18.600 words, 18 reactions/equations. 4 tables, 20 figures and 160 refs.). 


\section{Highlights}

- The history, manufacture, structure and electrochemistry of RVC are considered.

- Interrelated parameters of active area, mass transport and pressure drop are quantified.

- RVC offers a moderate volumetric electrode area and high volumetric porosity.

- Diverse electrochemical applications of virgin and coated RVC are illustrated.

- Critical areas deserving further research on this electrode material are proposed.

\section{Graphical abstract}

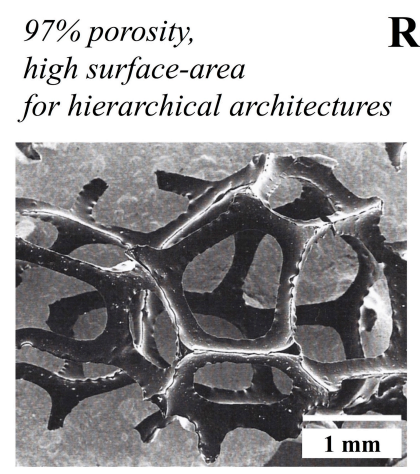

Bare porous structure
Reticulated vitreous carbon (RVC) Applications in sensors,

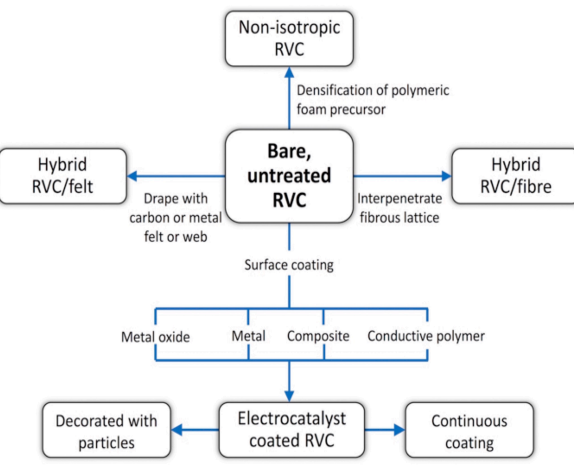

energy storage and environmental remediation

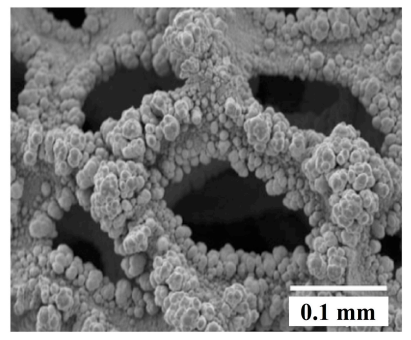

Metal-coated RVC 


\section{Contents}

1. Introduction

2. The manufacture and structure of RVC

2.1 Manufacture and modification

2.2 The structure of RVC

3. Physicochemical characterisation

3.1 Porosity and pressure drop

3.2 Volumetric area and mass transport

3.3 The critical electrolyte flow velocity

3.4 The characteristic length in RVC and comparison with other 3-D electrodes

4. Surface coatings on RVC

4.1 Electrodeposition of metals

4.2 Metal oxide coatings

4.3 Electrically conductive polymer films

4.4 Composite coatings

5. Environmental remediation

5.1 Cathodic metal ion removal

5.2 Oxidation of organics

5.3 Clean electrosynthesis

6 . Energy storage and conversion

6.1 Static batteries

6.2 Redox flow batteries

6.3 Fuel cells

6.4 Supercapacitors

7. Electrode kinetics, sensing and monitoring

7.1 Traditional electroanalysis

7.2 Recent sensors

8. Modified RVC electrodes

9. Summary

10. Important areas for further research 


\section{Symbols}

a Microelectrode radius $\quad \mathrm{cm}$

$A \quad$ Active electrode area $\quad \mathrm{cm}$

$A_{e} \quad$ Electrode area per unit electrode volume $\quad \mathrm{cm}^{-1}$

$A_{s} \quad$ Nominal area of trigonal strut $\mathrm{cm}^{2}$

$A_{s v} \quad$ Electrode area per unit solid volume $\quad \mathrm{cm}^{-1}$

$A_{X S} \quad$ Cross-sectional area of porous solid for electrolyte flow $\quad \mathrm{cm}^{2}$

$B \quad$ Breadth of electrode and channel $\mathrm{cm}$

d A characteristic length $\quad \mathrm{cm}$

$d_{e} \quad$ Equivalent (hydraulic) diameter of electrode $\mathrm{cm}$

$\begin{array}{lll}d_{p} & \text { Pore diameter } \mathrm{cm}\end{array}$

$d_{s} \quad$ Strut thickness $\quad \mathrm{cm}$

$D$ Diffusion coefficient of electroactive species $\mathrm{cm}^{2} \mathrm{~s}^{-1}$

$F \quad$ Faraday constant $\quad \mathrm{C} \mathrm{mol}^{-1}$

$k_{m} \quad$ Mass transport coefficient $\mathrm{cm} \mathrm{s}^{-1}$

$I_{L} \quad$ Limiting current under convective-diffusion $\quad \mathrm{A}$

$l_{p}$ Pore length $\mathrm{cm}$

$l_{s}$ Strut length $\mathrm{cm}$

$L \quad$ Length of porous electrode $\quad \mathrm{cm}$

$M \quad$ A constant in equation (7) dimensionless

$N \quad$ A constant in equation (7) dimensionless

$p \quad$ Pressure $\quad \mathrm{Pa}$

$Q \quad$ Volumetric flow rate of electrolyte $\mathrm{cm}^{3} \mathrm{~s}^{-1}$

$S \quad$ Separation between electrode and membrane $\mathrm{m}$

$v \quad$ Linear electrolyte flow velocity past the RVC surface $\mathrm{cm} \mathrm{s}^{-1}$

$v_{\text {crit }}$ Critical flow velocity $\mathrm{cm} \mathrm{s}^{-1}$

$V_{e} \quad$ Volume of RVC electrode $\mathrm{cm}^{3}$

$X_{a} \quad$ Fractional conversion of reactant dimensionless

$z \quad$ Number of electrons in the reaction dimensionless

\section{Greek}

$\varepsilon \quad$ Volumetric porosity

$\sigma \quad$ Dispersion ratio, $\sigma=d_{p} / d_{s}$

$\kappa \quad$ Permeability of the porous medium

$\gamma \quad$ Pore aspect ratio, $\gamma=1 / d_{p}$

$v \quad$ Kinematic viscosity of electrolyte

$\rho \quad$ Fluid density of electrolyte

$\mu \quad$ Dynamic viscosity of electrolyte

dimensionless

dimensionless

$\mathrm{cm}^{2}$

dimensionless

$\mathrm{cm}^{2} \mathrm{~s}^{-1}$

$\mathrm{g} \mathrm{cm}^{-3}$

$\mathrm{g} \mathrm{cm}^{-1} \mathrm{~s}^{-1}$

\section{Dimensionless groups}

$R e \quad$ Reynolds number, $R e=v d / v$

dimensionless 
Sh Sherwood number, $S h=k_{m} d / D$

dimensionless

Sc Schmidt number, $S c=v / D$

dimensionless

\section{Abbreviations}

BDD boron-doped diamond

CFU colony-forming units

CNFs carbon nanofibres

COD chemical oxygen demand

CT computed tomography

EIS electrochemical impedance spectroscopy

EF electro-Fenton

EtAQ 2-ethyl-9,10-anthraquinone

FTIR Fourier transform infrared

GCMS gas chromatography mass spectrometry

ITO indium-doped tin oxide

MAA methacrylic acid

MFC microbial fuel cell

ppi pores per linear inch

PEDOT poly(3,4-ethylenedioxythiophene) polystyrene sulfonate

PPy polypyrrole

PZQ praziquantel

RCE rotating cylinder electrode

RFB redox flow battery

RVC reticulated vitreous carbon

SEM scanning electron microscopy

TCF trichlorfon

TiNT titanate nanotubes

TOC total organic carbon 


\section{Introduction}

The restricted active surface area and low mass transport at two-dimensional, flow-by electrodes severely limits their space-time yield in electrochemical conversion processes. The implementation of three-dimensional electrodes can address these issues by providing high active surface area and high mass transport of the electroactive species [1]. Various porous, three-dimensional materials in a flow-though configuration are used for this purpose, including packed beds, stacked meshes, foams and felts [2]. Metal, carbon-based, and ceramic-coated materials are available.

Reticulated vitreous carbon (RVC) is a solid foam constituted by open cells of vitreous carbon, a material with high electrical and thermal conductivity. The adjective reticulated means "constructed, arranged or marked like a net or part of a network". $\mathrm{RVC}$ is has a remarkably high surface area and high void volume, which translate into low resistance to electrolyte fluid flow. The rigid structure of RVC has low density and a low thermal expansion coefficient along with a relatively wide chemical and thermal stability, except in strongly oxidizing media. These characteristics have encouraged applications in diverse areas such as fuel filtration or chemical catalyst supports as well as in fundamental and applied electrochemistry.

$\mathrm{RVC}$ is comprised of rigid open-cells, i.e., pores which are spatially connected within skeletal, strut boundaries to form a network; the pores form a continuous phase [4]. Three-dimensional electrode materials such as RVC allow operating flow cells at high current densities while producing low pressure drop. Moreover, the material can be coated with catalysts or hold active materials within its pores. RVC is brittle and needs 
mechanical support, especially in filter-press flow cells where the compression of the electrode material has to be carefully controlled. As with other porous materials, the potential and current distribution through the electrode has to be considered due to the restricted conductivity of this very high (typically ca. 97\%) porosity material, corresponding to a relative density of only $3 \%$.

Its importance as a 3-D electrode, together with other carbon materials, has been reviewed [2] and manufacturer's data are available [3]. An early electroanalytical review indicating the promise of RVC was provided by Wang in 1981 [5]. Earlier information on RVC and its electrochemical characteristics were provided in a 2004 review [6]. Recently, the properties and applications of RVC were considered for hydrogen and oxygen evolution [7]. Recent advances in the characterization of solids via tomography [8], 3-D printing of polymeric precursors [9], and modelling of porous electrodes [10], help justify renewed attention to the structural properties of RVC.

The time-line in Figure 1 shows some of the highlights from solid foam structure and RVC electrode studies over more than 30 years. Conceptually and mathematically, the structure of RVC may be considered as a homogeneous, three-dimensional network of pores bounded by a skeletal carbon framework interrupted by a high pore density. In order to appreciate the unusual nature of RVC, it is important to understand the manufacture, structure and property relationships (Figure 2), which continue to result in electrochemical and other applications. RVC is fragile; the material can be easily cut to size and shaped by, e.g., a sharp steel blade or a tensioned steel wire but suitable eye protection should be used to safeguard against stray barbs. 


\section{The manufacture and structure of RVC}

\subsection{Manufacture and modification}

Historically, the first patent for the manufacture of RVC in 1969 [13] followed a patent for glassy carbon production which was granted in 1963 [12]. RVC is produced by heating a polymerized resin precursor containing foaming agents in an inert atmosphere at $120^{\circ} \mathrm{C}$, followed by a second high temperature $\left(700-1100{ }^{\circ} \mathrm{C}\right)$ treatment that carbonizes and vitrifies the precursor foam. Polyurethane and phenolic resins are the preferred starting materials but alternatives include furfuryl alcohol (2furanmethanol) and epoxy resins. RVC can also be prepared from high molar mass thermoplastic hydrocarbons [30]. The properties of RVC are determined by a number of factors, including: resin composition, solvent, solution viscosity, curing agents, precursor foam pore size and treatment temperature. Throughout these stages, the precursor foam suffers a linear shrinkage of $c a .30 \%$.

Some studies have considered RVC manufacture from alternative precursors. For example, a polyurethane foam-clay foam precursor, infused with furfuryl alcohol, then carbonised at $900{ }^{\circ} \mathrm{C}$ for $2 \mathrm{~h}$ in an argon atmosphere has been reported [31]. X-ray diffraction, scanning electron microscopy and Raman spectroscopy techniques were applied to characterise the resultant RVC. It was claimed that addition of clay permitted control of the cell size of carbon foams. The foams from clay precursors had a higher content of open cells allowing furfuryl alcohol to diffuse uniformly, producing high-density foams of higher electrical conductivity. 
While the majority of studies have utilised isotropic RVC, there is the possibility of tailoring its densification (typically by selective resin impregnation followed by heating) to modify its isotropy for specialised uses [32]. RVC can be readily coated by a range of materials to increase its diversity, as illustrated in section 4 .

\subsection{The structure of RVC}

From a fundamental viewpoint, the structure of RVC is close to classical mathematical porosity problems of packing pores into a given space, which were considered as early as 1887 in the Kelvin conjecture [11]. Kelvin considered how space could be partitioned into cells of equal volume with the least area of surface between them to find the most efficient bubble foam. He proposed a foam based on the bitruncated cubic honeycomb, known as the Kelvin structure. This is a convex uniform honeycomb formed by the truncated octahedron, which is a 14-faced space-filling polyhedron (a tetradecahedron), with 6 square faces and 8 hexagonal faces. Kelvin proposed that a 14-sided truncated octahedron having a very slight curvature of the hexagonal faces, i.e., a foam of bi-truncated cubic honeycomb is the most efficient one. The Kelvin conjecture was widely accepted and no counter-example was known for more than 100 years, until it was disproved in 1994 by the Weaire-Phelan structure [20]. The latter is a complex 3-dimensional structure representing an idealised foam of isometric pores found from a mathematical computer simulations of a solid foam. Such complex structures have been recently produced by rapid prototyping techniques and their flow properties have been studied [33]. 
The structure of RVC may be considered as an interpenetrating network of interconnected pores bounded by skeletal vitreous carbon struts. The material has a free void volume (volumetric porosity) of between $90 \%$ and $97 \%$, depending on the ppi (pores per linear inch) porosity grade and an approximate volumetric surface area of $65 \mathrm{~cm}^{-1}$, for the 100 ppi grade [3]. The material does not burn after heating to bright incandescence in air followed by removal of the heat source. Heating above $315^{\circ} \mathrm{C}$ in air, however, results in significant oxidation, producing a material showing enhanced chemisorption. RVC is highly resistant to intercalation by materials that disintegrate graphite and is inert to a wide range of very reactive acids, bases, and organic solvents. RVC can be obtained from suppliers of electrode materials.

Figure 3 presents SEM images of 10, 30, 60 and 100 ppi grade samples of RVC, showing that several porosity grades with a pore size in the range 0.1 to $1 \mathrm{~mm}$ have a similar structure. Solid foams are classically characterised by geometric features of the pores, such as a) pore "diameter", $\left.d_{p}, \mathrm{~b}\right)$ pore length, $\left.l_{p}, \mathrm{c}\right)$ pore aspect ratio, $\gamma=1 / d_{p}, \mathrm{~d}$ ) pore orientation and e) pore volume fraction, i.e., volumetric porosity, $\varepsilon$. Four variables need to be taken into account to characterise the structure of a particular sample of RVC foam: a) the number of pores per linear inch (ppi), b) the strut length, $\left.l_{s}, \mathrm{c}\right)$ the strut thickness, $d_{s}$ and d) the surface area of the trigonal strut, $A_{s}$.

The honeycomb skeletal structure of carbon shown in Figure 4 for 10, 30, 60 and 100 ppi samples is formed by strands of carbon or struts. These strands unite at a so-called trigonal strut, providing a tetrahedral body that gives rigidity to the RVC. An advantage of this open structure, in contrast to other carbon foams, is that flow 
permeability is high and thus a flowing aqueous electrolyte experiences a relatively low pressure drop. For instance, from 0.75 (10 ppi) to 15 mbar (100 ppi) at a mean linear flow velocity of $400 \mathrm{~cm} \mathrm{~s}^{-1}[6]$.

To characterise the structure of RVC samples, the lengths and widths of the carbon struts have been measured [35]. The area of the trigonal struts has been determined for all porosity grades [6]. The strut length was measured from the centre of the limiting trigonal struts (Figure 4), where the centre of the trigonal struts was taken at the centre of the estimated point of intersection of the three component struts of the trigonal strut. Similarly, strut thickness measurements have been taken of a carbon strut half-way between two trigonal struts. The trigonal strut area was measured by using an inscribed circle to approximate it (Figure 5a). The area of this circle was used as the area of the trigonal strut [34]. The characteristic trigonal strut in RVC results from the fact that this shape leads to the minimisation of surface free energy during formation of the foam from the initial colloidal emulsion. Figures 5b) and 5c) show images indicating the length and thickness of the strut and the cell size distribution in the RVC, respectively.

Figure 6 shows an SEM micrograph of two neighbouring pores, which are interconnected, sharing a common boundary [36]. The brittle nature of RVC leads to a high number of broken struts at the sample edges, which further complicates dimensional measurements. Individual cell dimensions were preferably taken from unbroken cells, which particularly impact the number of cells available for analysing the low porosity grade samples. The struts in a sample of RVC can vary considerably 
in length and width, depending on the porosity grade. The accuracy of any measurement is hampered by the need to define clearly where the transition from trigonal to single strut takes place. In high porosity (ppi) grade RVC, the skeletal strands in its structure become smaller and thinner.

Average measurements from all RVC samples are summarised in Table 1 and illustrate that data collection via the SEM provide useful data to characterise the RVC structure. Measuring strut length and thickness is straightforward as illustrated in Figure 5. The window area is equivalent to pore size in such open pore foams and was calculated from the results for cell length and size in the line direction and perpendicular to the line direction, as shown in Figure 5c). These two lengths were used to achieve an ellipsoidal area, which was taken as the approximate window area. As Table 1 shows, the higher porosity grades of RVC are very isotropic. The structure of RVC involves a pore network and two adjoining pores are shown in the manner of fused alveoli in the SEM micrograph of Figure 6. The distribution of pore sizes in RVC has been established by analysis of multiple SEM images, as shown for 10 ppi and 30 ppi porosity grades in Figure 7 [36]. The data show a moderately wide distribution of pore size about the expected maxima of approximately $1 \mathrm{~mm}$ and 1.8 $\mathrm{mm}$, the higher grade showing a narrower profile.

The length and area characteristic dimensions in the RVC structure also decrease with smaller pore size, as seen in Figure 8a) and 8b), respectively. Geometrical measurements of four porosity grades of RVC are summarised in Table 1. One of the most important characteristics is the electrode area per unit electrode volume (or 
"volumetric area"), $A_{e}$, which increases linearly with the RVC grade, leading to a maximum of $c a .65 \mathrm{~cm}^{2} \mathrm{~cm}^{-3}$ for the 100 ppi porosity grade. Figures 9a) to 9c) clearly show a geometric relationship between volumetric area, pore diameter and strut length. Such results provide important structural information, based on simple image measurements such as determining the average strut length, $l_{s}$. The decrease of strut length in higher porosity grades is shown in Figure 9d). The dispersion ratio is defined as the ratio of pore diameter to strut thickness:

$$
\sigma=d_{p} / d_{s}
$$

Progress with instrumentation and software for structural analysis of solids has facilitated a movement away from pixels and 2-D representations to voxels and 3-D appreciation of structure using techniques, such as X-ray computed tomography in concert with software for digitised image manipulation, despite the inherently data rich nature of this approach [37]. Moreover, mathematical models are available for the estimation of the thermal [38] and electrical [39] conductivity of these structures.

Surface defects on the RVC strut surface, such as ripples can often be traced to the manufacturing process and have been considered in detail elsewhere [40]. The degree of graphitisation of RVC can be characterised, in comparison to other carbon materials, by Raman spectroscopy and X-ray diffraction. For example, Baldan et al. studied RVC carbonized at different temperatures [41]. The crystallite size was determined and the results from Raman spectroscopy contrasted in terms of the implemented formulae. It was highlighted that heat treatment reduced the presence of 
structural defects and that X-ray diffraction is more accurate for the characterization of crystallite size in such materials.

\section{Physicochemical characterisation}

\subsection{Porosity and pressure drop}

The simplified case of single phase, incompressible liquid flow through a homogeneous porous solid is considered as is common with aqueous electrolytes. $\mathrm{RVC}$ is a highly porous solid foam experiencing a relatively low pressure drop, $\Delta p$, across an electrode when a steady volumetric flow rate of electrolyte, $Q$, passes uniformly through it, with a mean linear velocity, $v$, past the solid electrode surface. The pressure drop over the porous electrode is important since it directly affects the pump size and electrolyte circulation power requirements as well as the type and degree of sealing needed in the electrochemical cell. At relatively low flow rates, the flow regime is laminar and a linear transport law, the empirical Darcy's law expression [42], may be used to relate $\Delta p$ over a uniform, porous medium of length $L$ to the volumetric flow rate through it, $Q$ :

$$
Q=-\kappa A_{X S} \Delta p / L
$$

where $\kappa$ is the permeability of the medium having a cross-sectional area $A_{X S}$. At higher flow rates, the incidence of turbulent flow makes the empirical Ergun equation more appropriate, as indicated in section 3.2.

\subsection{Volumetric area and mass transport}


The large surface area and high porosity of the RVC material has attracted great interest as high rates of conversion per unit volume can be achieved. Nevertheless, an electrochemical cell for RVC electrodes must consider current and potential distribution and minimization of internal resistance as well as developing high rates of mass transport of electroactive species to the electrode surface [43]. The electrode potential can be close to constant and the current distribution uniform over the electrode surface in low thickness material. In order to reduce the effects of parasitic reactions, attention should be given to the degree of reactant conversion and allowable potential drop, both being well-treated in the literature [44-46]. Assuming a mass transport controlled reaction, the global performance of a flow cell can be expressed as the product of average mass transport coefficient, $k_{m}$, and volumetric electrode area, $A_{e}$ [2]:

$$
k_{m} A_{e}=I_{L} / V_{e} z F_{C}
$$

where $I_{L}$ is the limiting current, $z$ the number of electrons, $F$ the Faraday constant, $A_{e}$ the volumetric electrode area, $V_{e}$ the electrode volume and $c$ the bulk concentration of electroactive species.

One of the simplest methods for determining $k_{m} A_{e}$ is direct estimation of the limiting current, $I_{L}$ from linear sweep voltammetry of cupric ion removal on RVC from $1 \mathrm{mmol}$ $\mathrm{dm}^{-3} \mathrm{Cu}^{2+}$ ions in $\mathrm{pH} 2$ sulphate solution at $298 \mathrm{~K}$ under controlled flow conditions. $I_{L}$ values are shown as a function of $\mathrm{Cu}^{2+}$ ion concentration in Figure 10a). Under controlled flow conditions, the mass transport environment can be described by 
dimensionless numbers $[43,44]$. For an electrolyte of known viscosity, composition and temperature, the product of the mass transport coefficient, $k_{m}$, and the volumetric electrode area, $A_{e}$, can be expressed by an empirical power law:

$$
k_{m} A_{e}=a v^{b}
$$

where $v$ is the electrolyte velocity; $a$ and $b$ are empirical constants that depend on electrode shape and type of flow. The product $k_{m} A_{e}$ can be found from conversion data using an RVC flow cell. An example is the work by Whyte et al. [35] on cupric ion

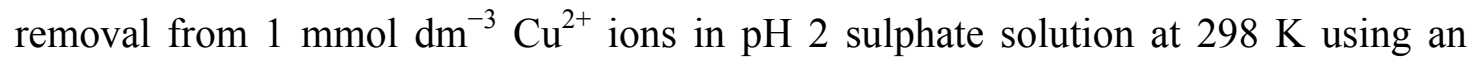
RVC cathode in a divided, rectangular, flow-by cell in the batch recycle mode to a $2500 \mathrm{~cm}^{3}$ reservoir. Under potentiostatic control of the cathode such that complete mass transport control of copper deposition occurred, the concentration of cupric ions, $c_{(t)}$, in a reservoir of volume $V_{R}$ could be related to its initial value, $c_{(0)}$, via a simple first order expression:

$$
c_{(t)}=c_{(0)} \exp \left[-k_{m} A_{e}\left(V_{e} / V_{R}\right) t\right]
$$

or in linearised form:

$$
\ln \left[c_{(t)} / c_{(0)}\right]=-k_{m} A_{e}\left(V_{e} / V_{R}\right) t
$$

Figure 10b) shows a plot of $k_{m} A_{e}$ as a function of mean linear electrolyte velocity, obtained from semilogarithmic plots of $c_{(t)} / c_{(0)} v s$. time for four porosity grades of 
RVC, allowing $k_{m} A_{e}$ to be found from the linear slopes using equation (6). The $k_{m} A_{e}$ values for RVC are seen to: a) be comparable to, but slightly lower than, those for reticulated nickel and b) increase with porosity grade, the 100 ppi material having the highest values.

The product $k_{m} A_{e}$ can also be estimated from pressure drop measurements and application of the Ergun equation, which relates pressure drop per unit length of the RVC electrode, $\Delta p / L$, to mean linear electrolyte velocity, $v$ :

$$
\Delta p / L v=M v+N
$$

where $M$ and $N$ are empirical constants [45,47]. Linear plots of $\Delta p / L v$ as a function of $v$ for four porosity grades of RVC in an electrolyte containing $1 \mathrm{mmol} \mathrm{dm}{ }^{-3} \mathrm{Cu}^{2+}$ ions in $\mathrm{pH} 2$ sulphate solution at $298 \mathrm{~K}$ (Figure 10c), allow the constants $M$ and $N$ to be found from the slope and intercept on the $\Delta p / L v$ axis, facilitating the characterisation of RVC porosity.

The volumetric electrode area, $A_{e}$, is related to the electrode area per unit solid volume, $A_{s v}$, and electrode porosity, $\varepsilon$, by:

$$
A_{e}=A_{s v}(1-\varepsilon)
$$

The dynamic viscosity of the electrolyte is the product of the kinematic viscosity and the fluid density: 


$$
\mu=v \rho
$$

The parameters $e, A_{e}$ and $\Delta p / l$ are useful in comparing the area and performance of RVC with other porous, 3-dimensional electrode materials.

\subsection{The critical electrolyte flow velocity}

For high reactant conversion in an RVC flow by cell, the radial diffusion time, $r^{2} / 2 D$, should be much shorter than the electrolyte residence time in the reactor. It is useful to define a dimensionless parameter, $\phi$ :

$$
\phi=2 v / 4 D L A_{e}^{2}
$$

At the critical linear velocity, $v_{\text {crit }}$, pore diffusion is equal to residence time and equation (10) becomes:

$$
A_{e}=\left(2 \varepsilon v_{c r i t} / D L\right)^{1 / 2}
$$

Figure 11 shows a log-log plot of the fractional conversion of reactant $\left(1-c_{(t)} / c_{(0)}\right), X_{a}$, against $v$, which allows the critical velocity to be estimated from extrapolation of the linear regions on the $\left(1-c_{(t)} / c_{(0)}\right)$ axis to a fractional conversion of $100 \%$ [35]. Equation (11) allows the $A_{e}$ values of the 10,30,60 and 100 ppi grades to be estimated as $13 \mathrm{~cm}^{-1}, 25 \mathrm{~cm}^{-1}, 45 \mathrm{~cm}^{-1}$ and $64 \mathrm{~cm}^{-1}$, respectively. 


\subsection{The characteristic length in RVC and comparison with other 3-D electrodes}

The characteristic length in RVC can be pore, channel or particle based. For example, it can be based on pore diameter, $d_{p}$, which is sometimes referred to as the equivalent diameter of a rectangular flow channel [2]:

$$
d_{e}=2 B S /(B+S)
$$

where $B$ is the breadth of the flow channel, which is the same as the width of the electrode and $S$ is the separation between the electrode and the membrane in a flow-by configuration.

This characteristic length can be used in the empirical correlation of Reynolds, Sherwood and Schmidt numbers to describe mass transport in terms of the porous electrode, flow conditions and transport properties of the electrolyte $[1,43,44]$ :

$$
S h=a R e^{b} S c^{c}
$$

In order to place RVC in perspective, its volumetric porosity and volumetric area are given alongside other porous, 3-dimensional electrode materials in Table 2. Several trends are apparent: a) the open-pore foams, including RVC all have a volumetric porosity of at least $97 \%, b)$ the porosity of foams is much higher than metal meshes, c) the latter can have superior volumetric area and d) the volumetric area of electrodes increases for higher porosity grades, e.g., for RVC, the values range from $8.5 \mathrm{~cm}^{-1}(10$ ppi grade) to $66 \mathrm{~cm}^{-1}$ (100 ppi grade). 
One of the features of RVC electrodes is versatility (Figure 12). The core material may be modified to be non-isotropic by densification or a second fibrous network may be interposed to produce a hybrid foam/fibre structure. The surface of the material can be modified by many different electrocatalysts, either as continuous films or as particulate decorations.

\section{Surface coatings on RVC}

\subsection{Electrodeposition of metals}

Figure 13 shows a segmented RVC cathode Hull cell used to study copper deposition from dilute metal solutions, in this case $0.050 \mathrm{~mol} \mathrm{dm}{ }^{-3} \mathrm{Cu}^{2+}$ in $0.5 \mathrm{~mol} \mathrm{dm}{ }^{-3} \mathrm{Na}_{2} \mathrm{SO}_{4}$ at $\mathrm{pH} 2$ [51]. The morphology of the metallic deposits as a function of current density on the RVC can be studied in this way. Figure 14 shows SEM microscopy images of copper coating on RVC. Figure 14a) shows that no copper nucleation takes place farthest from the anode, while closest to the anode the deposits are dendritic, as shown in Figure 14f). Copper nucleation on an electrode at $10 \mathrm{~mA} \mathrm{~cm}{ }^{-2}$ and smooth copper deposition at $20 \mathrm{~mA} \mathrm{~cm}{ }^{-2}$ can be seen in Figure 14b) and Figure 14c), respectively. Copper is deposited as localized nodules at $70 \mathrm{~mA} \mathrm{~cm}^{-2}$ and "cauliflower" structures at $80 \mathrm{~mA} \mathrm{~cm}{ }^{-2}$ in Figure 14d) and Figure 14e), respectively. As expected, current density drives the mechanism of deposition and its careful control, along with deposition time, can be exploited to produce tailored metalized RVC.

RVC has been used as a matrix for the electrodeposition of noble metals and alloys such as $\mathrm{Pd}, \mathrm{Pd}-\mathrm{Rh}$ and $\mathrm{Pt}-\mathrm{Rh}$ [52]. The electrode surface areas were determined by 
hydrogen and carbon dioxide absorption as a function of applied potential and the electrochemical behaviour studied with cyclic voltammetry. No significant differences were found in the absorption of carbon dioxide on the Pt-Rh alloys deposited on RVC and Au wires. This implies fully coated RVCs, which show higher electrocatalytic activity and corrosion resistance.

A flow-through cell has been used to study the nucleation of gold particles as a function of time to decorate the RVC electrodes with surfaces of $1.0 \mathrm{~cm}^{2}$ and $750 \mathrm{~cm}^{2}$ [53]. The deposition process at a given applied potential was dependent on the relatively high ohmic drop through the porous structure. On high surface area RVC, the density of gold nucleation sites was 30\% lower, but larger particles were produced. The electrochemical cell $C R$ time constant was found to be a way to control surface coverage and particle size.

Pt-loaded 60 ppi RVC electrodes have been operated under flooded and flow-through electrolyte conditions for ozone generation in sulfuric acid solutions [54]. The maximum achieved current efficiency was $2.2 \%$, resulting in an energy consumption of 3.0 $\mathrm{W} \mathrm{h} \mathrm{kg}^{-1}$. A higher concentration of sulfuric acid increased the ozone generation rate, while the electrolyte flow rate had little effect on the efficiency of the process. The Pt-loaded electrodes showed susceptibility to catalyst loss, as shown in the SEM images of the electrode surfaces before and after electrolysis (Figure 15). More appropriate Pt deposition conditions could have been used to produce more compact morphologies and improved coverage of the RVC surface. 


\subsection{Metal oxide coatings}

Metal oxide coatings have proved to be important as electrocatalysts for batteries (section 6), solar cells and electrosynthesis (section 5.3). For example, Tissot and Fragnière coated 30 ppi RVC with $\mathrm{PbO}_{2}$ and used them as anodes for the continuous oxidation of cyanide in alkaline conditions [55]. The electrodes showed good stability over $120 \mathrm{~h}$ of operation and the oxidation occurred with an efficiency of approximately $50 \%$. The authors also provided an estimation of the mass transport coefficient at the RVC electrodes under different electrolyte flow rates. Czerwinski and Zelazowska also studied the electrochemical performance of $\mathrm{PbO}_{2}$ deposited on RVC and Pt-loaded RVC in sodium hydroxide, sodium borate and sulfuric acid solutions [56]. An important finding was that coated RVC electrodes can show a comparable behaviour to that of similarly coated metal electrodes. The lead dioxide coating was more irreversible in borate solutions, while the presence of $\mathrm{Pt}$ on the RVC surface significantly affected the deposition mechanism in all the media studied. The effects of oxygen and hydrogen evolution at $\mathrm{Pt}$, however, were not considered.

The electrochemical behaviour of $\mathrm{MnO}_{2}$ deposited on RVC by cyclic voltammetry in sulfuric acid has been investigated in detail [57]. The $\mathrm{MnO}_{2}$ films were produced by anodic oxidation of $\mathrm{Mn}^{2+}$ ions and compact uniform coatings were produced at higher electrolyte stirring rates. The authors claimed that restricted mass transport to the interior of the pores resulted in a simultaneous chemical deposition mechanism that reduced the stability of the coatings. Coating of the RVC in a flow-by configuration, rather than by poorly controlled electrolyte stirring, could avoid these effects. 20 ppi 
grade RVC was suggested as a current collector or cathodic mass holder in zincmanganese dioxide batteries.

RVC coated with $\mathrm{TiO}_{2}$ and $\mathrm{CuO} / \mathrm{TiO}_{2} / \mathrm{Al}_{2} \mathrm{O}_{3}$ catalysts via electrophoresis has been applied to the degradation of paracetamol in the presence of hydrogen peroxide [58]. It was found that the 100 ppi RVC anodes coated with $\mathrm{CuO} / \mathrm{TiO}_{2} / \mathrm{Al}_{2} \mathrm{O}_{3}$ allowed removal of $90 \%$ of the drug in ca. $2 \mathrm{~h}$, in contrast to the ca. $4 \mathrm{~h}$ required using a $\mathrm{TiO}_{2}$-coated RVC. The application of UV light to induce a photoelectrochemical reaction resulted in $98 \%$ degradation of paracetamol in only $1 \mathrm{~h}$. Reaction intermediates, such as benzoquinone and carboxylic acids, were detected by using UV spectroscopy and apparently reduced the reaction rate of the degradation process.

A patent describes RVC coated with tin-doped indium oxide (ITO) nanoparticles, and possible additional catalysts, including many combinations of doped tin oxide, antimony oxide, gallium oxide, indium oxide, zinc oxide, copper oxide and aluminum oxide [59]. The resulting hybrid electrodes prepared from suspensions can provide a versatile platform for a variety of applications in analysis and electrocatalysis, such as water oxidation and oxidation of organics by surface-bound transition metal catalysts [60].

\subsection{Electrically conductive polymer films}

The deposition of conductive polymers on RVC electrode has also received consideration. This is the case of polyaniline films produced by chemical and electrochemical methods. Low-stability polyaniline/poly(p-styrenesulfonic acid) films 
were first prepared from aqueous solutions followed by thermal treatment [61]. Thicker electrodeposited polyaniline coatings have been studied by cyclic voltammetry and electrochemical impedance spectroscopy [62], revealing that the thickness of the RVC reduced charge transfer resistance, particularly when the polyaniline was electrodeposited. Analysis of the films by SEM, suggested that the potential distribution on the RVC in various morphologies resulted in different polyaniline oxidation rates.

Polypyrrole films on RVC have been considered for controlled drug release. For example, the antischistosomiasis compounds, praziquantel and trichlorfon, have been co-deposited into polypyrrole films on RVC using electrochemical methods [63]. Trichlorfon could be released from the films facilitating further development of in-vivo drug delivery applications; at $-400 \mathrm{mV} v s$. SCE, $6.43 \mu \mathrm{mol}$ could be released after $1 \mathrm{~h}$. In another study, heparin-doped polypyrrole RVC electrodes were developed for the separation of heparin [64]. Thrombin was successfully absorbed on the electrodes at a potential of $-0.3 \mathrm{~V} v s . \mathrm{Ag} / \mathrm{AgCl}$ but the application of a positive potential did not yield a significant release of the protein. The use of a medium of high $\mathrm{NaCl}$ content $(4 \mathrm{~mol}$ $\mathrm{dm}^{-3}$ ) could be used for this purpose.

Polypyrrole deposited on RVC has been studied as a microbial fuel cell electrode by Korean workers [65]. The authors claimed a power enhancement with a maximum power density of $1.2 \mathrm{~mW} \mathrm{~cm}^{-3}$. Polythiophenes such as poly(3,4ethylenedioxythiophene) polystyrene sulfonate (PEDOT) have attracted much interest as stable, electronically conducting polymers for electronics and electrochemical 
sensor applications. A recent Wollongong University $\mathrm{PhD}$ thesis has extensively examined PEDOT electrodeposited on RVC to produce high surface area, flowthrough electrode structures [66]. In particular, such composite structures were shown to be promising for capacitive deionisation.

\subsection{Composite coatings}

A range of polymer-ceramic and ceramic-metal composite coatings have been deposited on RVC using vapour deposition, sol-gel, electrophoretic and electrodeposition techniques. For instance, high surface area electrodes consisting of thin layers of nanostructured, $\mathrm{N}$-doped indium tin oxide (nanoITO) on RVC have been reported [60]. These highly stable electrodes were produced by binding phosphonate derivatives of a rutile catalyst, giving a $\mathrm{RVC} /$ nanoITO- $\mathrm{Ru}^{\mathrm{II}}-\mathrm{OH}_{2}{ }^{2+}$ coating. The oxidation of benzyl alcohol to benzaldehyde was performed with $75 \%$ current efficiency. As mentioned in section 4.2, a patent application includes composite materials containing nanoparticles of conductive, transparent metal oxide catalysts, such as tin-doped indium oxide (ITO) on RVC [59].

Polyaniline/palladium composites can be deposited on RVC electrochemically, and show interesting behaviour for hydrogen adsorption [67]. The distribution of the $5 \mathrm{~nm}$ palladium crystals depended heavily on the concentration of polyaniline and on the mode of deposition. A two-step deposition resulted in a better distribution of the crystals. As expected, these composites had a lower hydrogen/palladium ratio than palladium/RVC electrodes. 
The enhancement of an RVC structure by the introduction of a fibrous web provides an improved support for many electrocatalysts to form a composite electrode surface. Such webs may be introduced by microwave treatments of precursor-coated RVC surfaces [68], metallic nanoparticles being one obvious electrocatalyst. Ion-doped polymer composite films on RVC have been studied for battery applications, as illustrated in section 6.1.

\section{Environmental remediation}

Table 3 provides a profile of environmental remediation studies involving RVC. Contaminants have ranged from single metals in uncomplexed electrolytes to high relative molar mass organic molecules. Both cathodic and anodic treatments have utilised RVC electrodes; coated and hybrid electrode surfaces have been used in addition to bare RVC. The majority of studies have involved batch recirculation through a divided, rectangular channel flow cell, e.g., $[19,69,70]$. Single pass of an effluent stream through a cascade cell, having 8 identical catholyte compartments, has been demonstrated to reduce the concentration of a $100 \mathrm{mg} \mathrm{dm}^{-3}$ acidic cupric ion stream to $<1 \mathrm{mg} \mathrm{dm}^{-3}$ [71]. A wide variety of contaminants, electrolytes and reactions is evident in Table 3, ranging from deposition of single metals from uncomplexed media [19,69], anionic complexes [35] or reduction of toxic metal ions [72,73], deposition of one metal from a mixture [35] and the effect of the electrolyte medium [74]. In the case of organic contaminants, such as model or actual dyes, oxidation can be achieved by direct anodic treatment, in-situ peroxide generation [75], an oxygen transfer anode [76] or an electro-Fenton $[77,78]$ process.

\subsection{Cathodic metal ion removal}


A case study has illustrated the superiority of a $25 \mathrm{~cm}^{3} 100$ ppi RVC cathode over a carbon plate for cupric ion removal from an acid solution in a simple, cation exchange membrane divided $\mathrm{H}$-cell consisting of two $250 \mathrm{~cm}^{3}$ beakers [79]. During 1 hour operation at constant current, the concentration of $\mathrm{Cu}^{2+}$ was reduced from $650 \mathrm{ppm}$ to below $1 \mathrm{ppm}$. The normalized change of concentration $v s$. time was then used to determine the product of mass transport coefficient and electrode area as a means to quantify the performance of the electrode materials. RVC showed a value of $2.0 \times 10^{-4}$ $\mathrm{s}^{-1}$, nearly one order of magnitude higher than the plate electrode. The authors noted that the metal ion removal workshop described had been effective at engaging environmental science and engineering students with electrochemical environmental technology.

A segmented flow reactor using RVC cathodes under potentiostatic control has been successfully used to selectively recover $\mathrm{Ag} / \mathrm{Cu} / \mathrm{Zn}$ and $\mathrm{Cu} / \mathrm{Cd} / \mathrm{Zn}$ from electroplating baths [80]. It was found that the process was highly dependent on the solution $\mathrm{pH}$, but less dependent on the RVC porosity or electrolyte flow rate.

The removal of $\mathrm{Zn}$ is also possible in flow reactors using RVC cathodes. Iacovangelo and Will [81] studied the morphology and deposition distribution of $\mathrm{Zn}$ at RVC electrodes using X-ray imaging. Deposition took place in bromine-containing solution for the $\mathrm{Zn}-\mathrm{Br}_{2}$ battery. RVC grades from 45 to 100 ppi were evaluated, as well as the effect of flow rate and current density. The penetration of the metallic deposit into the porous structure was poor, due to ohmic effects, but the use of dendrite inhibitors resulted in compact morphologies. Following previous work, Lanza et al. [82] studied 
the current density distribution throughout the volume of the electrodes from the thickness of the metallic deposit using tomography after the electrolysis. As expected, the local current within the RVC material was higher at electrode edges and affected by the distance from the counter-electrodes. In this study, the concentration of $\mathrm{Zn}^{2+}$ in an acid chloride bath was reduced from 50 to $0.1 \mathrm{mg} \mathrm{dm}^{-3}$ in less than $40 \mathrm{~min}$.

\subsection{Oxidation of organics}

The reduction of $\mathrm{Cr}(\mathrm{VI})$ to $\mathrm{Cr}(\mathrm{III})$ ions in acid solution at a polyaniline coated $60 \mathrm{ppi}$ RVC cathode in a flow cell was studied from a reactor kinetics perspective by Ruotolo and Gobulin [83]. Mass transport rate control was highlighted as well as the necessity of cathodic protection to extend the stability of the polyaniline film. The optimization of hydrodynamic conditions was later performed, showing that at a mean linear flow velocity of $27 \mathrm{~cm}^{-1}$ mass transfer was maximized [73]. More significantly, this group later estimated the mass transport coefficient at RVC electrodes from the reactant conversion over time using mathematical reactor models [84]. $k_{m}$ was determined for various flow rates. For example, at a linear flow velocity of $27 \mathrm{~cm}^{-1}$ it was $c a .1 .85 \mathrm{x}$ $10^{-2} \mathrm{~cm} \mathrm{~s}^{-1}$. Current vs. potential measurements related to the theoretical potential profile at the electrodes were found unsuitable for the same purpose, as the porosity and tortuosity of RVC was not considered. Such models deserve more attention, particularly when tortuosity data is available, e.g., from acoustic studies [85], or for similar materials [86].

The indirect oxidation of aromatic compounds and azo-dyes in industrial wastewater by an anodic Fenton treatment has become an attractive method in recent years, and 
RVC electrodes can be effective cathodes. For instance, Fenton's reagent $\left(\mathrm{Fe}^{2+} / \mathrm{H}_{2} \mathrm{O}_{2}\right)$ has been successfully produced electrochemically under mildly acidic solutions using RVC cathodes, permitting the oxidation of $1 \mathrm{~kg}$ of phenol at $\mathrm{SnO}_{2}$-coated $\mathrm{Ti}$ foam anodes with an associated electrical charge consumption of $6.3 \mathrm{kA} \mathrm{h}$ at $100 \mathrm{~A} \mathrm{~m}^{-2}$ [87]. This was carried out by $\mathrm{Fe}^{2+}$ ion addition or by reducing $\mathrm{Fe}^{3+}$ ions electrochemically in the reactor with the simultaneous electrochemical production of $\mathrm{H}_{2} \mathrm{O}_{2}$ via reduction of dissolved oxygen. Hydroxyl radicals $\left(\mathrm{OH}^{*}\right)$ are produced in solution by reaction of $\mathrm{Fe}^{2+}$ ions with $\mathrm{H}_{2} \mathrm{O}_{2}$ as indicated in the following reactions:

$$
\begin{aligned}
& \mathrm{O}_{2}+2 \mathrm{H}^{+}+2 \mathrm{e}^{-}=\mathrm{H}_{2} \mathrm{O}_{2} \\
& \mathrm{Fe}^{2+}+\mathrm{H}_{2} \mathrm{O}_{2}=\mathrm{Fe}^{3+}+\mathrm{OH}^{-}+\mathrm{OH}^{\cdot} \\
& \mathrm{Fe}^{3+}+\mathrm{e}^{-} \leftrightarrow \mathrm{Fe}^{2+}
\end{aligned}
$$

This system enabled the continuous generation of both $\mathrm{H}_{2} \mathrm{O}_{2}$ and $\mathrm{Fe}^{2+}$ ions at the cathode, allowing the control of in-situ $\mathrm{OH}^{*}$ formation. Oxygen necessary for production of $\mathrm{H}_{2} \mathrm{O}_{2}$ was regenerated at the anode by oxidation of water:

$$
\mathrm{H}_{2} \mathrm{O}-2 \mathrm{e}^{-}=1 / 2 \mathrm{O}_{2}+2 \mathrm{H}^{+}
$$

The hydroxyl radical is a powerful oxidant capable of oxidizing a large variety of organic pollutants, to produce dehydrogenated or hydroxylated derivatives, prior to conversion into $\mathrm{CO}_{2}$ and $\mathrm{H}_{2} \mathrm{O}$. The generation of $\mathrm{H}_{2} \mathrm{O}_{2}$ in chloride and sulfate acid 
media at RVC cathodes in a filter-press cell was also considered by Álvarez and Pletcher [88]. Using 100 ppi RVC, current efficiencies of $70 \%$ could be achieved. Relevant to an electro-Fenton processes, it was seen that the presence of $\mathrm{Fe}^{2+}$ posed no impediment to the formation of peroxide.

Decolourisation and mineralization of azo dyes such as orange-G can be performed using the electro-Fenton reaction at $\mathrm{TiO}_{2}$ anodes via the generation of $\mathrm{H}_{2} \mathrm{O}_{2}$ at $\mathrm{RVC}$ cathodes [26]; it was noted that the current efficiency of $\mathrm{H}_{2} \mathrm{O}_{2}$ production was highly dependent on the concentration and acidity of the electrolyte. Furthermore, Levafix Blue CA and Levafix Red CA reactive dyes can be removed from waste waters by anodically electro-generated Fenton's reagent using RVC as cathode [89]. The oxidation was monitored over time by UV-visible absorbance measurements, chemical oxygen demand and HPLC. After 90 min treatment in a batch cell, both dyes were 99\% mineralized with a combined COD removal of $82.2 \%$.

Destruction of pharmaceutical products by electrochemical means can prevent their discharge to natural waters, where they can pose a risk to the environment and, potentially, the water supply for human consumption. This is the case of the common antiseptic triclosan (5-chloro-2-(2,4-dichlorophenoxy)phenol). Knust et al. have evaluated its direct reduction at RVC electrodes in a dimethylformamide medium containing $0.10 \mathrm{~mol} \mathrm{dm}^{-3}$ tetra-n-butylammonium tetrafluoroborate [90]. Cyclic voltammetry at glassy carbon electrodes revealed three reduction peaks for triclosan and potentiostatic electrolysis at different cathodic potentials resulted in different by- 
products. For an initial concentration of $0.02 \mathrm{~mol} \mathrm{dm}^{-3}$ at an applied potential of -2.1 $\mathrm{V} v s$. SCE, a reactant conversion of $81 \%$ was achieved.

Cathodic reduction of $\mathrm{Cr}(\mathrm{VI})$ to $\mathrm{Cr}(\mathrm{III})$ in waste electroplating baths has been studied at 30, 45, 65 and 100 ppi RVC electrodes in a divided parallel-plate reactor with batch recirculation of electrolyte [72]. The current efficiency of the reaction was determined by the applied potential in the cell. At $-0.8 \mathrm{~V} v s . \mathrm{Ag} / \mathrm{AgCl}$, the efficiency was only $24 \%$ but a $100 \%$ reduction of $\mathrm{Cr}(\mathrm{VI})$ was achieved. Significantly, the relation of the porosity of RVC to the mass transport and volumetric electrode area developed under flow was studied and mass transport coefficient estimated for each ppi grade. The highest value was observed at 30 ppi RVC. The concentration of $\mathrm{Cr}(\mathrm{VI})$ decreased up to $<0.1 \mathrm{mg} \mathrm{dm}^{-3}$ after $43 \mathrm{~min}$ of reduction, a level below that set by environmental regulations.

The application of RVC anodes to soil remediation has been explored too. RVC grade 100 ppi has been impregnated via the sol-gel method with $\mathrm{TiO}_{2}$ for this purpose [91]. It was found that the electroosmotic flow and proton generation was significantly increased by the anatase coating, increasing the rate of phenanthrene removal from clay soil samples. An $80 \%$ reduction in the concentration of the organic compound was achieved, and similar results could be expected from other hydrocarbon pollutants.

Anodic oxidation of dyes such as methyl orange in industrial wastewater treatment has been carried out at nanostructured $\beta-\mathrm{PbO}_{2}-\mathrm{RVC}$ anodes [76]. Such 3-D electrodes 
were prepared form aqueous $\mathrm{Pb}(\mathrm{II})$ in methanesulfonic acid and showed long stability. Removal efficiencies of $>95 \%$ were achieved under $30 \mathrm{~min}$ at $600 \mathrm{~mA}$ due to $\mathrm{OH}^{\circ}$ radicals formed during the oxidation of water at sufficiently positive potentials. In the same work, faster decolourisation was observed when the RVC anodes were coated with at titanate nanotubes (TiNT)/ $\mathrm{PbO}_{2}$ composites. TiNT were obtained through the hydrothermal synthesis method and their presence allowed a higher current density at positive potentials, possibly due to enhanced absorption of the organic compound. A total organic carbon removal of $45 \%$ was observed after 120 min using the TiNT/ $\mathrm{PbO}_{2}$-coated electrodes in contrast to $24 \%$ observed with the $\mathrm{RVC} / \mathrm{PbO}_{2}$ coatings. The influence of the RVC porosity $(20,45,60,80$, and 100 ppi) when preparing the $\mathrm{PbO}_{2}$ coatings to degrade methyl orange was also studied [92]. The authors found that the most effective electrode was 45 ppi RVC coated with a composite of $\mathrm{PbO}_{2}$ and TiNT, which fully covered the substrate. In contrast, thick deposits on $>60$ ppi RVC grew mostly at the external surface of the porous material, producing a planar-like electrode. Total decolourisation and gradual mineralisation were improved by the adsorption of methyl orange on TiNT.

A recent paper has reported the oxidation of Reactive Black 5 via an electro-Fenton process in a divided flow cell employing RVC electrodes and comparing this method to direct oxidation on boron-doped diamond electrodes [78]. The concentration of $\mathrm{Fe}^{2+}$ has a direct relationship to the removal rate of the dye in Figure 16, reaching total colour removal in under 90 min. $\mathrm{H}_{2} \mathrm{O}_{2}$ generated at the $\mathrm{RVC}$ electrodes reached concentrations over $0.4 \times 10^{-3} \mathrm{~mol} \mathrm{dm}^{-3}$ in the electrolyte when a potential of $-0.4 \mathrm{~V}$ vs. $\mathrm{Ag} / \mathrm{AgCl}$ was applied to the cell. The costly boron-doped diamond electrodes 
showed more catalytic activity than the unmodified RVC towards dye oxidation. The simultaneous direct oxidation and electro-Fenton process resulted in significantly higher energy consumption.

\subsection{Clean electrosynthesis}

The electrosynthesis of both organic and inorganic compounds can be performed at RVC electrodes directly or with the aid or redox mediators. With the aim of improving the production of $\mathrm{H}_{2} \mathrm{O}_{2}$ at RVC electrodes, a three-phase system that employs 2-ethyl9,10-anthraquinone as redox catalyst has been developed by Gyenge and Oloman [93]. The process involved an organic phase (tributylphosphate), an aqueous phase (tetrabutylammonium perchlorate and sulfuric solution with cationic surfactants) and a gas phase to produce $\mathrm{H}_{2} \mathrm{O}_{2}$-containing emulsions. In a batch reactor, product concentrations up to $0.61 \mathrm{~mol} \mathrm{dm}^{-3}$ were obtained at a maximum current efficiency of $68 \%$.

Another route to the cathodic electrosynthesis of $\mathrm{H}_{2} \mathrm{O}_{2}$ at $\mathrm{RVC}$ electrodes utilises a hybrid electrochemical-ultrasonic flow reactor [94]. Using 10 ppi RVC and alkaline conditions ( $\mathrm{pH} \mathrm{10),} \mathrm{it} \mathrm{was} \mathrm{found} \mathrm{that} \mathrm{the} \mathrm{application} \mathrm{of} \mathrm{ultrasound} \mathrm{increased} \mathrm{the} \mathrm{mass}$ transport to the electrodes so that current efficiencies of nearly $60 \%$ were achieved for peroxide generation in contrast to only $20 \%$ observed in the purely electrochemical process.

The field of organic photoelectrosynthesis has recently been profiled by Nguyen et al. [95]. Since the enhancement of many electrochemical reactions by light can be readily 
achieved, the authors have given examples of RVC use in anodic oxidations to achieve cyclisation and functionalization. For instance, combined photovoltaic-electrode processes could find application in the recycling of oxidants such as $\mathrm{Ce}(\mathrm{IV})$ or gaseous hydrogen production. Examples include the solar-assisted oxidation of aromatic compounds, aromatic alcohols or dithioketals.

Recent studies have described the electrochemical synthesis of CdSe semiconducting particles at activated RVC electrodes with the aim of scaling up the production of these materials [96]. Alkaline ( $\mathrm{pH} 11)$ precursors were based on potassium chloride solutions containing $\mathrm{CdSO}_{4}$ and methacrylic acid. $\mathrm{RVC}$ electrodes are first coated with Se so that electrogenerated $\mathrm{Se}^{2-}$ can react with $\mathrm{Cd}^{2+}$ ions in the electrolyte. The nanoparticles produced had sizes under $5 \mathrm{~nm}$, but showed a high distribution of sizes. The stirred electrolyte conditions could be superseded by the use of RVC as a flowthrough electrode in a continuous flow cell.

Electrochemical debromination by reduction of decabromodiphenyl ether to dimethylformamide and dimethyl sulfoxide can be considered as an example of the synthesis of organics at RVC electrodes [97]. Cyclic voltammetry related the presence of bromine atoms to each of the observed cathodic peaks. Different product species were found after the batch electrolysis when using dimethylformamide or dimethyl sulfoxide as solvents and the product distribution depended on the cell potential, more cathodic values increasing the number of removed bromine ions. A conversion efficiency of $25 \%$ was achieved. The authors claimed that complete debromination is 
possible but more work is needed to optimize the conditions of the electrochemical process.

\section{Energy storage and conversion}

\subsection{Static batteries}

As pointed out by Valvo et al. [98] 3-D, porous materials provide a highly promising substrate for Li-ion batteries. RVC has been demonstrated to increase charge capacity per unit area, energy and power density as well as being a versatile material for metal coating, electro-polymerisation and modification with nanoparticles for use as battery current collectors. Previously, a short review of RVC as a battery electrode was published [27], which considered the possibilities of using RVC to overcome the limitations of various types of batteries, such as zinc-carbon, $\mathrm{NiOOH}$, lead acid as well as in Pd-based capacitors. The high surface area of RVC, in combination with catalyst modification, could lead to improvement of the energy density of common batteries. For instance, $\mathrm{MnO}_{2}$ films on RVC were studied at the University of Southampton as a mean to increase the surface area of substrate acting as current collector for lithium microbatteries [28]. A capacity per footprint area increase of 250 fold was claimed in comparison to flat substrates. The charge capacity of the battery was highly dependent on the thickness of the $\mathrm{MnO}_{2}$ deposits and this was the basis for establishing a limitation on the grounds of the solid-state diffusion of lithium. A practical outcome of such RVC substrates in batteries is the high discharge rate. Another example is the current collectors for lead acid batteries prepared by Czerwiński et al. [99], where 20 ppi RVC was coated by a 20 to $40 \mu \mathrm{m}$ thickness of lead by electrodeposition in methanesulfonic acid. The specific energy of the battery was increased by $50 \%$ mainly 
due to the low weight of the RVC/lead collector while the thicker lead coatings showed the longest cycling life and the highest power performance.

Conductive polymer composites prepared by anodic deposition onto RVC have been evaluated as cathodes in lithium batteries. The stability of polyaniline-based coatings over prolonged cycling becomes critical and it is highly dependent on the current density [61]. Other work has used cyclic voltammetry, electrochemical impedance spectroscopy and charge-discharge cycling to characterize several RVC/polypyrrole electrodes [100], which could also be doped with ions to add functionality to the substrate. The addition of $\mathrm{ClO}_{4}^{-}$and poly(styrenesulphonate) allowed the coatings to work as anion and cathion exchanger films, respectively. A bi-layer material RVC/PPy/poly(styrenesulfonate) was also prepared. Charge-discharge cycling experiments showed that $\mathrm{RVC} / \mathrm{PPy}$ electrodes had a maximum specific charge capacity of $95 \mathrm{~mA} \mathrm{~h} \mathrm{~g}^{-1}$.

\subsection{Redox flow batteries}

Redox flow batteries (RFBs) have become one of the more promising options for gridscale energy storage [101]. The inert, large surface area electrically conductive support

offered to electrocatalysts by RVC led to them being considered as a suitable carbon material in several studies [102], particularly in the case of the soluble lead RFB, but also for the zinc-bromine and vanadium systems. From a practical point of view, the most critical aspects in the application of RVC to this technology are the cycling stability of the material, flow blockage (in hybrid RFBs involving metal deposition) 
and the electrical resistivity of the connection between the porous material and carbon polymer bipolar plates.

The development of the undivided soluble lead flow battery in methanesulfonic acid has involved RVC and planar, carbon-HDPE composite electrodes during its several scale-up stages. Different RVC electrodes were considered as a means of increasing volumetric electrode area and mass transport in the flow cells [103]. A carbon-polymer composite plate with a fused RVC layer and a plate with a scraped RVC layer were studied. When compared, the first allowed obtaining higher cell potential of $2.10 \mathrm{~V}$ to be achieved with a higher current efficiency of $87 \%$. Further optimization of the operational conditions demonstrated that the 3-dimensional RVC electrode allowed the limiting current density to be increased to $200 \mathrm{~mA} \mathrm{~cm}$ at a flow rate of $10 \mathrm{~cm} \mathrm{~s}^{-1}$ [104], the resulting lower current densities permitting uniform deposits and better adhesion to the carbon substrate. Ultimately, a FM01-1C cell stack using RVC (16.0 $\mathrm{cm} \times 4.0 \mathrm{~cm} \times 0.1 \mathrm{~cm})$ positive and negative electrodes showed charge and voltage efficiencies of $64 \%$ and $88 \%$, respectively, with uniform distribution of the deposits when charging at $20 \mathrm{~mA} \mathrm{~cm}^{-2}$ [105]. Extended cycling revealed that the failure modes were related to the formation of $\mathrm{Pb}$ dendrites and $\mathrm{PbO}_{2}$ sludge.

Banerjee et al. [106] have described an undivided soluble lead flow battery utilising a pair of dense graphite sheet current collectors $(3.5 \mathrm{~cm} \times 3.5 \mathrm{~cm} \times 1 \mathrm{~mm})$ covered with 20, 30, or 45 ppi RVC. The interelectrode distance was $0.5 \mathrm{~cm}$ and electrolyte was circulated at a flow rate of $50 \mathrm{~cm}^{3} \mathrm{~min}^{-1}$. When employed as negative plate current collectors, RVC provided a high surface area for lead deposition and stripping during 
charge and discharge. It was observed, however, that these porous materials trapped $\mathrm{PbO}_{2}$ particles at the positive electrode and hampered the discharge reaction. Issues with blockage and increasing pressure drop could be anticipated at scale-up in hybrid RFBs involving metal deposition.

Previously, the suitability of RVC electrodes in the zinc-bromine RFB was investigated so as to increase the operational current density [107]. RVC grades 60 and 100 ppi produced low pressure drops and acceptable electrical connections to the plates, but cellulose screens were needed between these materials and the zinc deposit to prevent short-circuiting. It was found that RVC grade 100 ppi could increase cell potential due to its large surface area, allowing current efficiencies of $83 \%$, although the behaviour of the cell depended on the retention of the solid polydiallyldimethylammonium complex formed in that particular electrolyte. Using X-ray imaging of RVC electrodes, Iacovangeo and Will [81] showed that the distribution of Zn deposits in a zinc-bromine flow cell depends mostly on the current distribution at the electrodes. Most deposits accumulated at the outer surface the RVC, but this can be explained by the use of a flow-by configuration instead of the more advantageous flow-through configuration. The addition of fluorosurfactants and butyrolactone permitted deposits having more advantageous morphologies to be achieved. In modern zinc-bromine cells, bromine complexes are present as emulsions [108]. In spite of the possible increase in operational current density, RVC has not been applied to these devices in flow-through configuration. Promising advances could lie in the improvement of the interphase between RVC and carbon polymer composite plates, e.g., by controlled thermal bonding under compression. 
The electrochemical characteristics of RVC towards the $\mathrm{V}(\mathrm{IV}) / \mathrm{V}(\mathrm{V})$ redox couple were studied using voltammetric techniques and rotating disc electrode experiments [109]. The results were compared to the use of carbon felt, which has since become a common electrode material for vanadium RFBs. Approaches to increase electrolyte flow are considered essential to maximize cell performance and modified electrode architectures are being considered [110]. Carbon felt coupled to an RVC flow field could effectively increase mass transport to the felt while reducing pressure drop trough the battery stack, provided a low resistance electrical connection is established between them.

RVC was evaluated, along with other carbon and metal electrode materials, for the positive electrode of divided zinc-cerium hybrid RFB [111]. While RVC provided low pressure drop, carbon felt was preferred due to its superior active area per unit electrode volume, which extended the range of operational current density of the battery. In view of the corrosion susceptibility of carbon materials under highly oxidant Ce(IV) ions, platinised RVC electrodes protected from corrosion would be interesting materials for this application as would hybrid foam/fibre hybrid electrodes.

Alternative RFB chemistries receive increasing attention and RVC could be advantageously implemented in some of these devices. For instance, Ruggeri et al. [112] have proposed a lithium-air RFB using semi-solid electrolytes. In this flow cell, the negative and positive electrolytes consist of an organic lithium salt and a superporous carbon suspension, respectively, in non-aqueous media. RVC 100 ppi grade coated with superporous carbon using polyvinylidene fluoride as binder is used as the positive electrode for the $\mathrm{O}_{2}$ reaction. The flow cell with a RVC electrode showed higher potential and lower impedance in comparison to a cell with a carbon 
paper electrode. The authors noted that the open structure of RVC played a key role in permitting an energy efficient flow of the viscous semi-solid electrolyte.

Although carbon felt is preferred in most RFBs, RVC electrodes should receive consideration. This robust substrate allows electrolyte flow with low hydraulic pressure drop and can be easily coated with diverse catalysts, in contrast to carbon felt.

\subsection{Fuel cells}

Alkaline PEM fuel cells have utilised RVC as an electrode support. For example, the material is one of the porous, 3-D catalysts supports considered for use in the electrodes of direct borohydride fuel cells [113]. The authors considered that gold particles sputtered onto the RVC surface provided a particularly effective catalyst for borohydride oxidation. Seven grades of RVC were evaluated, from 10 ppi to $100 \mathrm{ppi}$, high porosity grades giving increased cell current and kinetic rate constants. It was noted that the material thickness and uneven potential (and current) distribution had an adverse effect on charge transfer rates.

Xie et al. have reviewed the field of bioelectrodes [114]. As pointed out by the authors, RVC electrodes have found application in microbial fuel cells due to their biocompatibility, high surface area, low cost and high conductivity. Furthermore, recent advances have incorporated advanced materials such as carbon nanotubes to form hierarchical "nanowebs" within the RVC structure $[29,115]$. Uniform biofilms could develop on this substrate, resulting in an increased activity towards acetate degradation in comparison to bare RVC, reaching current densities up to $6.8 \mathrm{~mA} \mathrm{~cm}^{-2}$ even in the absence of electrolyte flow. 
Electricity generation from artificial wastewater using an upward flow microbial fuel cell has also been considered [25]. Cylindrical anodes, made of grade 10 and 20 ppi RVC, had a volume of $190 \mathrm{dm}^{3}$. Sucrose was the electron donor species at the anode, while hexacyanoferrate was the redox mediator at the cathode. The internal resistance of the cell (maximum of $84 \Omega$ ) was found to be a limiting factor, although an alternative filter-press configuration might reduce this resistance by increasing the $\mathrm{RVC} /$ current collector contact area and decreasing the thickness of the porous electrode material. The authors reported continuous operation of the cell over five months, reaching power densities up to $170 \mathrm{~mW} \mathrm{~m}^{-2}$ and an associated chemical oxygen demand (COD) of $2.0 \mathrm{~g} \mathrm{dm}^{-3} \mathrm{day}^{-1}$. A significant cause for the low efficiency of the system was undesired methanogenic activity.

A batch RVC electrode-based microbial fuel cell for coupled energy generation and waste water treatment was also developed [116]. The cell used sodium acetate as the electron donor species. Both anode and cathode were separated $2.5 \mathrm{~cm}$ and consisted of 60 ppi grade $\mathrm{RVC}$. The division included a proton ion exchange membrane. In order to operate at $\mathrm{pH}$ 7.0, phosphate buffers were employed as electrolytes, although the anolyte contained additional ammonia, magnesium and sodium salts. A volumetric power density of $40 \mathrm{~W} \mathrm{~m}^{-3}$ was claimed with maximum volumetric currents of $540 \mathrm{~A}$ $\mathrm{m}^{-3}$, the performance being limited by the rate of cathodic oxygen reduction. The microbial population was reported to have at least a 6-month lifetime, during which time, cell potential and current were monitored. 
A microbial fuel cell enabling phosphate recovery as struvite from digested sewage sludge has been studied [117]. The reduction of $\mathrm{FePO}_{4}$ contained in the sludge took place at RVC 100 ppi grade cathodes, via the mediation of Methylene Blue and the activity of Escherichia coli. The resulting orthophosphate solution can then be combined with magnesium chloride and ammonium hydroxide to precipitate the fertilizer. The power density $v s$. current density and the polarization behaviour of the microbial fuel cell are shown in Figure 17c). The composition of the sludge was monitored with optical emission spectroscopy, while the recovered products were analysed by X-ray powder diffraction and NMR, showing the absence of heavy metal contaminants.

A miniature fuel cell using Shewanella oneidensis in a sodium lactate substrate and RVC electrode has been described [118]. The cell developed a maximum power density of $24 \mathrm{~mW} \mathrm{~m}^{-2}$ using RVC electrodes without the addition of redox mediators. When anthraquinone-2,6-disulfonate was added to the medium, the output power was significantly increased, although this effect was more significant when using graphite felt electrodes. The authors noted that the current and power densities were higher at RVC than at graphite felt, resulting in lower current output at optimal solution flow

rates. The measured values were $0.54 \mathrm{~mA}$ for $\mathrm{RVC}$ at $7 \mathrm{~cm}^{-3} \mathrm{~min}^{-1}$, in contrast to 3.7 $\mathrm{mA}$ for at $4 \mathrm{~cm}^{-3} \mathrm{~min}^{-1}$ at graphite felt.

\subsection{Supercapacitors}

Manganese dioxide, deposited in various ways on RVC and other carbon supports, has been considered for competitive use in supercapacitors [119]. For instance, 0.2-0.5 
$\mathrm{cm}^{3}$ blocks of 20 ppi RVC were used as a substrate for electrodeposition of thin layers of Pd and Pd-rich Pd-Rh alloys [120]. The hydrogen absorption behaviour of Pd-based deposits in $0.5 \mathrm{~mol} \mathrm{dm}^{-3} \mathrm{H}_{2} \mathrm{SO}_{4}$ was not affected by the underlying RVC. It was found that phase transitions control the rate of hydrogen absorption and desorption onto these electrodes. RVC coated with $\mathrm{Pd}$ and $\mathrm{Au}$ showed stability over 700 hydrogen absorption-desorption cycles that simulated the operation of a supercapacitor. Further study of the of specific capacitance, power, and energy was performed for temperatures between 283 and $313 \mathrm{~K}$ [121], revealing that $\mathrm{Pd}-\mathrm{Rh}$ and $\mathrm{Pd}-\mathrm{Pt}$ alloys with $90-95 \%$ Pd content showed the best performance. Specific capacitances up to 4,500 $\mathrm{F} \mathrm{g}^{-1}$ were achieved with an associated specific power of $750 \mathrm{~W} \mathrm{~g}^{-1}$.

Advanced carbon-based electrochemical capacitors can also be constructed using RVC as substrate. For instance, hierarchical carbon nanotube-RVC assemblies have been recently proposed by Narayanan et al. [122]. Carbon nanotubes were obtained via chemical vapour deposition from a ferrocene/xylene precursor. When compared to the bare RVC, a fifty-fold enhancement of the electrochemical double layer capacitance was verified at the hierarchical material in a $1.0 \mathrm{~mol} \mathrm{dm}^{-3} \mathrm{KCl}$ solution. Furthermore, the Faradaic charge was increased ca. 1000 -fold as measured by cycliv voltammetry in a $1.0 \times 10^{-3} \mathrm{~mol} \mathrm{dm}{ }^{-3} \mathrm{KCl}$ solution. The authors suggested that using concentrated ionic species in solution could significantly increase the capacitance of the material. Other methods for modifying the RVC skeleton by infilling with high surface area materials are considered in sections 8 and 10 . 
Polypyrrole-coated nylon lycra fabric for a possible electrode for wearable electronics capacitors has been electrochemically studied attached to RVC [123]. The textile material was coated with polypyrrole via chemical polymerization and showed a specific capacitance of $123.3 \mathrm{~F} \mathrm{~g}^{-1}$ at a scan rate of $10 \mathrm{mV} \mathrm{s}^{-1}$ in cyclic voltammetry in $1 \mathrm{~mol} \mathrm{dm}{ }^{-3} \mathrm{NaCl}$ solution. The material retained its electrochemical properties over a 1000 stretching cycles. RVC itself could be coated with doped conductive polymers as a means of producing high surface area static supercapacitors.

\section{Electrode kinetics, sensing and monitoring}

\subsection{Traditional electroanalysis}

Applications of RVC in electroanalysis were considered in Wang's early review in 1981 [5] and updated in a later review [6]. Early devices were simple amperometric flow detectors [16], followed by spectroelectrochemical detectors [124]. Electrode kinetics for electroanalysis have been considered in a book edited by Compton et al. [125]. In this section, several recent examples serve to illustrate modern trends in the use of RVC electrodes.

\subsection{Recent sensors}

Table 4 provides six examples of recent sensor studies using RVC electrodes. The species determined include hydrazine [126], neutravidin [127], acetaminophen, uric acid, dopamine [128], glucose [129] and phenolic compounds [130]. For example, Shedge and Creager [127] considered enhanced strategies to modify RVC substrates to reduce the non-specific binding of high-molecular-weight proteins that often decreases the selectivity of biosensors. RVC modification with phenylacetic acid or polyethylene 
glycol showed reduced activity towards interferences. Neutravidin detection on the polyethylene glycol-modified electrode in Figure 18 resulted in a detection limit as low as $52 \mathrm{ng} \mathrm{cm}^{-3}$.

It is worth mentioning that, under appropriate conditions, simple RVC biosensors can show a better performance for electroanalysis than more advanced materials, such as graphene foam [128]. Figueiredo-Filho et al. reported that the hydrophobic nature of graphene hampered the recording of cyclic voltamograms for dopamine hydrochloride, uric acid and acetaminophen. Only the treatment of the graphene foam with acetone could improve its response in respect to RVC, as shown by the cyclic voltammograms in $1 \mathrm{mmol} \mathrm{dm}{ }^{-3}$ hexaammineruthenium(III) chloride shown in Figure 19 [128]. Nevertheless, the authors pointed out that RVC electrodes presented higher linear ranges and lower limit of detection for the analytes studied.

Berrettoni et al. have concisely described an electrochemical sensor for indirect detection of a bacterial population [132]. The authors used a machined block of RVC embedded in epoxy resin as an ultra-microelectrode array to monitor the population of Staphylococcus aureus via normal pulse voltammetry. The method was claimed to quantify the bacterial concentration in filtered solutions by using the current response at chosen potentials. The technique appeared successful in detecting levels as low as 1 or 2 cells $\mathrm{cm}^{-3}$ of $S$. aureus.

\section{Modified RVC electrodes}


It has been noted that an RVC cylinder embedded in an insulating resin, followed by polishing of the circular end, provides a random microelectrode array of irregular vitreous carbon surfaces [133]. The mass transport rate of species to the electrode is under hemispherical diffusion and depends only on the electrode dimensions. For a disc embedded in an insulating plane, the limiting current becomes:

$$
I_{L}=4 z F D c a
$$

where $a$ is the microelectrode radius.

A series of papers has appeared on a laboratory rotating cylinder of RVC, typically 1.0 cm diameter and $1.2 \mathrm{~cm}$ height $\left(V_{e}=0.94 \mathrm{~cm}^{3}\right)$. In $1 \mathrm{mmol} \mathrm{dm}{ }^{-3} \mathrm{Cu}^{2+}$ in $0.5 \mathrm{~mol} \mathrm{dm}^{-3}$ $\mathrm{Na}_{2} \mathrm{SO}_{4}$ at $298 \mathrm{~K}$ [21], the limiting current was proportional to rotation speed raised to a power of $0.53-0.71$, depending on the porosity grade. The product $k_{m} A_{e}$ was $c a .0 .51$ $\mathrm{s}^{-1}$ at $1500 \mathrm{rev} \mathrm{min}^{-1}$. Mass transport as a function of rotation speed was compared to other RCEs. Similar electrodes have been used for rapid laboratory trials of copper [134] and cadmium [135] ion removal from mmol dm ${ }^{-3}$ concentration solutions, using controlled potential coulometry. SEM images of the metal deposit morphology showed that the coverage of RVC was incomplete and that dendritic growth developed over time. Finally, the enhancement of mass transport by jet flow has been quantified in 1 mmol dm ${ }^{-3} \mathrm{Cu}^{2+}$ in $0.5 \mathrm{~mol} \mathrm{dm}^{-3} \mathrm{Na}_{2} \mathrm{SO}_{4}$ at $298 \mathrm{~K}$ [136]. For 60 ppi RVC RCE at low rotation rates, jet electrolyte flow at $3.5 \mathrm{~cm}^{3} \mathrm{~s}^{-1}$ increased the mass transport rate by a factor of 1.46. In the case of 100 ppi RVC, the maximum mass transport enhancement was about 1.26 . 
Using RVC as a preformed, inert scaffold for electrolyte flow, a wide range of nanostructured materials can be electrodeposited by electrodeposition, electrophoresis, anodising and their hybridisation, e.g., [137,138]. For example, a 35\% wt. Sn bronze alloy has been electrodeposited at $20 \mathrm{~mA} \mathrm{~cm}^{-3}$ on 100 ppi RVC from an electrolyte containing $0.05 \mathrm{~mol} \mathrm{dm}^{-3} \mathrm{Sn}^{2+}$ and $0.1 \mathrm{~mol} \mathrm{dm}^{-3} \mathrm{Cu}^{2+}$ in the presence of $0.01 \mathrm{~mol} \mathrm{dm}^{-}$ ${ }^{3}$ hydroquinone antioxidant and $0.01 \%$ vol. ForaFac 1098 perfluorinated cationic surfactant in $2.3 \mathrm{~mol} \mathrm{dm}^{-3}$ methanesulfonic acid at $298 \mathrm{~K}$ [139].

In order to modify internal porosity and increase the substrate area for electrocatalysts, submicron diameter conductive fibres may be used. For example, a "nanoweb" may be formed on the RVC surface. Wallace et al. have used chemical vapour deposition to realise multiwalled carbon nanotube webs on 45 ppi RVC substrates with a view to producing high performance electrodes for microbial electrosynthesis of acetate ions $[29,115]$. As shown in Figure 20, the nanoweb can cover the RVC structure uniformly, providing additional surface area for chemical or biological functionalization. The authors claimed a 1.7 higher current density and a 2.6 fold faster production rate, normalized to total surface area.

Earlier studies on "hairy" RVC electrodes for batteries have been conducted [140]. The authors described the modification of an RVC substrate with in situ generated carbon nanofibres via the catalytic decomposition of ethylene at $775 \mathrm{~K}$. The fibre diameter and morphology as well as the fibre layer thickness depended on the loading of nickel hydroxide which is later reduced in an $\mathrm{H}_{2}$-containing athmosphere, as shown 
by SEM and $\mathrm{N}_{2} / \mathrm{Kr}$-physisorption. For instance, a nickel concentration of $0.5 \mathrm{~g} \mathrm{~g}^{-1}$ of RVC produced fibres with a diameter of 30 to $90 \mathrm{~nm}$. The coverage of RVC with the hairy foam resulted in a dramatic increase in the surface area, going from $0.12 \mathrm{~m}^{2} \mathrm{~g}^{-1}$ for bare 100 ppi RVC to $146 \mathrm{~m}^{2} \mathrm{~g}^{-1}$ for the hairy variant.

Carbon nanotube "carpets" are another example of hierarchical nanostructures built onto RVC [141]. An additional silica sol-gel coating or an oxygen-plasma treatment was performed to increase the wettability of the typically hydrophobic nanotube layer. Contact angle measurements showed that the amorphous silica coating resulted in long-lasting hydrophilic behaviour. This was confirmed by measuring the hydraulic pressure drop during fluid-flow experiments. The hydrophilic RVC-nanotube material had a reduced resistance to flow in comparison to the untreated substrate.

There are many examples of RVC forming a useful scaffold for biochemical and microbial species. For example, the early detection of Candida albicans biofilms has been considered [131]. The change in the redox potential and peak current of $\mathrm{K}_{3} \mathrm{Fe}(\mathrm{CN})_{6}$ measured by cyclic voltammetry and differential pulse voltammetry at an RVC electrode was related to the development of a bacterial biofilm. The diffusion coefficient of the active species at uncoated RVC was $2.2 \times 10^{-3} \mathrm{~cm}^{2} \mathrm{~s}^{-1}$ in contrast to $7.0 \times 10^{-3} \mathrm{~cm}^{2} \mathrm{~s}^{-1}$ at the biofilm-coated electrode. It was claimed that this method had a superior resolution to a typical drop plate method while giving detection results under $2 \mathrm{~h}$. 
RVC can be made by impregnation of existing RVC or a polymeric foam precursor, such as polyurethane, followed by heating and vitrification. RVC made via these two routes, impregnation and replication, using an epoxy resin, has been compared in a flow permeability study [142]. Vitreous carbon foams produced from the polyurethane foam template showed higher hydraulic permeability, at the cost of lower mechanical strength. Maximum volumetric porosities of 0.94 and 0.89 could be obtained by replication and infiltration methods, respectively.

\section{Summary}

1. RVC is a rigid, solid foam comprised of open-cells, i.e., pores which are spatially connected within skeletal, strut boundaries to form a network. RVC is a useful electrode material, particularly when high current densities, a low resistance to fluid flow, a high volumetric porosity and the ability to hold infused materials within controlled pore sizes are required.

2. This porous material has been manufactured since the mid-1960s, the most common route being carbonisation of a resin coated, open-cell polyurethane foam. Typically, the precursor is dried and cured at $120^{\circ} \mathrm{C}$ then carbonised at $700-1100{ }^{\circ} \mathrm{C}$.

3. The material allows a one-piece, continuous structure, in contrast to particulate beds which rely upon compression/gravity for adequate electrical conductivity; the electrodes have a high isotropy. The very high porosity, allows passage of gases and liquids with a low pressure drop. Dilute slurry electrolytes can be accommodated using large pore grades. 
4. The high volumetric porosity of $c a .97 \%$ limits the electrical conductivity compared to solid carbon and conductive metal structures.

5. Early uses in electrochemistry were primarily in electroanalysis, controlled flow electrode kinetics and sensors. Other common uses have included filter materials. The diversity of RVC use has included a scaffold for biomaterials and a template for metal or conductive polymer foams.

6. Despite the increasing diversity of available porous, 3-D electrodes in metals and carbons, RVC has remained an important specialised electrode in laboratory and pilotscale studies of electroanalysis; its uses have diversified, e.g., to static and some flow through batteries.

7. The structure and physical properties of RVC can be modified by densification during, or after, manufacture and by coating after fabrication.

8. The diversity of RVC can continue to evolve using techniques such as 3-D printing to control texture and nanowebs to modify porosity together with the ability to support electrocatalyst particles in 3-dimensional, open pore networks.

9. The versatility of the material is further extended by bendable slices for flexible batteries and "hairy" fibre-coated RVC for sensors.

\section{Important areas for further research}

Several aspects of RVC electrodes deserve further study to improve our understanding of its structure and electrochemical behaviour, leading to extended applications in electrochemical technology: 
1. The application of X-ray computed tomography (XRCT) to the structure of RVC [143]. Paired with the digital rendering of the porous matrix, the resulting 3-D finite element meshes could be used for automatic quantitative structural analysis and the simulation of mechanical, thermal and fluid-flow properties.

2. 3-D printing to produce versatile, digitally-tailored fast and hybrid carbon foam prototypes, e.g., [144-146] and similar to development in metals [33].

3. Tailoring of physical properties, e.g., auxetic foams [147], including 3-D printed varieties [148].

4. Mixed electrode materials, e.g., metal-carbon, such as high surface area nanostructured nickel [149] on RVC.

5. Advanced surface catalyst impregnation, e.g., flexible textiles such as elasticated [150] yarn electrodes [151] or exfoliated graphene products [152].

6. Advanced surface coatings, including conductive polymers, e.g., [153] and electrodeposited particle-metal matrix composites [154], including nanoparticles [155].

7. When sufficiently thin, e.g., $<1 \mathrm{~mm}, \mathrm{RVC}$ electrodes become much more flexible and elastic carbon foams are possible, e.g., [156].

8. RVC could also prove to be a versatile template for the production of metal foams, as polymer foams have [157]. 
9. Diverse hybrid electrodes may be realised by modifying RVC with interpenetrating fibrous or nanotubular structures (e.g., metals, carbons or composites) as supports or as surface coatings. Examples include carbon meringue foams from a French group [158] or carbonised candy floss, pore-filling RVC hybrid electrodes [159].

10. Polymer electrodes based on ethylene oxide linked materials of mean molar mass 100,000 [160] could be applied in-situ to an RVC electrode surface for use in solid state lithium batteries.

\section{Acknowledgements}

FCW is grateful to many important contributors during structural, materials and electrochemical research on solid foams such as $\mathrm{RVC}$, including $\mathrm{PhD}$ theses by Ian Whyte (University of Southampton, 1991), Gavin W. Reade (University of Portsmouth, 1996), Jens M. Friedrich (University of Southampton, 2006) and Richard Critchley (University of Southampton, 2013). Discussions with Prof Derek Pletcher have been valuable. LFA acknowledges the financial support of CONACYT SEP. FCW, CPDL and LFA acknowledge the facilitating of this research by the EPSRC Centre for Doctoral Training in Energy Storage and its Applications (EP/L016818/1). No new data were created during the preparation of this critical review. 


\section{References}

[1] D. Pletcher, F.C. Walsh, Industrial Electrochemistry, 2nd ed., Chapman and Hall, London, 1990.

[2] D. Pletcher, F.C. Walsh, Three-dimensional electrodes, in: D. Gernders, N. Weinberg (Eds.), Electrochemistry for a Cleaner Environment, The Electrosynthesis Company, New York, 1992: pp. 51-100.

[3] ERG Materials and Aerospace Co., ed., Reticulated vitreous carbon, Ergaerospace.com. http://www.ergaerospace.com/literature/erg_rvc.pdf (accessed January 26, 2016).

[4] F. Dullien, Porous Media. Fluid Transport and Pore Structure, 2nd ed., Academic Press, San Diego, 1992.

[5] J. Wang, Reticulated vitreous carbon - a new versatile electrode material, Electrochim. Acta. 26 (1981) 1721-1726. doi:10.1016/0013-4686(81)851560 .

[6] J.M. Friedrich, C. Ponce de León, G.W. Reade, F.C. Walsh, Reticulated vitreous carbon as an electrode material, J. Electroanal. Chem. 561 (2004) 203-217. doi:10.1016/j.jelechem.2003.07.019.

[7] M.I. Awad, M.M. Saleh, T. Ohsaka, Recent progress in the electrochemistry of planar and reticulated vitreous carbon: Fundamentals and applications, Current Topics in Electrochemistry. 17 (2012) 15-40.

[8] G. Tondi, S. Blacher, A. Léonard, A. Pizzi, V. Fierro, J.M. Leban, A. Celzard, X-ray microtomography studies of tannin-derived organic and carbon foams, Microscopy and Microanalysis. 15 (2009) 384-394. doi: $10.1017 /$ S1431927609990444.

[9] C.R. Rambo, N. Travitzky, K. Zimmermann, P. Greil, Synthesis of TiC/Ti$\mathrm{Cu}$ composites by pressureless reactive infiltration of $\mathrm{TiCu}$ alloy into carbon preforms fabricated by 3D-printing, Materials Letters. 59 (2005) 1028-1031. doi:10.1016/j.matlet.2004.11.051.

[10] M. Kırca, A. Gül, E. Ekinci, F. Yardım, A. Mugan, Computational modeling of micro-cellular carbon foams, Finite Elem. Anal. Des. 44 (2007) 45-52. doi:10.1016/j.finel.2007.08.008.

[11] E.G. Klarreich, Foams and honeycombs, American Scientist. 88 (2000) 152161.

[12] R. Bernard, The Plessey Co Ltd, Bodies and shapes of carbonaceous materials and processes for their production, US Patent 3,109,712 A, 1963.

[13] G. Moutaud, Societé Le Carbone-Lorraine, Process for the manufacture of macroporous vitreous carbon, US Patent 3,446,593 A, 1969.

[14] A.N. Strohl, D.J. Curran, Reticulated vitreous carbon flow-through 
electrodes, Anal. Chem. 51 (1979) 353-357. doi:10.1021/ac50039a009.

[15] W.J. Blaedel, J. Wang, Characteristics of a rotated porous flow-through electrode, Anal. Chem. 52 (1980) 1697-1700. doi:10.1021/ac50061a037.

[16] D.J. Curran, T.P. Tougas, Electrochemical detector based on a reticulated vitreous carbon working electrode for liquid chromatography and flow injection analysis, Anal. Chem. 56 (1984) 672-678.

doi: $10.1021 / \mathrm{ac} 00268 \mathrm{a} 019$.

[17] I.C. Agarwal, A.M. Rochon, H.D. Gesser, A.B. Sparling, Electrodeposition of six heavy metals on reticulated vitreous carbon electrode, Water Research. 18 (1984) 227-232. doi:10.1016/0043-1354(84)90073-3.

[18] G.H. Heider, S.V. Sasso, K. Huang, A.M. Yacynych, H.J. Wieck, Electrochemical platinization of reticulated vitreous carbon electrodes to increase biosensor response, Anal. Chem. 62 (1990) 1106-1110. doi:10.1021/ac00210a003.

[19] D. Pletcher, I. Whyte, F.C. Walsh, J.P. Millington, Reticulated vitreous carbon cathodes for metal ion removal from process streams part I: Mass transport studies, J. Appl. Electrochem. 21 (1991) 659-666. doi:10.1007/BF01034042.

[20] D. Weaire, R. Phelan, A counter-example to Kelvin's conjecture on minimal surfaces, Philosophical Magazine Letters. 69 (1994) 107-110. doi:10.1080/09500839408241577.

[21] A.H. Nahlé, G.W. Reade, F.C. Walsh, Mass transport to reticulated vitreous carbon rotating cylinder electrodes, J. Appl. Electrochem. 25 (1995) 450455. doi:10.1007/BF00260687.

[22] C. Ponce de León, D. Pletcher, Removal of formaldehyde from aqueous solutions via oxygen reduction using a reticulated vitreous carbon cathode cell, J. Appl. Electrochem. 25 (1995) 307-314. doi:10.1007/BF00249648.

[23] P.N. Bartlett, D. Pletcher, J. Zeng, Approaches to the integration of electrochemistry and biotechnology I. Enzyme-modified reticulated vitreous carbon electrodes, J. Electrochem. Soc. 144 (1997) 3705-3710. doi:10.1149/1.1838079.

[24] E. Gyenge, J. Jung, B. Mahato, Electroplated reticulated vitreous carbon current collectors for lead-acid batteries: opportunities and challenges, J. Power Sources. 113 (2003) 388-395. doi:10.1016/S0378-7753(02)00553-0.

[25] Z. He, S.D. Minteer, L.T. Angenent, Electricity generation from artificial wastewater using an upflow microbial fuel cell, Environ. Sci. Technol. 39 (2005) 5262-5267. doi:10.1021/es0502876.

[26] Y.B. Xie, X.Z. Li, Interactive oxidation of photoelectrocatalysis and electroFenton for azo dye degradation using $\mathrm{TiO}_{2}-\mathrm{Ti}$ mesh and reticulated vitreous carbon electrodes, Materials Chemistry and Physics. 95 (2006) 39-50. 
doi:10.1016/j.matchemphys.2005.05.048.

[27] A. Czerwiński, Z. Rogulski, S. Obrębowski, H. Siwek, I. Paleska, M. Chotkowski, M. Łukaszewski, RVC as new carbon material for batteries, J. Appl. Electrochem. 39 (2009) 559-567. doi:10.1007/s10800-009-9791-8.

[28] P. Johns, M. Roberts, J. Owen, Conformal electrodeposition of manganese dioxide onto reticulated vitreous carbon for 3D microbattery applications, J. Mater. Chem. 21 (2011) 10153-10159. doi:10.1039/C0JM04357E.

[29] L. Jourdin, S. Freguia, B.C. Donose, J. Chen, G.G. Wallace, J. Keller, V. Flexer, A novel carbon nanotube modified scaffold as an efficient biocathode material for improved microbial electrosynthesis, J. Mater. Chem. A. 2 (2014) 13093-13102. doi:10.1039/C4TA03101F.

[30] Y. Aoki, PhD Thesis, University of Bath, 1993.

[31] G. Harikrishnan, T. Umasankar Patro, D.V. Khakhar, Reticulated vitreous carbon from polyurethane foam-clay composites, Carbon. 45 (2007) 531535. doi:10.1016/j.carbon.2006.10.019.

[32] E. Bruneton, B. Narcy, A. Oberlin, Carbon-carbon composites prepared by a rapid densification process I: Synthesis and physico-chemical data, Carbon. 35 (1997) 1593-1598. doi:10.1016/S0008-6223(97)00118-8.

[33] A. Inayat, J. Schwerdtfeger, H. Freund, C. Körner, R.F. Singer, W. Schwieger, Periodic open-cell foams: Pressure drop measurements and modeling of an ideal tetrakaidecahedra packing, Chem. Eng. Sci. 66 (2011) 2758-2763.

[34] J.M. Friedrich, Characterisation of electrode materials for electrochemical reactors, PhD thesis, University of Southampton, 2006.

[35] I. Whyte, Reticulated vitreous carbon cathodes for metal ion removal from process streams, PhD thesis, University of Southampton, 1991.

[36] G.W. Reade, Mass transport to rotating reticulated vitreous carbon cylinder electrodes, PhD thesis, University of Portsmouth, 1996.

[37] R.A. Ketcham, W.D. Carlson, Acquisition, optimization and interpretation of $\mathrm{X}$-ray computed tomographic imagery: applications to the geosciences, Computers \& Geosciences. 27 (2001) 381-400. doi:10.1016/S00983004(00)00116-3.

[38] A.G. Leach, The thermal conductivity of foams. I. Models for heat conduction, J. Phys. D: Appl. Phys. 26 (1993) 733-739. doi:10.1088/0022$3727 / 26 / 5 / 003$.

[39] R. Phelan, D. Weaire, E.A.J.F. Peters, G. Verbist, The conductivity of a foam, J. Phys.: Condens. Matter. 8 (1996) L475-L482. doi:10.1088/0953$8984 / 8 / 34 / 002$.

[40] E.S. Gonçalves, M.C. Rezende, N.G. Ferreira, Dynamics of defects and 
surface structure formation in reticulated vitreous carbon, Brazilian J. Physics. 36 (2006) 264-266. doi:10.1590/S0103-97332006000300008.

[41] M.R. Baldan, E.C. Almeida, A.F. Azevedo, E.S. Gonçalves, M.C. Rezende, N.G. Ferreira, Raman validity for crystallite size $L_{\mathrm{a}}$ determination on reticulated vitreous carbon with different graphitization index, Applied Surface Science. 254 (2007) 600-603. doi:10.1016/j.apsusc.2007.06.038.

[42] R.K. Sinnott, J.M. Coulson, J.F. Richardson, Coulson \& Richardson's Chemical Engineering: Chemical Engineering Design, 4 ed., Elsevier, 2005.

[43] F.C. Walsh, A First Course on Electrochemical Engineering, The Electrochemical Consultancy, Romsey, 1993.

[44] D.J. Pickett, Electrochemical Reactor Design, 2nd ed., Elsevier, Amsterdam, 1979.

[45] S. Langlois, F. Coeuret, Flow-through and flow-by porous electrodes of nickel foam. I. Material characterization, J. Appl. Electrochem. 19 (1989) 43-50. doi:10.1007/BF01039388.

[46] S. Langlois, F. Coeuret, Flow-through and flow-by porous electrodes of nickel foam Part III: theoretical electrode potential distribution in the flowby configuration, J. Appl. Electrochem. 20 (1990) 740-748. doi:10.1007/BF01094300.

[47] S. Langlois, F. Coeuret, Flow-through and flow-by porous electrodes of nickel foam. II. Diffusion-convective mass transfer between the electrolyte and the foam, J. Appl. Electrochem. 19 (1989) 51-60. doi:10.1007/BF01039389.

[48] M.G. Konicek, G. Platek, Reticulate electrode cell removes heavy metals from rinse waters, New Mater. New Processes. 2 (1983) 232-235.

[49] R. Alkire, P.K. Ng, Studies on flow-by porous electrodes having perpendicular directions of current and electrolyte flow, J. Electrochem. Soc. 124 (1977) 1220-1227. doi:10.1149/1.2133531.

[50] A. Tentorio, U. Casolo-Ginelli, Characterization of reticulate, three dimensional electrodes, J. Appl. Electrochem. 8 (1978) 195-205. doi:10.1007/BF00616422.

[51] R.C. Tangirala, C.T.J. Low, C. Ponce de León, S.A. Campbell, F.C. Walsh, Copper deposition at segmented, reticulated vitreous carbon cathode in Hull cell, Trans. Inst. Met. Finish. 88 (2010) 84-92. doi:10.1179/174591910X12646070884872.

[52] A. Czerwiński, M. Lukaszewski, A. Żurowski, H. Siwek, S. Obrebowski, Selected electrochemical properties of noble metals and their alloys electrodeposited on reticulated vitreous carbon, J. New Mat. Electrochem. Systems. 9 (2006) 419-429. 
[53] T.S. Olson, R.A. Rincón, D.A. Brevnov, P. Atanassov, Gold-decorated flowthrough electrodes: effect of electrochemical time constant on electrodeposition of $\mathrm{Au}$ particles on reticulated vitreous carbon, Electrochem. Solid-State Lett. 13 (2010) D11-D14. doi:10.1149/1.3272881.

[54] M.I. Awad, M.M. Saleh, T. Ohsaka, Ozone electrogeneration on Pt-loaded reticulated vitreous carbon using flooded and flow-through assembly, J. Electrochem. Soc. 153 (2006) D207-D212.

[55] P. Tissot, M. Fragniere, Anodic oxidation of cyanide on a reticulated threedimensional electrode, J. Appl. Electrochem. 24 (1994) 509-512.

[56] A. Czerwiński, M. Żelazowska, Electrochemical behavior of lead dioxide deposited on reticulated vitreous carbon (RVC), J. Power Sources. 64 (1997) 29-34. doi:10.1016/S0378-7753(96)02496-2.

[57] Z. Rogulski, M. Chotkowski, A. Czerwiński, Electrochemical behavior of $\mathrm{MnO}_{2} / \mathrm{RVC}$ system, J. New Mat. Electrochem. Systems. 9 (2006) 401-408.

[58] H.C. Arredondo Valdez, G. García Jiménez, S. Gutiérrez-Granados, C. Ponce de León, Degradation of paracetamol by advance oxidation processes using modified reticulated vitreous carbon electrodes with $\mathrm{TiO}_{2}$ and $\mathrm{CuO} / \mathrm{TiO}_{2} / \mathrm{Al}_{2} \mathrm{O}_{3}$, Chemosphere. 89 (2012) 1195-1201.

[59] M. Mendez Agudelo, L. Alibabaei, J.J. Concepcion, J.D. Dares, T.J. Meyer, High surface area reticulated vitreous carbon-nanoparticle metal oxide electrodes, US2014/0311916 A1, 2014.

[60] M.A. Méndez, L. Alibabaei, J.J. Concepcion, T.J. Meyer, Electrocatalysis on oxide-stabilized, high-surface area carbon electrodes, ACS Catal. 3 (2013) 1850-1854. doi:10.1021/cs4003595.

[61] H. Tsutsumi, S. Yamashita, T. Oishi, Application of polyaniline/poly(pstyrenesulfonic acid) composite prepared by post-polymerization technique to positive active material for a rechargeable lithium battery, Synthetic Metals. 85 (1997) 1361-1362. doi:10.1016/S0379-6779(97)80272-X.

[62] C. Dalmolin, S.R. Biaggio, R.C. Rocha-Filho, N. Bocchi, Deposition of polyaniline on RVC electrodes: effect of substrate thickness, J. Solid State Electrochem. 11 (2006) 609-618.

[63] Y. Li, R.J. Ewen, S.A. Campbell, J.R. Smith, Electrochemically controlled release of antischistosomiasis agents from polypyrrole, J. Mater. Chem. 22 (2012) 2687-2694. doi:10.1039/C2JM15298C.

[64] X. Yang, C.O. Too, L. Sparrow, J. Ramshaw, G.G. Wallace, Polypyrroleheparin system for the separation of thrombin, Reactive and Functional Polymers. 53 (2002) 53-62.

[65] Y. Yuan, S.-H. Kim, Polypyrrole-coated reticulated vitreous carbon as anode in microbial fuel cell for higher energy output, Bull. Korean Chem. Soc. 29 (2008) 168-172. doi:10.5012/bkcs.2008.29.1.168. 
[66] M.S. Almoiqli, Nanostructured ICP-CNT electrodes for capacitive deionisation and water clean up, $\mathrm{PhD}$ thesis, University of Wollongong, 2014.

[67] A. Frydrychewicz, S.Y. Vassiliev, G.A. Tsirlina, K. Jackowska, Reticulated vitreous carbon-polyaniline-palladium composite electrodes, Electrochim. Acta. 50 (2005) 1885-1893. doi:10.1016/j.electacta.2004.08.041.

[68] P.C. Sherrell, J. Chen, J.M. Razal, I.P. Nevirkovets, C. Crean, G.G. Wallace, A. Minett, Advanced microwave-assisted production of hybrid electrodes for energy applications, Energy Environ. Sci. 3 (2010) 1979-1984. doi:10.1039/C0EE00352B.

[69] D. Pletcher, I. Whyte, F.C. Walsh, J.P. Millington, Reticulated vitreous carbon cathodes for metal ion removal from process streams part II: Removal of copper(II) from acid sulphate media, J. Appl. Electrochem. 21 (1991) 667-671. doi:10.1007/BF01034043.

[70] F.C. Walsh, D. Pletcher, I. Whyte, J.P. Millington, Electrolytic removal of cupric ions from dilute liquors using reticulated vitreous carbon cathodes, J. Chem. Technol. Biotechnol. 55 (1992) 147-155.

[71] D. Pletcher, I. Whyte, F.C. Walsh, J.P. Millington, Reticulated vitreous carbon cathodes for metal ion removal from process streams Part III: Studies of a single pass reactor, J. Appl. Electrochem. (1993).

[72] F. Rodriguez-Valadez, C. Ortiz-Éxiga, J.G. Ibanez, A. Alatorre-Ordaz, S. Gutierrez-Granados, Electroreduction of $\mathrm{Cr}$ (VI) to $\mathrm{Cr}$ (III) on reticulated vitreous carbon electrodes in a parallel-plate reactor with recirculation, Environ. Sci. Technol. 39 (2005) 1875-1879. doi:10.1021/es049091g.

[73] L.A.M. Ruotolo, J.C. Gubulin, Optimization of Cr(VI) electroreduction from synthetic industrial wastewater using reticulated vitreous carbon electrodes modified with conducting polymers, Chem. Eng. J. 149 (2009) 334-339. doi:10.1016/j.cej.2008.11.022.

[74] C. Ponce de León, D. Pletcher, The removal of $\mathrm{Pb}$ (II) from aqueous solutions using a reticulated vitreous carbon cathode cell - the influence of the electrolyte medium, Electrochim. Acta. 41 (1996) 533-541.

[75] Y.A. Bustos, J.G. Rangel-Peraza, M.N. Rojas-Valencia, E.R. Bandala, A. Álvarez-Gallegos, L. Vargas-Estrada, Treatment of industrial effluents by electrochemical generation of $\mathrm{H}_{2} \mathrm{O}_{2}$ using an $\mathrm{RVC}$ cathode in a parallel plate reactor, Environ Technol. (2015). doi:10.1080/09593330.2015.1086820.

[76] F.J. Recio, P. Herrasti, I. Sirés, A.N. Kulak, D.V. Bavykin, C. Ponce de León, F.C. Walsh, The preparation of $\mathrm{PbO}_{2}$ coatings on reticulated vitreous carbon for the electro-oxidation of organic pollutants, Electrochim. Acta. 56 (2011) 5158-5165.

[77] G. Zhang, F. Yang, M. Gao, X. Fang, L. Liu, Electro-Fenton degradation of azo dye using polypyrrole/anthraquinonedisulphonate composite film 
modified graphite cathode in acidic aqueous solutions, Electrochim. Acta. 53 (2008) 5155-5161.

[78] V.M. Vasconcelos, C. Ponce de León, J.L. Nava, M.R.V. Lanza, Electrochemical degradation of RB-5 dye by anodic oxidation, electroFenton and by combining anodic oxidation-electro-Fenton in a filter-press flow cell, J. Electroanal. Chem. (2015).

[79] G.A. Ottewill, G.W. Reade, S.A. Campbell, C. Ponce de Leon, F.C. Walsh, Electrochemical removal of metal ions from aqueous solution: a student workshop, J. Environ. Monit. 7 (2005) 943. doi:10.1039/b511142k.

[80] R. Suzuki, W.H. Li, M. Schwartz, K. Nobe, Segmented porous electrode flow reactors for the electrochemical treatment of commingled metal plating wastes, Plat. Surf. Finish. 82 (1995) 58-65.

[81] C.D. Iacovangelo, F.G. Will, Parametric study of zinc deposition on porous carbon in a flowing electrolyte cell, J. Electrochem. Soc. 132 (1985) 851857. doi:10.1149/1.2113972.

[82] M.R.V. Lanza, R. Bertazzoli, Removal of $\mathrm{Zn}$ (II) from chloride medium using a porous electrode: current penetration within the cathode, J. Appl. Electrochem. 30 (2000) 61-70. doi:10.1023/A:1003836418682.

[83] L.A.M. Ruotolo, J.C. Gubulin, Reduction of hexavalent chromium using polyaniline films. Effect of film thickness, potential and flow velocity on the reaction rate and polymer stability, J. Appl. Electrochem. 33 (2003) 12171222. doi:10.1023/B:JACH.0000003856.63371.73.

[84] L.A.M. Ruotolo, J.C. Gubulin, A mathematical model to predict the electrode potential profile inside a polyaniline-modified reticulate vitreous carbon electrode operating in the potentiostatic reduction of $\mathrm{Cr}(\mathrm{VI})$, Chem. Eng. J. 171 (2011) 1170-1177.

[85] H.S. Heui-Seol, Characterization of the acoustic properties of random porous media: reticulated vitreous carbon and aluminum foam, J. Korean Phys. Soc. 53 (2008) 607-616.

[86] M. Letellier, V. Fierro, A. Pizzi, A. Celzard, Tortuosity studies of cellular vitreous carbon foams, Carbon. 80 (2014) 193-202. doi:10.1016/j.carbon.2014.08.056.

[87] E. Fockedey, A. Van Lierde, Coupling of anodic and cathodic reactions for phenol electro-oxidation using three-dimensional electrodes, Water Research. 36 (2002) 4169-4175. doi:10.1016/S0043-1354(02)00103-3.

[88] A. Álvarez-Gallegos, D. Pletcher, The removal of low level organics via hydrogen peroxide formed in a reticulated vitreous carbon cathode cell, Part 1. The electrosynthesis of hydrogen peroxide in aqueous acidic solutions, Electrochim. Acta. 44 (1998) 853-861.

[89] H.S. El-Desoky, M.M. Ghoneim, R. El-Sheikh, N.M. Zidan, Oxidation of 
Levafix CA reactive azo-dyes in industrial wastewater of textile dyeing by electro-generated Fenton's reagent, J. Hazard. Mater. 175 (2010) 858-865. doi:10.1016/j.jhazmat.2009.10.089.

[90] K.N. Knust, M.P. Foley, M.S. Mubarak, S. Skljarevski, K. Raghavachari, D.G. Peters, Electrochemical reduction of 5-chloro-2-(2,4dichlorophenoxy)phenol (triclosan) in dimethylformamide, J. Electroanal. Chem. 638 (2010) 100-108. doi:10.1016/j.jelechem.2009.10.012.

[91] E. Méndez, E. Bustos, R. Feria, G. García, M. Teutli, Electrode materials a key factor to improve soil electroremediation, in: Y. Shao (Ed.), Electrochemical Cells - New Advances in Fundamental Researches and Applications, Rijeka, 2012: pp. 219-240.

[92] G. Ramírez, F.J. Recio, P. Herrasti, C. Ponce de León, I. Sirés, Effect of RVC porosity on the performance of $\mathrm{PbO}_{2}$ composite coatings with titanate nanotubes for the electrochemical oxidation of azo dyes, Electrochim. Acta. 204 (2016) 9-17. doi:10.1016/j.electacta.2016.04.054.

[93] E.L. Gyenge, C.W. Oloman, Electrosynthesis of hydrogen peroxide in acidic solutions by mediated oxygen reduction in a three-phase (aqueous/organic/gaseous) system Part I: Emulsion structure, electrode kinetics and batch electrolysis, J. Appl. Electrochem. 33 (2003) 655-663.

[94] J. González-García, C.E. Banks, B. Šljukić, R.G. Compton, Electrosynthesis of hydrogen peroxide via the reduction of oxygen assisted by power ultrasound, Ultrasonics Sonochemistry. 14 (2007) 405-412. doi:10.1016/j.ultsonch.2006.08.006.

[95] B.H. Nguyen, R.J. Perkins, J.A. Smith, K.D. Moeller, Photovoltaic-driven organic electrosynthesis and efforts toward more sustainable oxidation reactions, Beilstein J. Org. Chem. 11 (2015) 280-287. doi:10.3762/bjoc.11.32.

[96] S. Ham, S. Jeon, U. Lee, M. Park, K.J. Paeng, Electrochemical synthesis of CdSe nanoparticles using a Se-modified RVC electrode and mercaptoacetic acid as a stabilizer, Bull. Korean Chem. Soc. 30 (2009) 1201-1203.

[97] A.A. Peverly, E.M. Pasciak, L.M. Strawsine, E.R. Wagoner, D.G. Peters, Electrochemical reduction of decabromodiphenyl ether at carbon and silver cathodes in dimethylformamide and dimethyl sulfoxide, J. Electroanal. Chem. 704 (2013) 227-232. doi:10.1016/j.jelechem.2013.07.002.

[98] M. Valvo, M. Roberts, G. Oltean, B. Sun, D. Rehnlund, D. Brandell, K. Edstrom, Electrochemical elaboration of electrodes and electrolytes for 3D structured batteries, J. Mater. Chem. A. 1 (2013) 9281-9293. doi:10.1039/C3TA11921A.

[99] A. Czerwiński, Z. Rogulski, S. Obrebowski, Positive plate for carbon leadacid battery, Int J Electrochem Sci. 9 (2014) 4826-4839.

[100] C. Dalmolin, S.R. Biaggio, R.C. Rocha-Filho, N. Bocchi, Reticulated 
vitreous carbon/polypyrrole composites as electrodes for lithium batteries: Preparation, electrochemical characterization and charge-discharge performance, Synthetic Metals. 160 (2010) 173-179.

[101] P. Leung, X. Li, C. Ponce de León, L. Berlouis, C.T.J. Low, F.C. Walsh, Progress in redox flow batteries, remaining challenges and their applications in energy storage, RSC Adv. 2 (2012) 10125. doi:10.1039/c2ra21342g.

[102] M.H. Chakrabarti, N.P. Brandon, S.A. Hajimolana, F. Tariq, V. Yufit, M.A. Hashim, M.A Hussain, C.T.J. Low, P.V. Aravind, Application of carbon materials in redox flow batteries, J. Power Sources. 253 (2014) 150-166. doi:10.1016/j.jpowsour.2013.12.038.

[103] D. Pletcher, R. Wills, A novel flow battery: A lead acid battery based on an electrolyte with soluble lead(II) Part II. Flow cell studies, Phys. Chem. Chem. Phys. 6 (2004) 1779-1785. doi:10.1039/B401116C.

[104] D. Pletcher, R. Wills, A novel flow battery-A lead acid battery based on an electrolyte with soluble lead(II) III. The influence of conditions on battery performance, J. Power Sources. 149 (2005) 96-102.

doi:10.1016/j.jpowsour.2005.01.048.

[105] R.G.A. Wills, J. Collins, D. Stratton-Campbell, C.T.J. Low, D. Pletcher, F.C. Walsh, Developments in the soluble lead-acid flow battery, J. Appl. Electrochem. 40 (2009) 955-965. doi:10.1007/s10800-009-9815-4.

[106] A. Banerjee, D. Saha, T.N. Guru Row, A.K. Shulka, A soluble-lead redox flow battery with corrugated graphite sheet and reticulated vitreous carbon as positive and negative current collectors, Bull. Mater. Sci. 36 (2013) 163-170. doi:10.1007/s12034-013-0426-7.

[107] M. Mastragostino, S. Valcher, Polymeric salt as bromine complexing agent in a $\mathrm{Zn}-\mathrm{Br}_{2}$ model battery, Electrochim. Acta. 28 (1983) 501-505. doi:10.1016/0013-4686(83)85034-8.

[108] Butler, P. C., P.A. Eidler, P.G. Grimes, S.E. Klassen, R.C. Miles, Zinc/bromine batteries, in: D. Linden, T.B. Reddy (Eds.), Handbook of Batteries, McGraw-Hill, 2001.

[109] S. Zhong, M. Skyllas-Kazacos, Electrochemical behaviour of vanadium(V)/vanadium(IV) redox couple at graphite electrodes, J. Power Sources. 39 (1992) 1-9. doi:10.1016/0378-7753(92)85001-Q.

[110] D.S. Aaron, Q. Liu, Z. Tang, G.M. Grim, A.B. Papandrew, A. Turhan, T.A. Zawodzinski, M.M. Mench, Dramatic performance gains in vanadium redox flow batteries through modified cell architecture, J. Power Sources. 206 (2012) 450-453. doi:10.1016/j.jpowsour.2011.12.026.

[111] P. Leung, Development of a Zinc-Cerium Redox Flow Battery, University of Southampton, 2012.

[112] I. Ruggeri, C. Arbizzani, F. Soavi, A novel concept of semi-solid, li redox 
flow air $\left(\mathrm{O}_{2}\right)$ battery: a breakthrough towards high energy and power batteries, Electrochim. Acta. 206 (2016) 291-300.

doi:10.1016/j.electacta.2016.04.139.

[113] C. Ponce de León, A. Kulak, S. Williams, I. Merino-Jiménez, F.C. Walsh, Improvements in direct borohydride fuel cells using three-dimensional electrodes, Catalysis Today. 170 (2011) 148-154.

[114] X. Xie, C. Criddle, Y. Cui, Design and fabrication of bioelectrodes for microbial bioelectrochemical systems, Energy Environ. Sci. 8 (2015) 34183441. doi:10.1039/C5EE01862E.

[115] V. Flexer, J. Chen, B.C. Donose, P. Sherrell, G.G. Wallace, J. Keller, The nanostructure of three-dimensional scaffolds enhances the current density of microbial bioelectrochemical systems, Energy Environ. Sci. 6 (2013) 12911298. doi:10.1039/C3EE00052D.

[116] G. Lepage, F.O. Albernaz, G. Perrier, G. Merlin, Characterization of a microbial fuel cell with reticulated carbon foam electrodes, Bioresource Technology. 124 (2012) 199-207. doi:10.1016/j.biortech.2012.07.067.

[117] F. Fischer, C. Bastian, M. Happe, E. Mabillard, N. Schmidt, Microbial fuel cell enables phosphate recovery from digested sewage sludge as struvite, Bioresource Technology. 102 (2011) 5824-5830. doi:10.1016/j.biortech.2011.02.089.

[118] B.R. Ringeisen, E. Henderson, P.K. Wu, J. Pietron, R. Ray, B. Little, J.C. Biffinger, J.M. Jones-Meehan, High power density from a miniature microbial fuel cell using Shewanella oneidensis DSP10, Environ. Sci. Technol. 40 (2006) 2629-2634.

[119] J. Cao, X. Li, Y. Wang, F.C. Walsh, J.-H. Ouyang, D. Jia, Y. Zhou, Materials and fabrication of electrode scaffolds for deposition of $\mathrm{MnO}_{2}$ and their true performance in supercapacitors, J. Power Sources. 293 (2015) 657674. doi:10.1016/j.jpowsour.2015.05.115.

[120] M. Łukaszewski, A. Żurowski, A. Czerwiński, Hydrogen in thin Pd-based layers deposited on reticulated vitreous carbon-A new system for electrochemical capacitors, J. Power Sources. 185 (2008) 1598-1604. doi:10.1016/j.jpowsour.2008.08.002.

[121] M. Łukaszewski, K. Hubkowska, U. Koss, Characteristic of hydrogensaturated Pd-based alloys for the application in electrochemical capacitors, J. Solid State Electrochem. 16 (2012) 2533-2539.

[122] R. Narayanan, H. Vijwani, S.M. Mukhopadhyay, P.R. Bandaru, Electrochemical charge storage in hierarchical carbon manifolds, Carbon. 99 (2016) 267-271. doi:10.1016/j.carbon.2015.11.078.

[123] B. Yue, C. Wang, X. Ding, G.G. Wallace, Polypyrrole coated nylon lycra fabric as stretchable electrode for supercapacitor applications, Electrochim. Acta. 68 (2012) 18-24. doi:10.1016/j.electacta.2012.01.109. 
[124] H.D. Dewald, J. Wang, Spectroelectrochemical detector for flow-injection systems and liquid chromatography, Anal. Chim. Acta. 166 (1985) 163-170. doi:10.1016/S0003-2670(00)84863-1.

[125] R.G. Compton, G. Hancock (Eds.), Applications of kinetic modelling, in: Comprehensive Chemical Kinetics, Elsevier, Oxford, 1999.

[126] S. Babanova, U. Martinez, K. Artyushkova, K. Asazawa, H. Tanaka, P. Atanassov, Hydrazine sensor for quantitative determination of high hydrazine concentrations for direct hydrazine fuel cell vehicle applications, J. Electrochem. Soc. 161 (2014) H79-H85. doi:10.1149/2.005403jes.

[127] H.Y. Shedge, S.E. Creager, Evaluation of non-specific binding suppression schemes for neutravidin and alkaline phosphatase at the surface of reticulated vitreous carbon electrodes, Anal. Chim. Acta. 657 (2010) 154-162. doi:10.1016/j.aca.2009.10.044.

[128] L.C.S. Figueiredo Filho, D.A.C. Brownson, O. Fatibello Filho, C.E. Banks, Electroanalytical performance of a freestanding three-dimensional graphene foam electrode, Electroanalysis. 26 (2014) 93-102. doi:10.1002/elan.201300363.

[129] C. Deng, Y. Peng, L. Su, Y.-N. Liu, F. Zhou, On-line removal of redoxactive interferents by a porous electrode before amperometric blood glucose determination, Anal. Chim. Acta. 719 (2012) 52-56. doi:10.1016/j.aca.2012.01.008.

[130] N. Peña, A.J. Reviejo, J.M. Pingarrón, Detection of phenolic compounds in flow systems based on tyrosinase-modified reticulated vitreous carbon electrodes, Talanta. 55 (2001) 179-187. doi:10.1016/S0039-9140(01)004143.

[131] R.B. Congdon, A.S. Feldberg, N. Ben-Yakar, D. McGee, C. Ober, B. Sammakia, O.A. Sadik, Early detection of Candida albicans biofilms at porous electrodes, Analytical Biochemistry. 433 (2013) 192-201. doi:10.1016/j.ab.2012.10.016.

[132] M. Berrettoni, D. Tonelli, P. Conti, R. Marassi, M. Trevisani, Electrochemical sensor for indirect detection of bacterial population, Sensors and Actuators B: Chemical. 102 (2004) 331-335.

doi:10.1016/j.snb.2004.04.022.

[133] N. Sleszynski, J. Osteryoung, M. Carter, Arrays of very small voltammetric electrodes based on reticulated vitreous carbon, Anal. Chem. 56 (1984) 130 135. doi:10.1021/ac00266a004.

[134] G.W. Reade, A.H. Nahle, P. Bond, J.M. Friedrich, F.C. Walsh, Removal of cupric ions from acidic sulfate solution using reticulated vitreous carbon rotating cylinder electrodes, J. Chem. Technol. Biotechnol. 79 (2004) 935945. doi:10.1002/jctb.1076.

[135] G.W. Reade, P. Bond, C.P. de Leon, F.C. Walsh, The application of 
reticulated vitreous carbon rotating cylinder electrodes to the removal of cadmium and copper ions from solution, J. Chem. Technol. Biotechnol. 79 (2004) 946-953. doi:10.1002/jctb.1097.

[136] G.W. Reade, C. Ponce de León, F.C. Walsh, Enhanced mass transport to a reticulated vitreous carbon rotating cylinder electrode using jet flow, Electrochim. Acta. 51 (2006) 2728-2736. doi:10.1016/j.electacta.2005.08.009.

[137] F.C. Walsh, C. Ponce de León, D.V. Bavykin, C.T.J. Low, S.C. Wang, C. Larson, The formation of nanostructured surfaces by electrochemical techniques: a range of emerging surface finishes - Part 1: achieving nanostructured surfaces by electrochemical techniques, Trans. Inst. Met. Finish. 93 (2015) 209-224. doi:10.1179/0020296715Z.000000000252.

[138] F.C. Walsh, C. Ponce de León, D.V. Bavykin, C.T.J. Low, S.C. Wang, C. Larson, The formation of nanostructured surfaces by electrochemical techniques: a range of emerging surface finishes. Part 2: examples of nanostructured surfaces by plating and anodising with their applications, Trans. Inst. Met. Finish. 93 (2015) 241-247.

[139] F.C. Walsh, C.T.J. Low, Composite, multilayer and three-dimensional substrate supported, tin-based electrodeposits from methanesulphonic acid, Trans. Inst. Met. Finish. 94 (2016) 152-158.

[140] P.W.A.M. Wenmakers, J. van der Schaaf, B.F.M. Kuster, J.C. Schouten, "Hairy Foam": carbon nanofibers grown on solid carbon foam. A fully accessible, high surface area, graphitic catalyst support, J. Mater. Chem. 18 (2008) 2426-2436. doi:10.1039/B718673H.

[141] A.K. Karumuri, L. He, S.M. Mukhopadhyay, Tuning the surface wettability of carbon nanotube carpets in multiscale hierarchical solids, Applied Surface Science. 327 (2015) 122-130. doi:10.1016/j.apsusc.2014.10.154.

[142] A. Marukovich, O. Smorygo, V. Mikutski, A. Ilyushchanka, A. Pramono, Mechanical and hydraulic properties of open-cell vitreous carbon foams manufactured by different methods, Euro PM2015 - Non-Ferrous and Special Materials. (2015).

[143] E. Maire, X-ray tomography applied to the characterization of highly porous materials, Annu. Rev. Mater. Res. 42 (2012) 163-178. doi:10.1146/annurevmatsci-070511-155106.

[144] K. Alayavalli, D.L. Bourell, Fabrication of modified graphite bipolar plates by indirect selective laser sintering (SLS) for direct methanol fuel cells, Rapid Prototyping J. 16 (2010) 268-274. doi:10.1108/13552541011049289.

[145] C. Ponce de León, W. Hussey, F. Frazao, D. Jones, E. Ruggeri, S. Tzortzatos, R.D. Mckerracher, R.G.A. Wills, S. Yang, F.C. Walsh, The 3D Printing of a polymeric electrochemical cell body and its characterisation, Chem. Eng. Trans. 41 (2014) 1-6. doi:10.3303/CET1441001. 
[146] L.F. Arenas, F.C. Walsh, C. Ponce de León, 3D-printing of redox flow batteries for energy storage: A rapid prototype laboratory cell, ECS J. Solid State Sci. Technol. 4 (2015) P3080-P3085. doi:10.1149/2.0141504jss.

[147] R. Critchley, I. Corni, J.A. Wharton, F.C. Walsh, R.J.K. Wood, K.R. Stokes, A review of the manufacture, mechanical properties and potential applications of auxetic foams, Physica Status Solidi (B). 250 (2013) 19631982. doi:10.1002/pssb.201248550.

[148] R. Critchley, I. Corni, J.A. Wharton, F.C. Walsh, R.J.K. Wood, K.R. Stokes, The preparation of auxetic foams by three-dimensional printing and their characteristics, Advanced Engineering Materials. 15 (2013) 980-985. doi:10.1002/adem.201300030.

[149] F.J. Recio, P. Herrasti, L. Vázquez, C. Ponce de León, F.C. Walsh, Mass transfer to a nanostructured nickel electrodeposit of high surface area in a rectangular flow channel, Electrochim. Acta. 90 (2013) 507-513. doi:10.1016/j.electacta.2012.11.135.

[150] B.C. Kim, P.C. Innis, G.G. Wallace, C.T.J. Low, F.C. Walsh, W.J. Cho, K.H. $\mathrm{Yu}$, Electrically conductive coatings of nickel and polypyrrole/poly(2methoxyaniline-5-sulfonic acid) on nylon Lycra ${ }^{\circledR}$ textiles, Progress in Organic Coatings. 76 (2013) 1296-1301. doi:10.1016/j.porgcoat.2013.04.004.

[151] C. Zhao, S. Farajikhah, C. Wang, J. Foroughi, X. Jia, G.G. Wallace, 3D braided yarns to create electrochemical cells, Electrochem. Commun. 61 (2015) 27-31.

[152] C.T.J. Low, F.C. Walsh, M.H. Chakrabarti, M.A. Hashim, M.A. Hussain, Electrochemical approaches to the production of graphene flakes and their potential applications, Carbon. 54 (2013) 1-21. doi:10.1016/j.carbon.2012.11.030.

[153] J. Cao, Y. Wang, J. Chen, X. Li, F.C. Walsh, J.-H. Ouyang, Y. Zhou, Threedimensional graphene oxide/polypyrrole composite electrodes fabricated by one-step electrodeposition for high performance supercapacitors, J. Mater. Chem. A. 3 (2015) 14445-14457. doi:10.1039/C5TA02920A.

[154] F.C. Walsh, C. Ponce de León, A review of the electrodeposition of metal matrix composite coatings by inclusion of particles in a metal layer: an established and diversifying technology, Trans. Inst. Met. Finish. 92 (2014) 83-98. doi:10.1179/0020296713Z.000000000161.

[155] C.T.J. Low, R.G.A. Wills, F.C. Walsh, Electrodeposition of composite coatings containing nanoparticles in a metal deposit, Surf. Coat. Technol. 201 (2006) 371-383.

[156] S. Chen, G. He, H. Hu, S. Jin, Y. Zhou, Y. He, S. He, F. Zhao, H. Hou, Elastic carbon foam via direct carbonization of polymer foam for flexible electrodes and organic chemical absorption, Energy Environ. Sci. 6 (2013) 
2435-2439. doi:10.1039/C3EE41436A.

[157] D.T. Queheillalt, D.D. Hass, D.J. Sypeck, H.N.G. Wadley, Synthesis of open-cell metal foams by templated directed vapor deposition, Journal of Materials Research. 16 (2001) 1028-1036. doi:10.1557/JMR.2001.0143.

[158] A. Szczurek, V. Fierro, A. Pizzi, M. Stauber, A. Celzard, Carbon meringues derived from flavonoid tannins, Carbon. 65 (2013) 214-227.

[159] F.C. Walsh, Carbon fibre-RVC hybrid electrodes from carbonised sugar strands in RVC, Umpublished Work. (2016).

[160] L. Porcarelli, C. Gerbaldi, F. Bella, J.R. Nair, Super soft all-ethylene oxide polymer electrolyte for safe all-solid lithium batteries, Sci. Rep. (2016) 1-14. doi:10.1038/srep19892. 


\begin{tabular}{|c|c|c|c|c|c|}
\hline $\begin{array}{c}\text { Porosity } \\
\text { grade } \\
\text { / ppi }\end{array}$ & $\begin{array}{c}\text { Pore } \\
\text { diameter, } \\
d_{p} \\
/ \mathrm{cm}\end{array}$ & $\begin{array}{c}\text { Strut } \\
\text { thickness, } \\
d_{s} \\
/ \mathrm{cm}\end{array}$ & $\begin{array}{c}\text { Ergun } \\
\text { pore } \\
\text { diameter, } \\
d_{e} \\
/ \mathrm{cm}\end{array}$ & $\begin{array}{c}\text { Dispersion } \\
\text { ratio, } \\
\sigma=d_{p} / d_{s}\end{array}$ & $\begin{array}{c}\text { Volumetric } \\
\text { area, } \\
A_{e}=A / V_{e} \\
/ \mathbf{c m}^{-1}\end{array}$ \\
\hline 10 & 0.18 & 0.039 & 0.29 & 0.22 & 13.5 \\
\hline 30 & 0.10 & 0.020 & 0.16 & 0.20 & 24.6 \\
\hline 60 & 0.040 & 0.0380 & 0.10 & 0.20 & 38.0 \\
\hline 100 & 0.025 & 0.0056 & 0.057 & 0.22 & 67.5 \\
\hline
\end{tabular}

Table 1. Characteristic geometrical measurements on several porosity grades of RVC. Basis: analysis of multiple SEM images [36]. 


\begin{tabular}{|c|c|c|c|c|}
\hline $\begin{array}{l}\text { Electrode } \\
\text { type }\end{array}$ & $\begin{array}{l}\text { Electrode } \\
\text { material }\end{array}$ & $\begin{array}{l}\text { Volumetric } \\
\text { porosity, } \varepsilon\end{array}$ & $\begin{array}{c}\text { Volumetric } \\
\text { electrode } \\
\text { area, } A_{e} / \\
\mathrm{cm}^{-1}\end{array}$ & Ref. \\
\hline Packed bed & $\begin{array}{l}\text { Carbon granules } \\
(0.1-0.0001 \mathrm{~cm})\end{array}$ & 0.3 & 25 & [48] \\
\hline $\begin{array}{l}\text { Stacked } \\
\text { meshes }\end{array}$ & $\begin{array}{l}100 \text { mesh } \mathrm{Cu} \\
\text { screen } \\
150 \text { mesh } \mathrm{Cu} \\
\text { screen } \\
200 \text { mesh } \mathrm{Cu} \\
\text { screen }\end{array}$ & $\begin{array}{l}0.61 \\
0.69 \\
0.67\end{array}$ & $\begin{array}{l}143 \\
188 \\
245\end{array}$ & [49] \\
\hline $\begin{array}{l}\text { One-piece } \\
\text { foam }\end{array}$ & $\begin{array}{l}10 \text { ppi } \mathrm{Cu} \\
20 \text { ppi } \mathrm{Cu}\end{array}$ & $\begin{array}{l}0.975 \\
0.968\end{array}$ & $\begin{array}{l}6.9 \\
9.0\end{array}$ & {$[50]$} \\
\hline $\begin{array}{l}\text { One-piece } \\
\text { foam }\end{array}$ & $\begin{array}{l}45 \text { ppi Ni } \\
60 \text { ppi Ni } \\
100 \text { ppi Ni }\end{array}$ & $\begin{array}{l}0.973 \\
0.968 \\
0.975\end{array}$ & $\begin{array}{l}37.5 \\
57.5 \\
92.5\end{array}$ & [45] \\
\hline $\begin{array}{l}\text { One-piece } \\
\text { foam }\end{array}$ & $\begin{array}{l}10 \text { ppi } C \\
30 \text { ppi } C \\
45 \text { ppi } C \\
60 \text { ppi } C\end{array}$ & $\begin{array}{l}0.97 \\
0.97 \\
0.97 \\
0.97\end{array}$ & $\begin{array}{c}8.5 \\
18.0 \\
38.0 \\
66.0\end{array}$ & [3] \\
\hline
\end{tabular}

Table 2. Volumetric porosity and volumetric electrode area of RVC and other porous, 3-dimensional electrode materials [35]. 


\begin{tabular}{|c|c|c|c|c|c|}
\hline $\begin{array}{c}\text { Contaminan } \\
t\end{array}$ & Electrolyte & $\begin{array}{c}\text { Initial } \\
\text { Concentration }\end{array}$ & $\begin{array}{c}\text { Final } \\
\text { Concentration }\end{array}$ & Cell & Ref. \\
\hline $\mathrm{Cu}$ & $\begin{array}{c}0.5 \mathrm{Na}_{2} \mathrm{SO}_{4}, \\
\mathrm{pH} 2\end{array}$ & $\begin{array}{l}63 \mathrm{mg} \mathrm{dm}^{-3} \\
10 \mathrm{mg} \mathrm{dm}^{-3} \\
2 \mathrm{mg} \mathrm{dm}^{-3}\end{array}$ & $\begin{array}{l}<1 \mathrm{mg} \mathrm{dm}^{-3} \\
<0.4 \mathrm{mg} \mathrm{dm}^{-3} \\
<0.1 \mathrm{mg} \mathrm{dm}^{-3}\end{array}$ & $\begin{array}{c}\text { Divided, } \\
\text { rectangular channel } \\
\text { flow cell }\end{array}$ & $\begin{array}{c}{[19,69,} \\
70]\end{array}$ \\
\hline $\mathrm{Ag}$ & $\left(\mathrm{NH}_{4}\right)_{2} \mathrm{~S}_{2} \mathrm{O}_{3}$ & $108 \mathrm{mg} \mathrm{dm}^{-3}$ & $<2 \mathrm{mg} \mathrm{dm}^{-3}$ & $\begin{array}{c}\text { Divided, } \\
\text { rectangular channel } \\
\text { flow cell }\end{array}$ & {$[35]$} \\
\hline $\mathrm{Cu}, \mathrm{Cd}, \mathrm{Zn}$ & $\begin{array}{c}0.1 \mathrm{M} \mathrm{NaCl}, \\
\text { pH } 7\end{array}$ & $5 \mathrm{mM}$ & $\begin{array}{c}\text { Cu. Cd } \\
<<1 \mathrm{mg} \mathrm{dm}^{-3}\end{array}$ & $\begin{array}{c}\text { Divided, } \\
\text { rectangular channel } \\
\text { flow cell }\end{array}$ & [35] \\
\hline $\mathrm{Pb}$ & $\begin{array}{c}0.5 \mathrm{M} \mathrm{NaNO}_{3} \\
0.5 \mathrm{M} \mathrm{NaClO}_{4} \\
0.5 \mathrm{M} \mathrm{NaBF}_{4} \\
0.5 \mathrm{M} \mathrm{Na}_{2} \mathrm{SO}_{4} \\
\text { each at pH } 2\end{array}$ & $10 \mathrm{mg} \mathrm{dm}^{-3}$ & $<1 \mathrm{mg} \mathrm{dm}^{-3}$ & $\begin{array}{c}\text { Divided, } \\
\text { rectangular channel } \\
\text { flow cell }\end{array}$ & [74] \\
\hline $\mathrm{Cu}$ & $\begin{array}{c}1 \mathrm{M} \mathrm{Na}_{2} \mathrm{SO}_{4}, \\
\mathrm{pH} 2\end{array}$ & $63 \mathrm{mg} \mathrm{dm}^{-3}$ & $<1 \mathrm{mg} \mathrm{dm}^{-3}$ & $\begin{array}{l}8 \text { cathode divided, } \\
\text { single pass flow cell }\end{array}$ & {$[71]$} \\
\hline $\begin{array}{c}\text { Amaranth red } \\
\text { dye }\end{array}$ & $\begin{array}{c}0.1 \mathrm{M} \mathrm{Na}_{2} \mathrm{SO}_{4} \\
0.002 \mathrm{M} \mathrm{FeSO}_{4}\end{array}$ & $80 \mathrm{mg} \mathrm{dm}^{-3}$ & $<1 \mathrm{mg} \mathrm{dm}^{-3}$ & $\begin{array}{c}\text { Undivided, } \\
\text { rectangular channel } \\
\text { flow cell }\end{array}$ & [77] \\
\hline Blue basic 9 & $\begin{array}{l}0.05 \mathrm{M} \mathrm{Na}_{2} \mathrm{SO}_{4}, \\
0.001 \mathrm{M} \mathrm{FeSO}_{4}, \\
0.01 \mathrm{M} \mathrm{H}_{2} \mathrm{SO}_{4} \\
5.3 \mathrm{mM} \mathrm{H}_{2} \mathrm{O}_{2} \\
\end{array}$ & $26 \mathrm{mg} \mathrm{dm}^{-3}$ & $<3 \mathrm{mg} \mathrm{dm}^{-3}$ & $\begin{array}{c}\text { Divided, } \\
\text { rectangular channel } \\
\text { flow cell }\end{array}$ & [75] \\
\hline $\begin{array}{l}\text { Reactive } \\
\text { black } 5\end{array}$ & $\begin{array}{c}0.05 \mathrm{M} \mathrm{Na}_{2} \mathrm{SO}_{4} \\
0.001 \mathrm{M} \mathrm{FeSO}_{4} \\
0.01 \mathrm{M} \mathrm{H}_{2} \mathrm{SO}_{4} \\
5.3 \mathrm{mM} \mathrm{H}_{2} \mathrm{O}_{2}\end{array}$ & $63 \mathrm{mg} \mathrm{dm}^{-3}$ & $<6 \mathrm{mg} \mathrm{dm}^{-3}$ & $\begin{array}{c}\text { Divided, } \\
\text { rectangular channel } \\
\text { flow cell }\end{array}$ & [75] \\
\hline $\begin{array}{c}\text { Acid orange } \\
7\end{array}$ & $\begin{array}{c}0.05 \mathrm{M} \mathrm{Na}_{2} \mathrm{SO}_{4} \\
0.001 \mathrm{M} \mathrm{FeSO}_{4} \\
0.01 \mathrm{M} \mathrm{H}_{2} \mathrm{SO}_{4} \\
5.3 \mathrm{mM} \mathrm{H}_{2} \mathrm{O}_{2}\end{array}$ & $49 \mathrm{mg} \mathrm{dm}^{-3}$ & $<5 \mathrm{mg} \mathrm{dm}^{-3}$ & $\begin{array}{c}\text { Divided, } \\
\text { rectangular channel } \\
\text { flow cell }\end{array}$ & {$[75]$} \\
\hline
\end{tabular}

Table 3. Environmental and recycling applications of RVC.

Most studies used a 100 ppi RVC electrode at $c a .298 \mathrm{~K}$. 


\begin{tabular}{|c|c|c|c|c|}
\hline Species & Concentration & $\begin{array}{c}\text { Sensor } \\
\text { geometry }\end{array}$ & Technique & Ref. \\
\hline Hydrazine & $\begin{array}{c}0.05-5.0 \mathrm{~mol} \\
\mathrm{dm}^{-3}\end{array}$ & Flow-through & $\begin{array}{l}\text { Amperomerty at } \mathrm{Ni}_{(1-\mathrm{x})} \mathrm{La}_{\mathrm{x}} \\
\text { catalyst coating. }\end{array}$ & [126] \\
\hline Neutravidin & $0-20 \mathrm{~g} \mathrm{dm}^{-3}$ & Flow-through & $\begin{array}{c}\text { Amperomerty at neutravidin- } \\
\text { biotin complex coating. }\end{array}$ & [127] \\
\hline $\begin{array}{l}\text { Acetaminophen, } \\
\text { uric acid, } \\
\text { dopamine }\end{array}$ & $\begin{array}{c}2.5 \times 10^{-6}- \\
1.5 \times 10^{-4} \mathrm{~mol} \\
\mathrm{dm}^{-3}\end{array}$ & Static & $\begin{array}{c}\text { Amperometry by cyclic } \\
\text { voltammetry at bare RVC. }\end{array}$ & [128] \\
\hline Glucose & $\begin{array}{c}5.0 \times 10^{-5}- \\
4.0 \times 10^{-2} \mathrm{~mol} \\
\mathrm{dm}^{-3}\end{array}$ & Flow-through & $\begin{array}{l}\text { Electrolysis of interferents at } \\
\text { RVC followed by } \\
\text { amperometry at glucose } \\
\text { oxidase/ferrocenyl-1- } \\
\text { undecanethiol thin film. }\end{array}$ & [129] \\
\hline C. albicans & 138-6025 CFU* & $\begin{array}{c}\text { Static } \\
\text { electrode with } \\
\text { electrolyte } \\
\text { agitation }\end{array}$ & $\begin{array}{l}\text { Amperometry of reduction of } \\
\text { potassium ferricyanide by } \\
\text { biofilm. }\end{array}$ & [131] \\
\hline $\begin{array}{l}\text { Phenolic } \\
\text { compounds }\end{array}$ & $\begin{array}{c}5.0 \times 10^{-6}- \\
10.0 \times 10^{-5} \mathrm{~mol} \\
\mathrm{dm}^{-3}\end{array}$ & Flow-through & $\begin{array}{l}\text { Amperometry at tyrosinase on } \\
\text { RVC surface, inmobilized by a } \\
\text { carbodiimide/ glutaraldehyde. }\end{array}$ & [130] \\
\hline
\end{tabular}

* CFU: colony-forming units.

Table 4. Examples of recent sensors using RVC electrodes. 


\section{Figure captions}

Figure 1. A time-line for the implementation of reticulated vitreous carbon electrodes, indicating important developments in their structure, characteristics and applications. The Kelvin conjecture for efficient pore filling of space (1887) [11]; Glassy carbon manufacture (1963) [12]; RVC manufacture patent (1969) [13]; Flow-through electrodes and flow electrolysis (1979) [14]; Rotating flow-through RVC electrode (1980) [15]; Wang review of RVC electrodes in early electroanalysis (1981) [5]; Flow cell electrochemical detector (1984) [16]; Deposition of heavy metals (1984) [17]; Platinized RVC for biosensors (1990) [18]; Metal ion removal from process streams (1991) [19]; Weaire-Phelan computer simulation of pore structure (1994) [20]; Mass transport at RVC rotating cylinder electrodes (1995) [21]; Removal of formaldehyde in electrochemical flow reactors (1995) [22]; Enzyme-modified RVC for bioelectrosynthesis (1997) [23]; Application as current collectors in Pb-acid batteries (2003) [24]; Friedrich et al. review of RVC in applied electrochemistry (2004) [6]; Application of RVC as a microbial fuel cell electrode (2005) [25]; Application of RVC to anodic Fenton oxidation (2006) [26]; Review of RVC electrodes in batteries (2009) [27]; Application of RVC to 3Dmicrobatteries (2011) [28]; RVC hybrid electrode with nanotubular webs (2014) [29].

Figure 2. The interrelationships of structure, properties and applications for RVC electrodes.

Figure 3. SEM micrographs of: (a) 10, (b) 30, (c) 60, (d) 80 and e) 100 ppi (nominal pores per linear inch) porosity grades of RVC [34].

Figure 4. SEM micrographs of skeletal struts in: (a) 10, (b) 30 and (c) 100 ppi porosity grades of RVC [34]. 
Figure 5. SEM micrographs of 100 ppi RVC sample at various magnifications. The white lines indicate measurements that were taken to characterise the material. a) The white circle marks the region used to calculate the area of the trigonal strut. b) The white distance bars indicate the measurements taken to obtain the length and thickness of a strut. c) Cell length and width along the three white lines were measured to obtain information on cell size distribution and anisotropy [34].

Figure 6. An SEM micrograph of two neighbouring pores (fused 'alveoli') in 10 ppi porosity grade RVC, which are interconnected and share a common boundary [36].

Figure 7. Pore size distribution in 10 ppi and 30 ppi porosity grades of RVC from analysis of multiple SEM images. Data taken from Reade [36].

Figure 8. RVC area dimensions as a function of porosity grade: a) pore size and b) trigonal strut area. Data taken from Friedrich [34].

Figure 9. Relationships between volumetric electrode area or strut length and geometrical characteristics of RVC. a) volumetric electrode area, $A_{e}$ and porosity grade, b) volumetric electrode area, $A_{\mathrm{e}}$ and pore window size, c) volumetric electrode area, $A_{e}$ and strut length, $l_{s}$ and d) variation of strut length, $l_{s}$ with porosity grade. Data taken from Friedrich [34].

Figure 10. Determination of the product $k_{m} A_{e}$ for RVC using three methods: a) convective-diffusion limiting current measurements at 10 and $100 \mathrm{ppi}$ grades of RVC as a function of cupric ion concentration in $0.5 \mathrm{~mol}$ $\mathrm{dm}^{-3} \mathrm{Na}_{2} \mathrm{SO}_{4}$ at $\mathrm{pH} 2$ and $297 \mathrm{~K}$ at a mean linear flow velocity of 1.5 $\mathrm{cm} \mathrm{s}^{-1}$. Linear sweep voltammetry at $10 \mathrm{mV} \mathrm{s}^{-1}$, b) Plot of $k_{m} A_{e} v s . v$ for 10, 30, 60 and 100 ppi porosity grades of RVC for a divided, flow by reactor in the batch recirculation mode removing $\mathrm{Cu}^{2+}$ from 2500 $\mathrm{cm}^{3} 0.5 \mathrm{~mol} \mathrm{dm}^{-3} \mathrm{Na}_{2} \mathrm{SO}_{4}$ at $\mathrm{pH} 2$; c) pressure drop data and the Ergun 
equation for 10, 30, 60 and 100 ppi porosity grades of RVC via a plot of $\Delta p v / L v s . v$. Data taken from [35].

Figure 11. Plot of fractional reactant conversion vs. mean linear flow velocity for cupric ion removal onto 10, 30, 60 and 100 ppi grades of RVC cathode in a divided flow by reactor processing $0.5 \mathrm{~mol} \mathrm{dm}^{-3} \mathrm{Na}_{2} \mathrm{SO}_{4}$ at $\mathrm{pH} 2$ and $297 \mathrm{~K}$. Extrapolation to complete conversion allows the critical velocity to be estimated from the intercept on the vertical axis [35].

Figure 12. Strategies for modification of the structure or surface of RVC electrodes.

Figure 13. A segmented cathode Hull cell for metal electrodeposition studies. a) general arrangement and electrical circuit (DVM: digital voltmeter), b) front view of segmented cathode arrangement located in oblique side of cell, c) scanning electron micrograph of 80 ppi RVC [51].

Figure 14. Scanning electron micrographs showing copper deposition on an RVC electrode using $0.050 \mathrm{~mol} \mathrm{dm}^{-3} \mathrm{Cu}^{2+}$ in $0.5 \mathrm{~mol} \mathrm{dm}^{-3} \mathrm{Na}_{2} \mathrm{SO}_{4}$ at $\mathrm{pH} 2$ solution at various segmented electrodes and various applied currents after a 30 min electrolysis in the cell shown in Figure 13. a) position 10 (furthest from the anode) showing no significant copper deposit at 1 $\mathrm{mA} \mathrm{cm} \mathrm{cm}^{-2}$, b) nucleation of copper on position 9 at $10 \mathrm{~mA} \mathrm{~cm}$, c) smooth deposition of copper on position 7 at $20 \mathrm{~mA} \mathrm{~cm}^{-2}$, d) bulk deposition with localized nodules of copper on position 3 at $70 \mathrm{~mA}$ $\mathrm{cm}^{-2}$, e) nodular copper formation ('cauliflower' structures) on the electrode at position 2 at $80 \mathrm{~mA} \mathrm{~cm}^{-2}$ and $\mathrm{f}$ ) copper dendrite formation at position 1 (nearest the anode). Adapted and reproduced with permission from Tangirala et al. [51].

Figure 15. An example of electrosynthesis at RVC electrodes: SEMs for a) bare $\mathrm{RVC}$ and $\mathrm{RVC} / \mathrm{Pt}, \mathrm{b})$ before and $\mathrm{c}$ ) the surface after ozone production 
for 2 hours at a flooded RVC anode at $25{ }^{\circ} \mathrm{C}$. Pt was deposited from stationary $0.1 \mathrm{~mol} \mathrm{dm}{ }^{-3} \mathrm{H}_{2} \mathrm{SO}_{4}$ solution containing $5 \mathrm{mmol} \mathrm{dm}^{-3}$ platinate at $0.0 \mathrm{~V} v s . \mathrm{Ag} / \mathrm{AgCl}$ for 1 hour. Adapted and reproduced with permission from Awad et al. [54].

Figure 16. Electrochemical removal of Reactive Black dye on a 60 ppi anode. Normalized concentration decay of RB-5 against time at $-0.4 \mathrm{~V} v$ s. $\mathrm{Ag} / \mathrm{AgCl}$ in the presence of various $\mathrm{Fe}^{2+}$ concentrations: (घ) $0.0,(\bullet)$ $0.01,(\boldsymbol{\Delta}) 0.05$ and $\bullet) 0.10 \mathrm{mmol} \mathrm{dm}^{-3}$. Adapted and reproduced with permission from Vasconcelos et al. [78].

Figure 17. Power density vs. current density and polarization behaviour of a microbial fuel cell using an RVC anode. Adapted and reproduced with permission from Fischer et al. [117].

Figure 18. Neutravidin bioassay at an RVC electrode surface modified with phenylacetic acid and PEG. Adapted and reproduced with permission from Hedge and Creager [127].

Figure 19. An example of an electrochemical sensor using an RVC electrode: Typical cyclic voltammograms profiles for $1 \mathrm{mmol} \mathrm{dm}^{-3}$ hexaammineruthenium(III) chloride in $0.1 \mathrm{~mol} \mathrm{dm}^{-3} \mathrm{KCl}$ at potential sweep rates of 5-500 $\mathrm{mV} \mathrm{s}^{-1}$ at a) the freestanding 3D-RVC and b) the pretreated 3D-GF electrode. Adapted and reproduced with permission from Figueiredo-Filho et al. [128].

Figure 20. SEM images of a carbon nanotube "nanoweb" deposited on RVC; a) bare RVC; b), c) and d) "nanoweb" at different magnifications. Adapted and reproduced with permission from Flexer et al. [115]. 


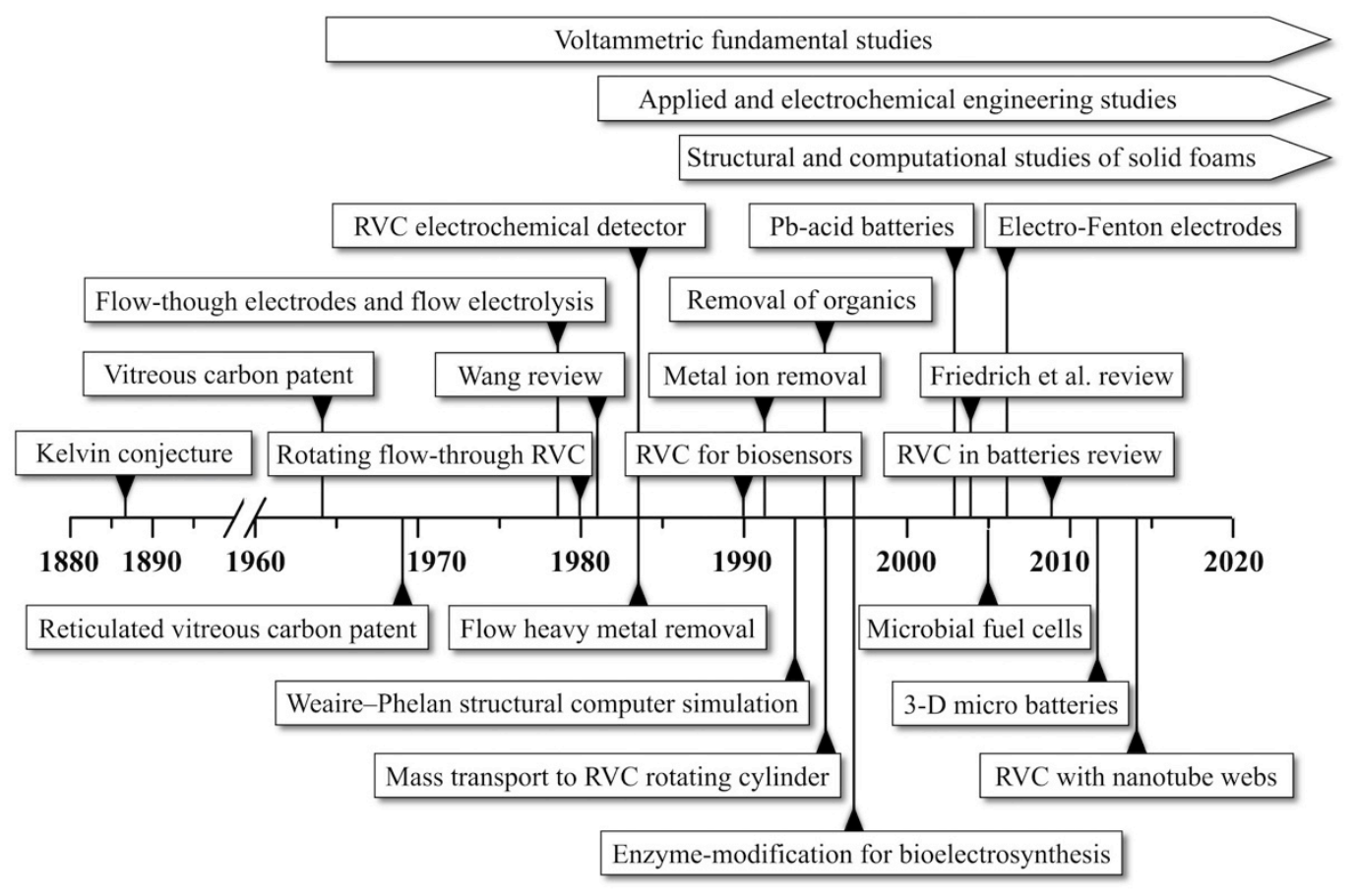

Figure 1. 


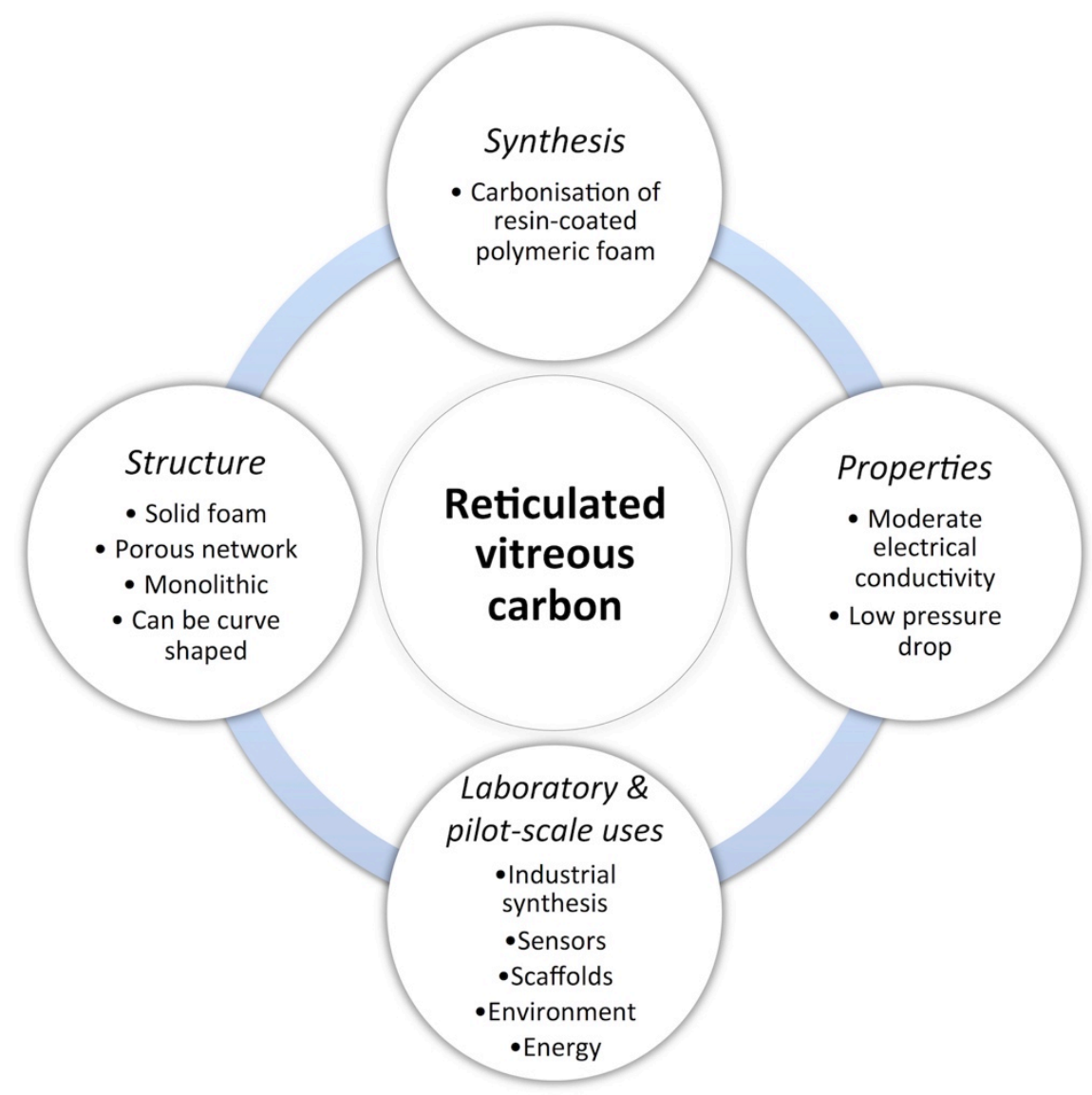

Figure 2. 

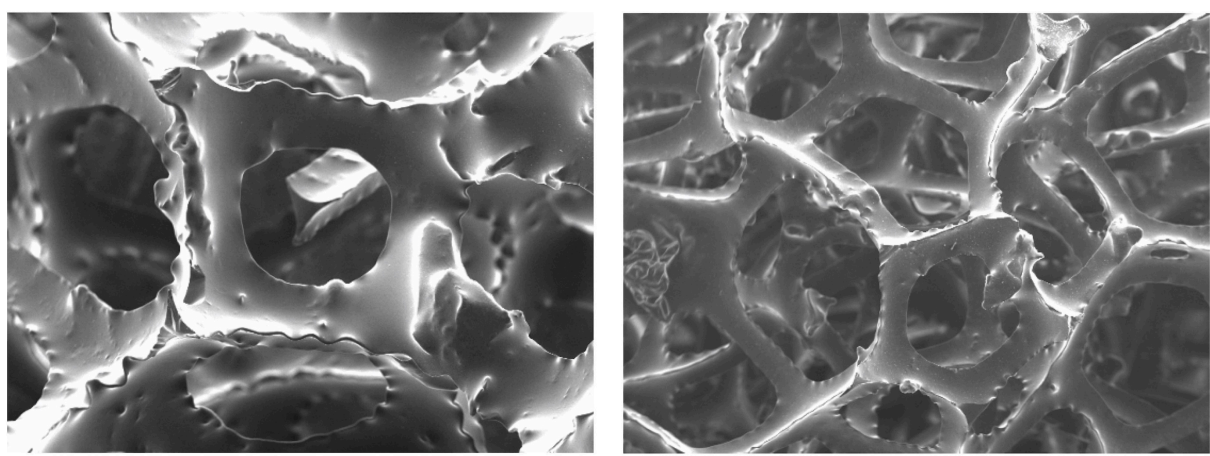

a)

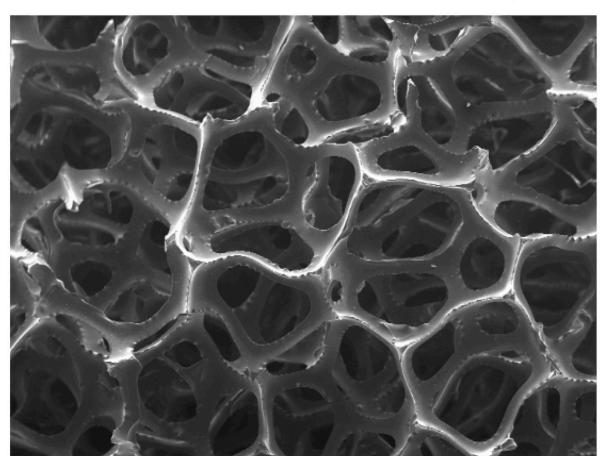

b)

$500 \mu \mathrm{m}$

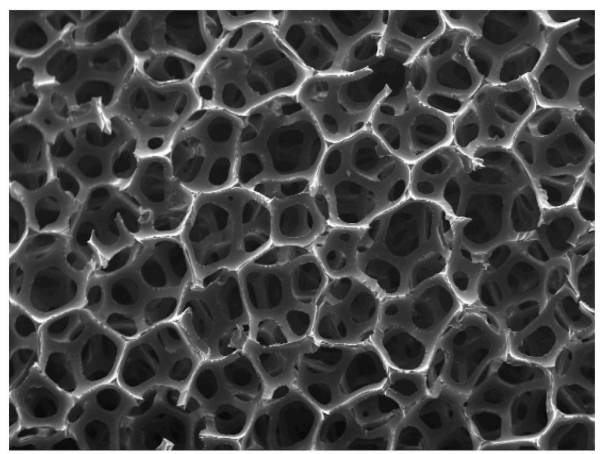

c)

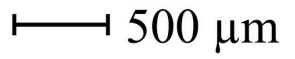

d)

$\longmapsto 500 \mu \mathrm{m}$

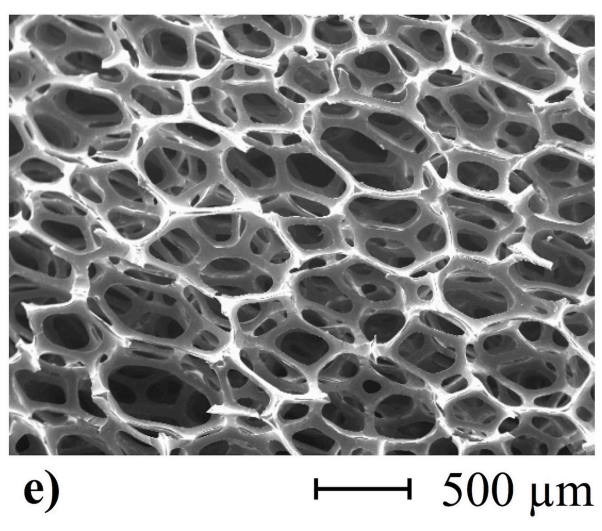

Figure 3. 

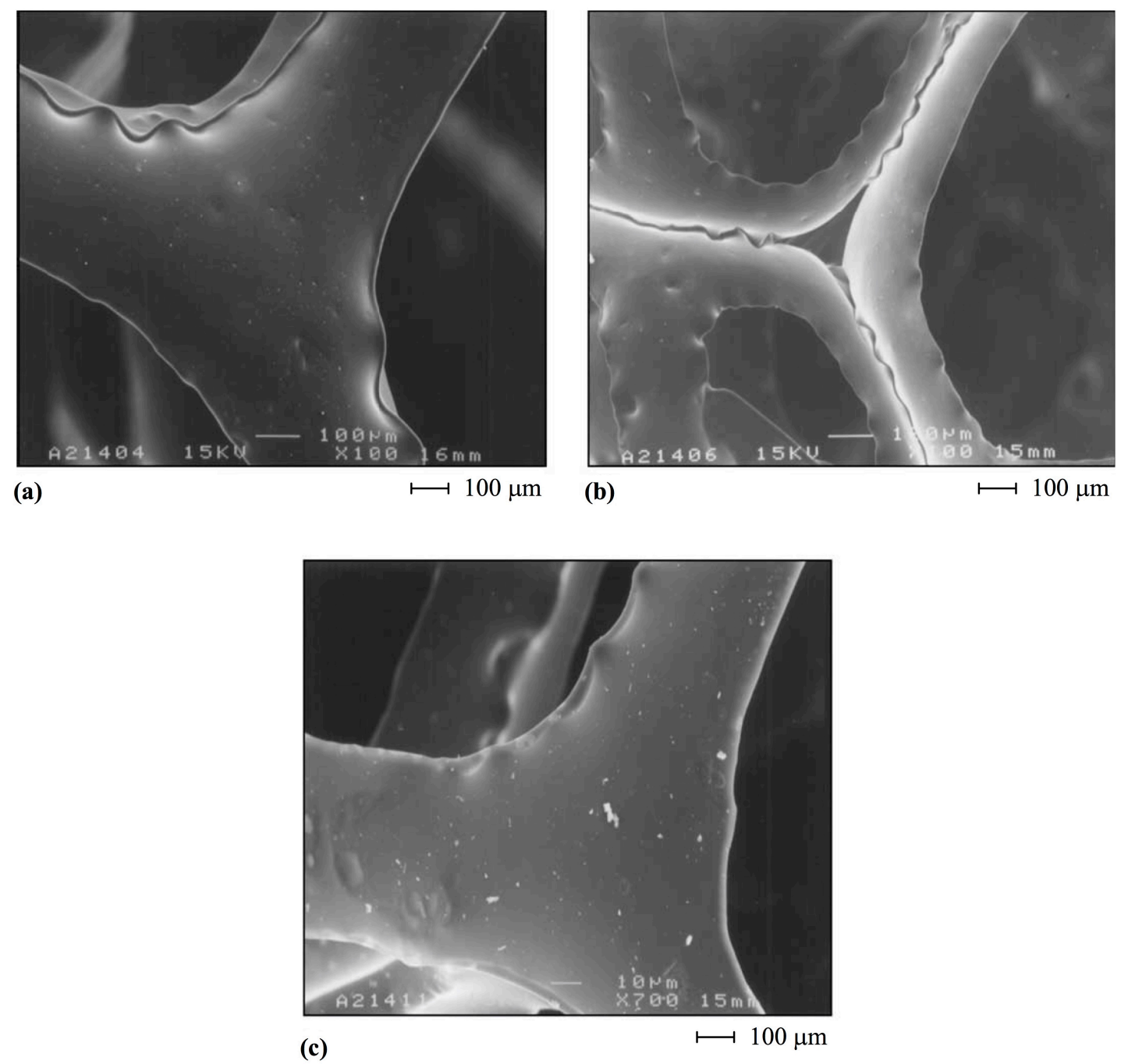

Figure 4. 


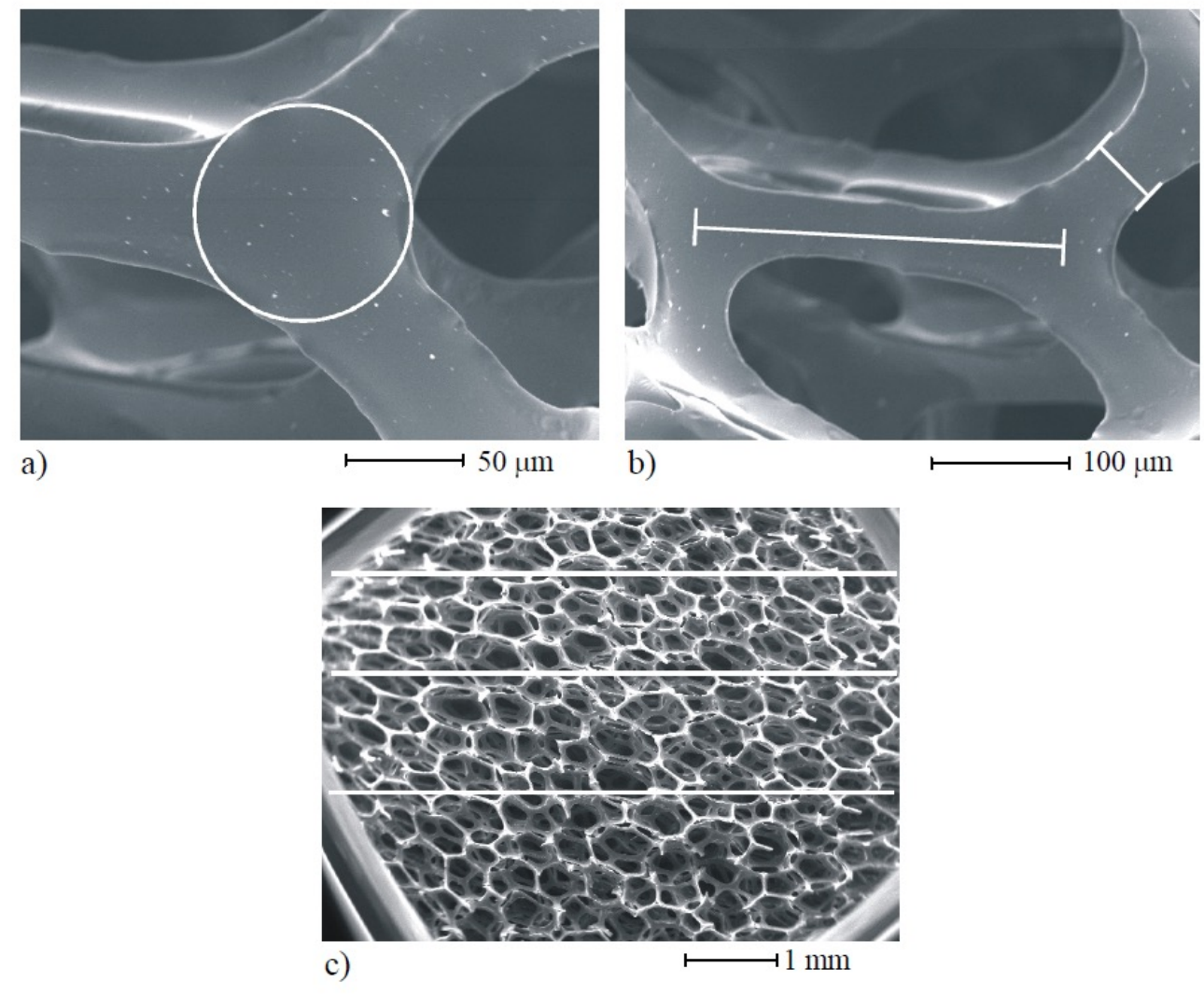

Figure 5. 


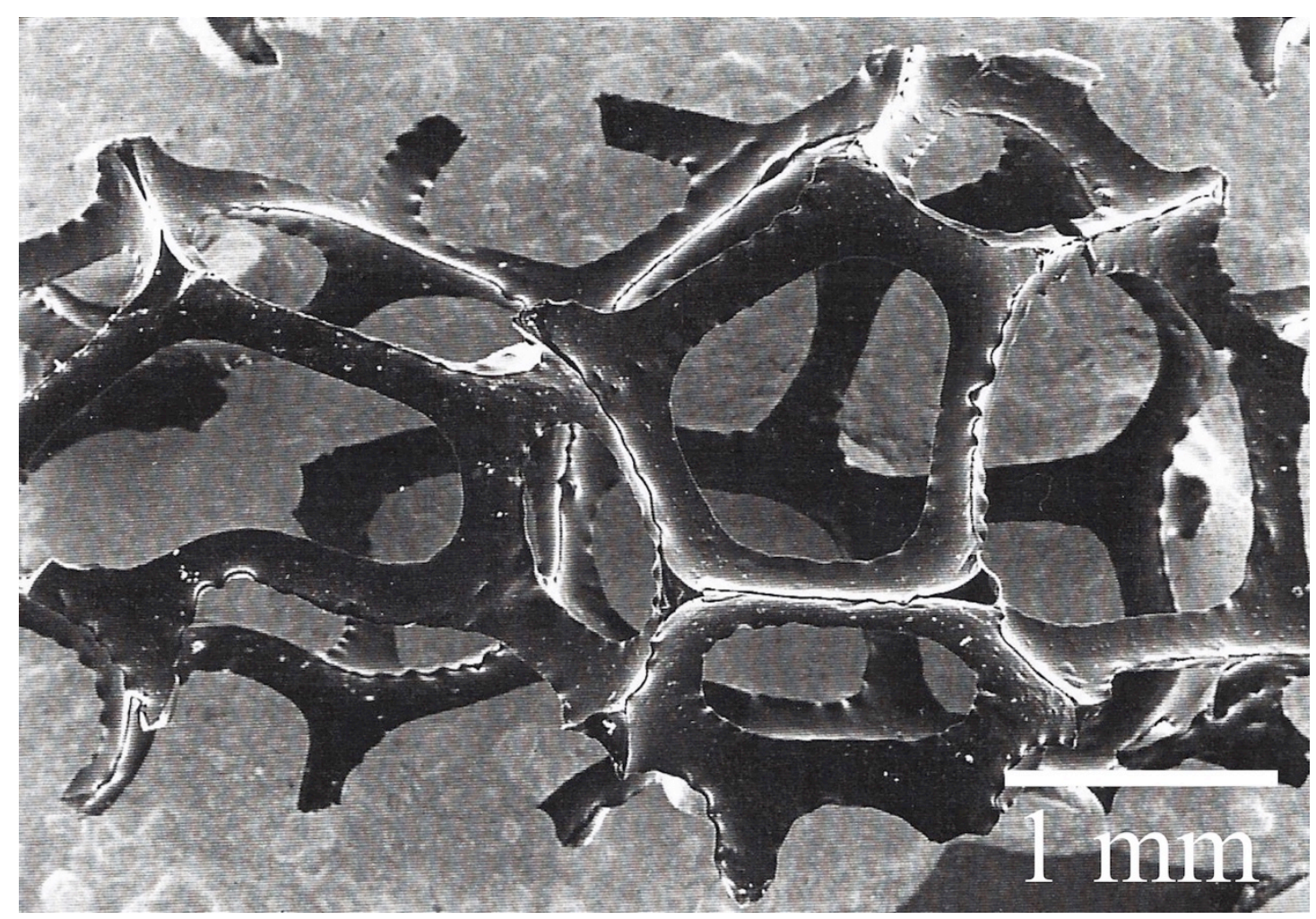

Figure 6. 


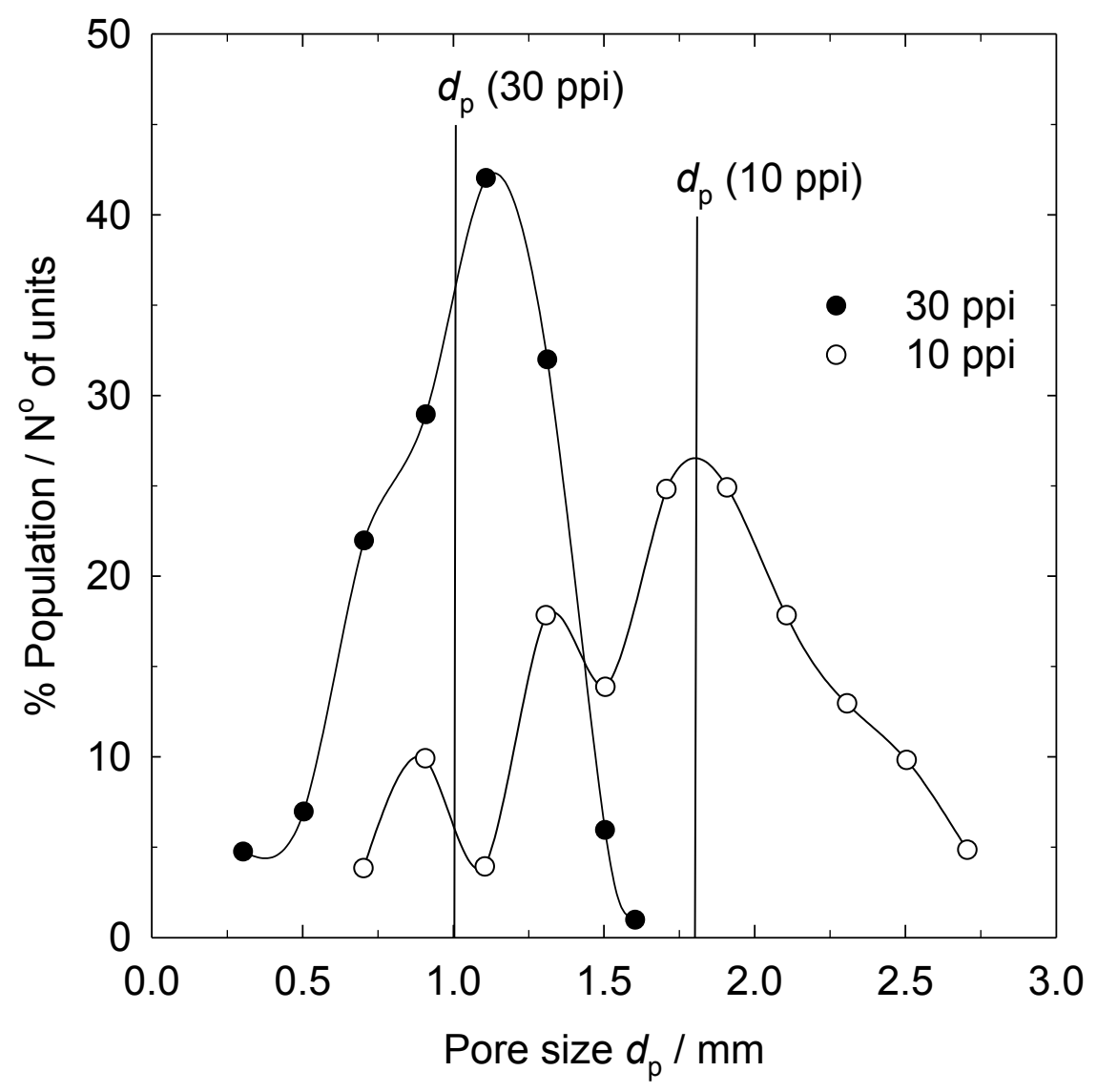

Figure 7. 


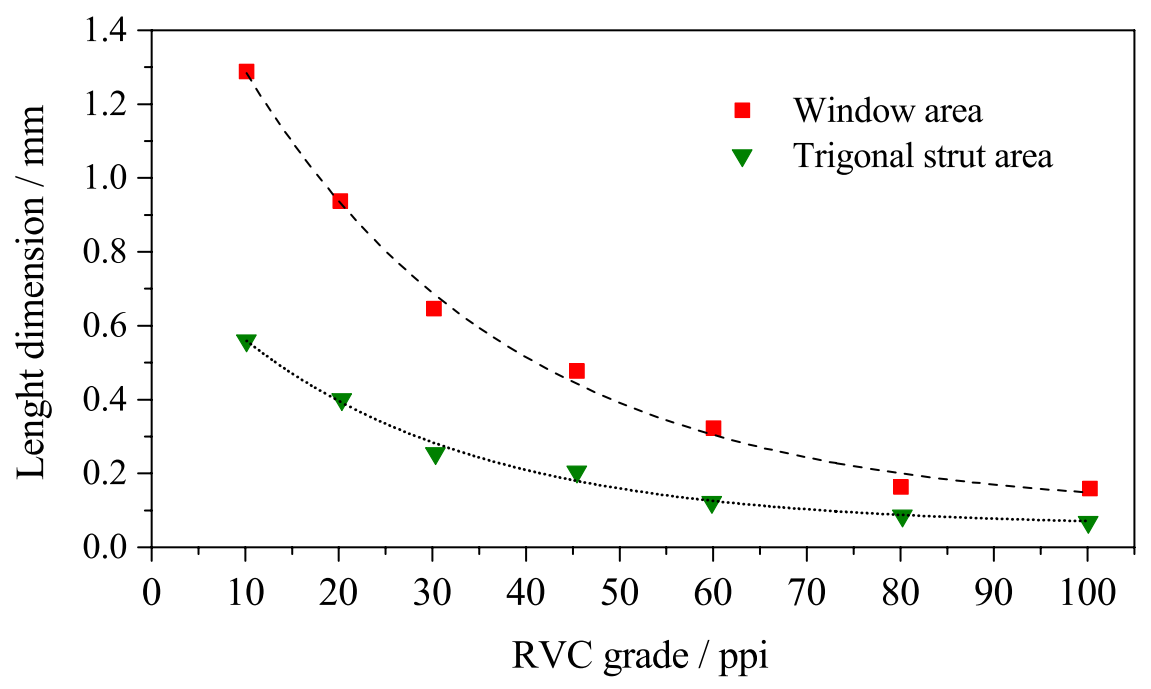

Figure 8a).

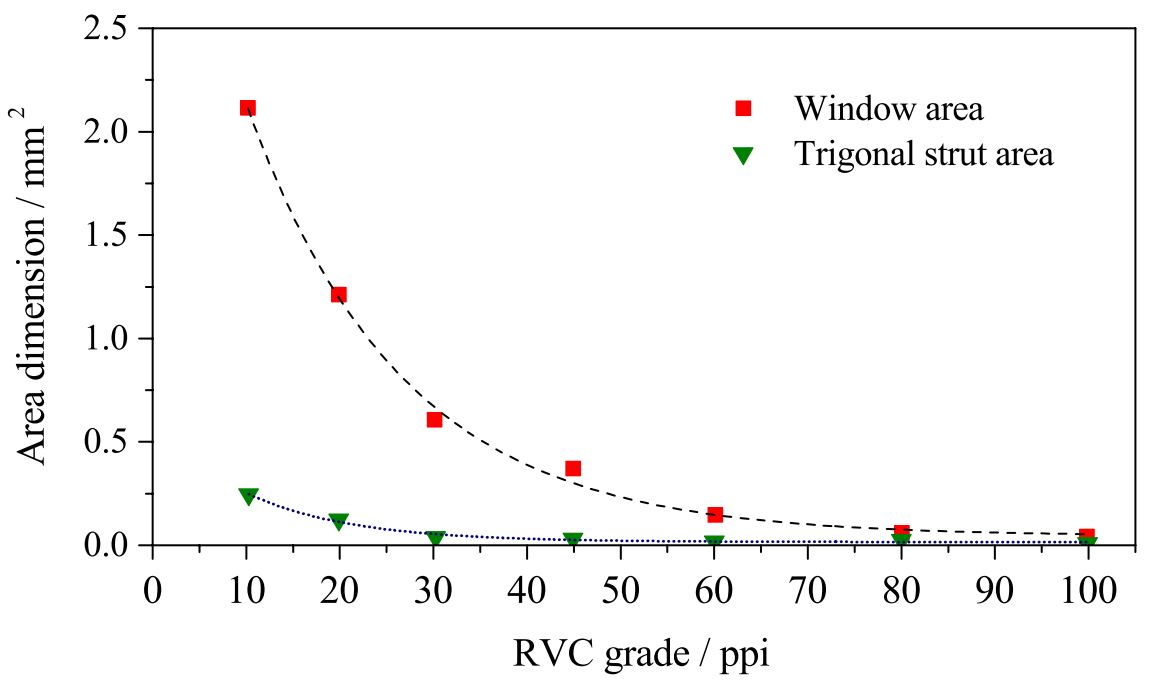

Figure 8b). 


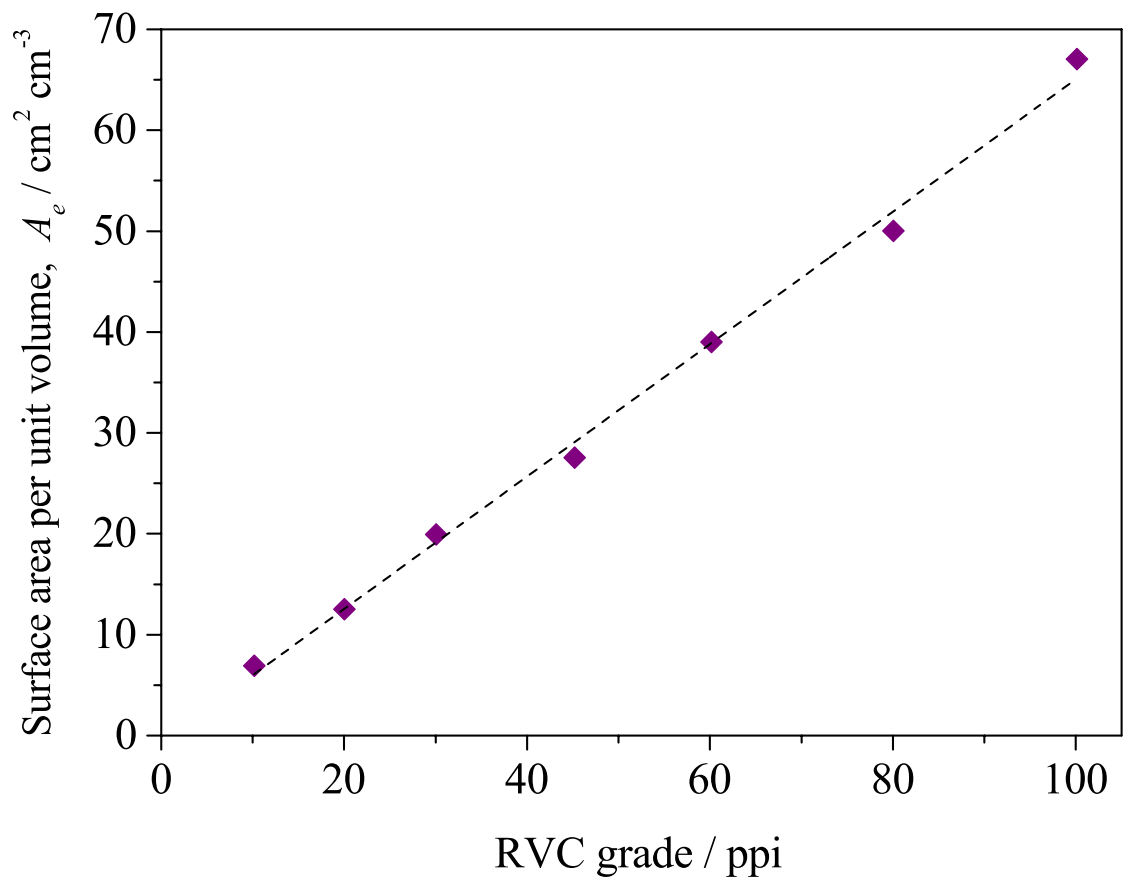

Figure 9a).

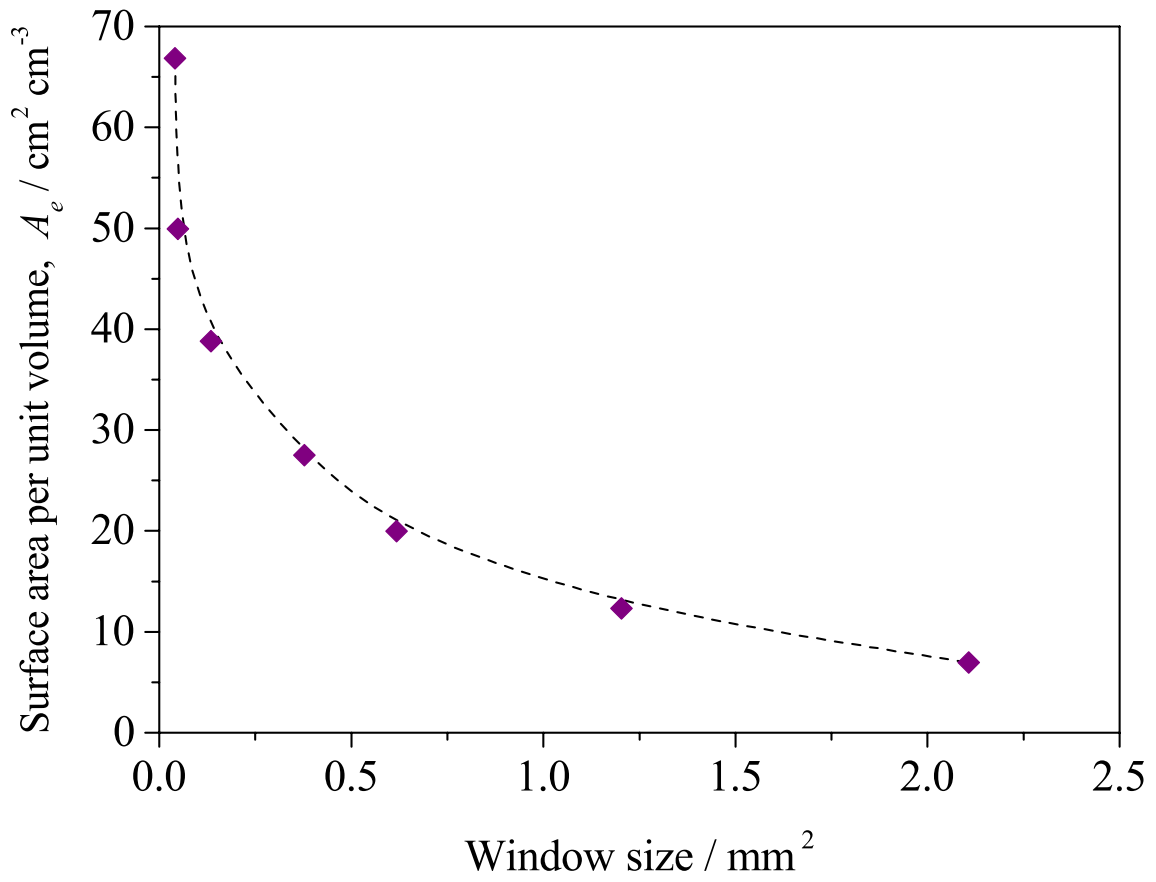

Figure 9b). 


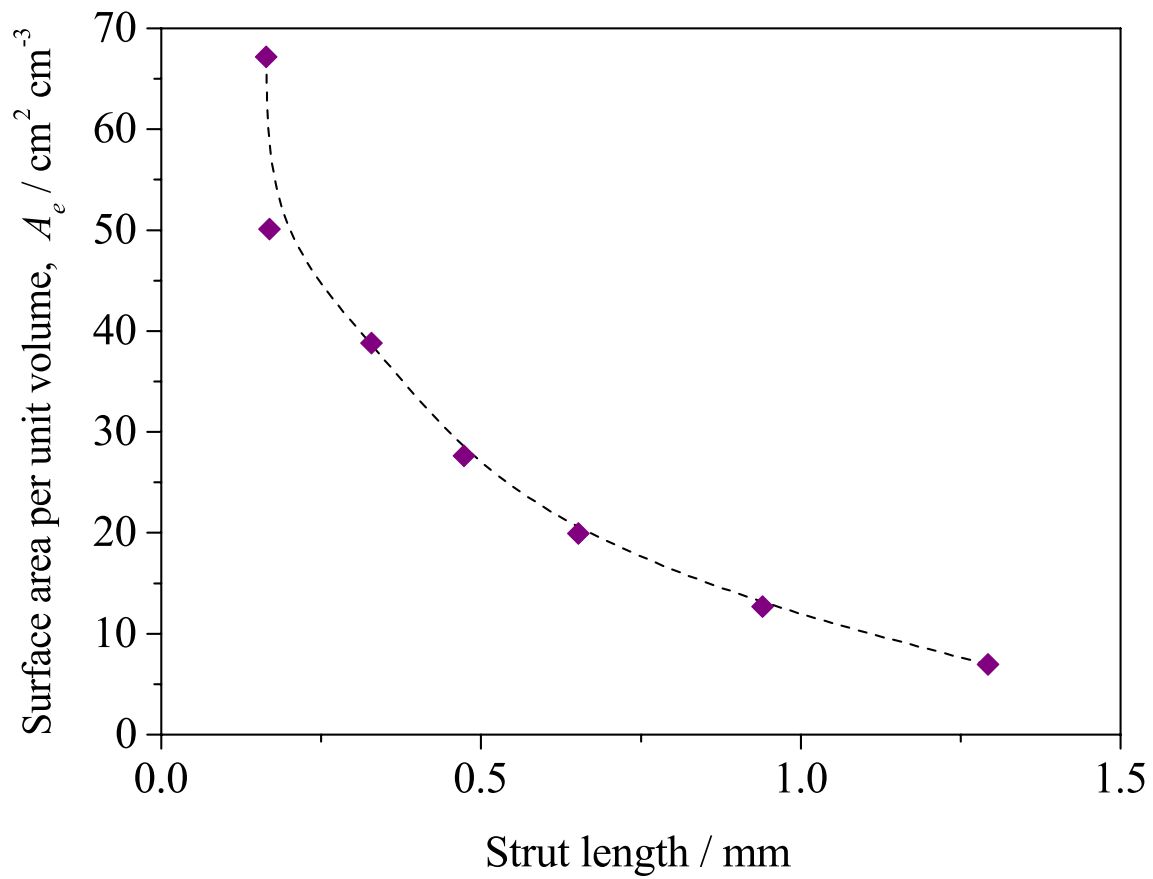

Figure 9c).

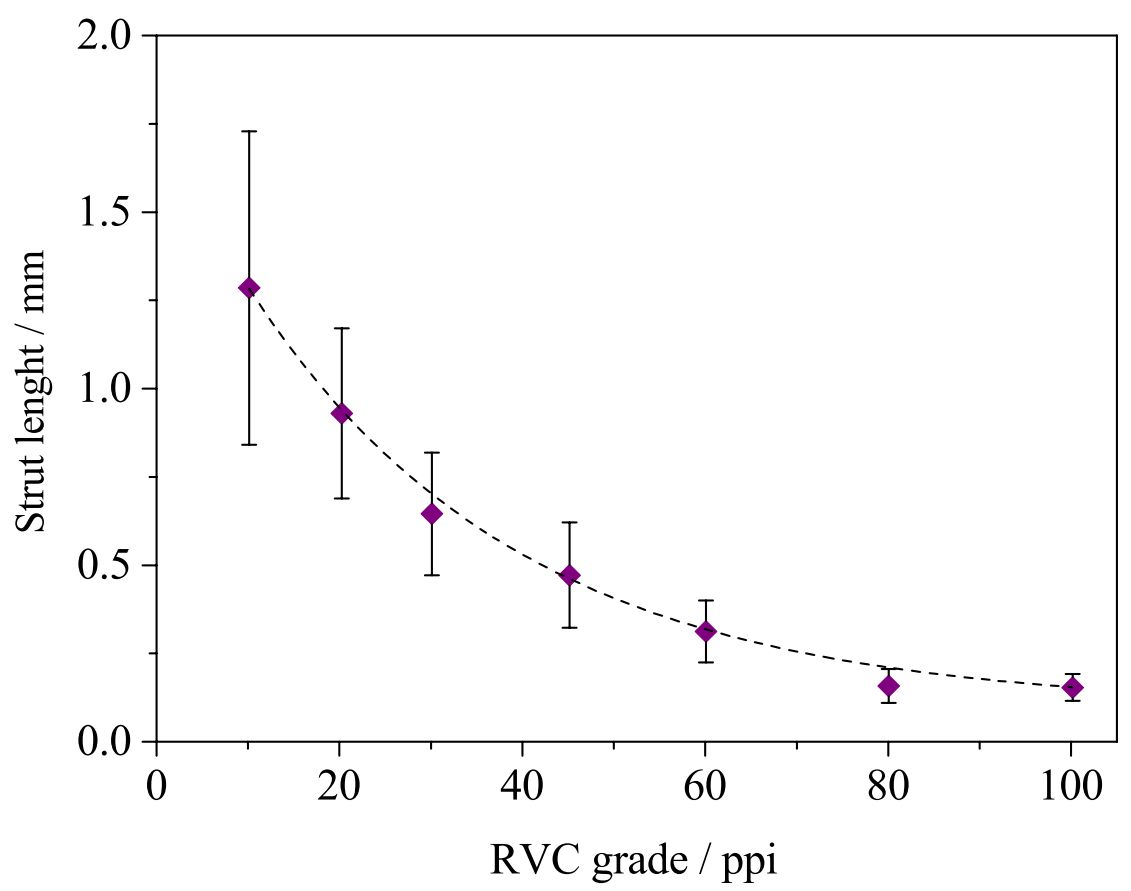

Figure 9d). 


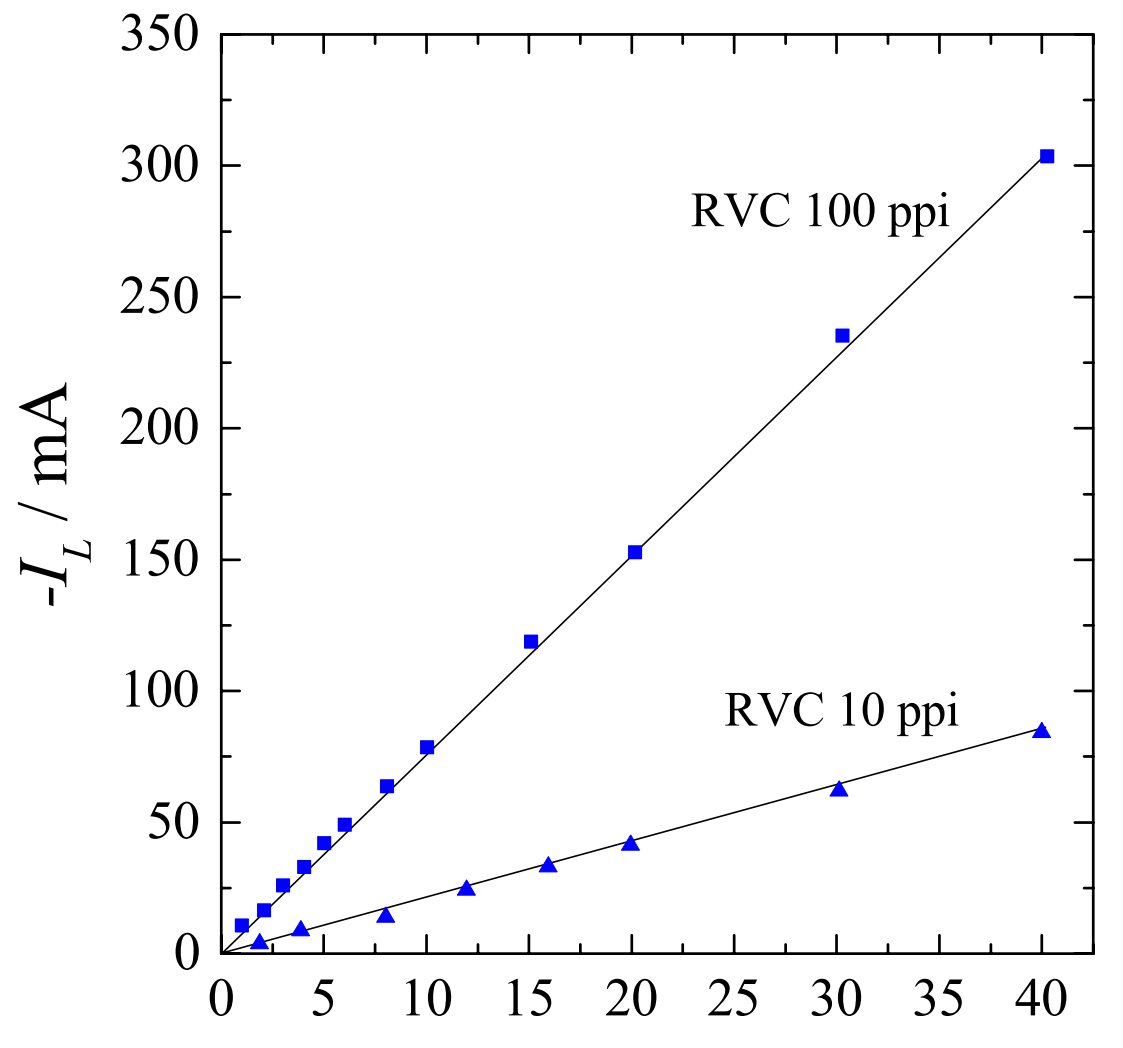

Cupric ion concentration / ppm

Figure 10a). 


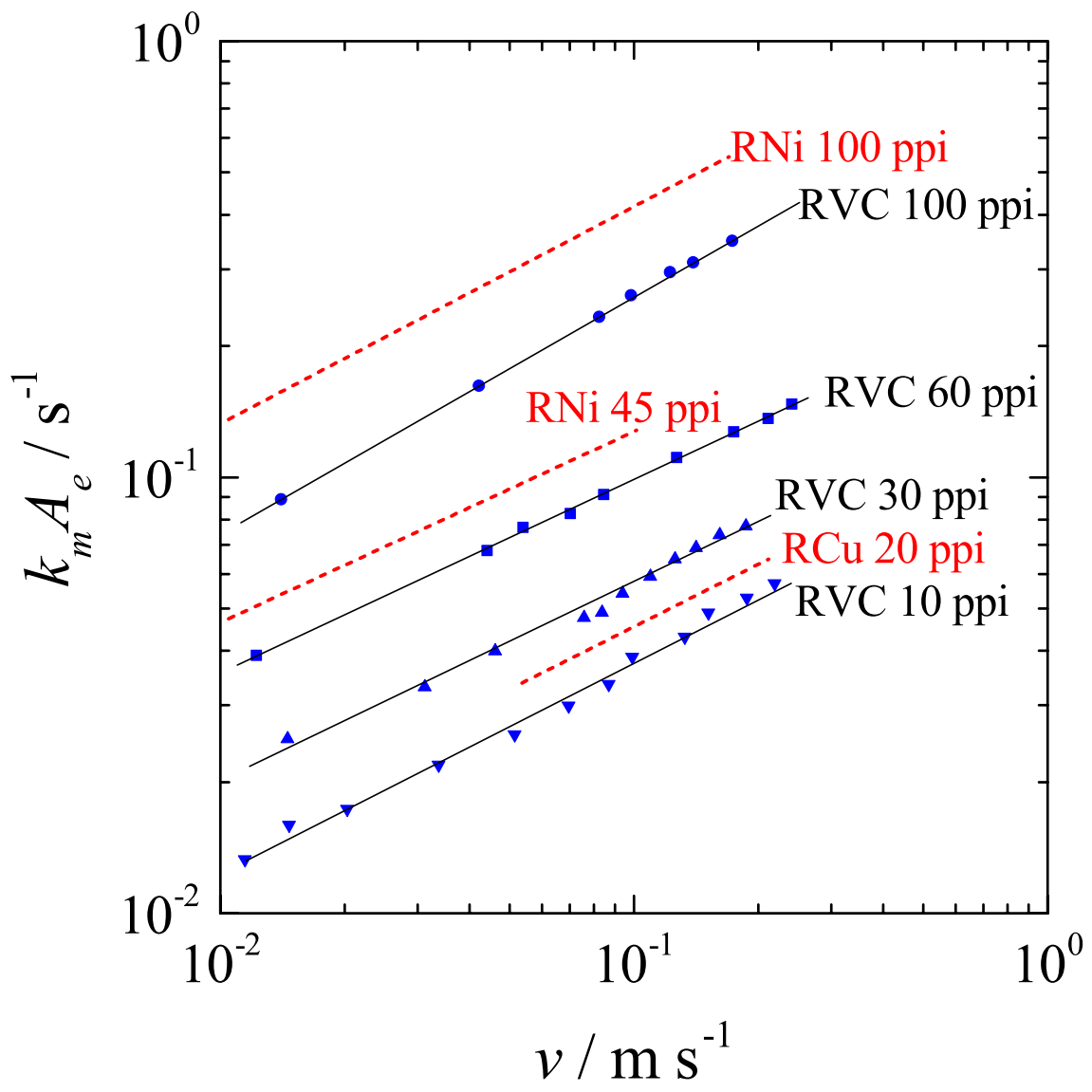

Figure 10b). 


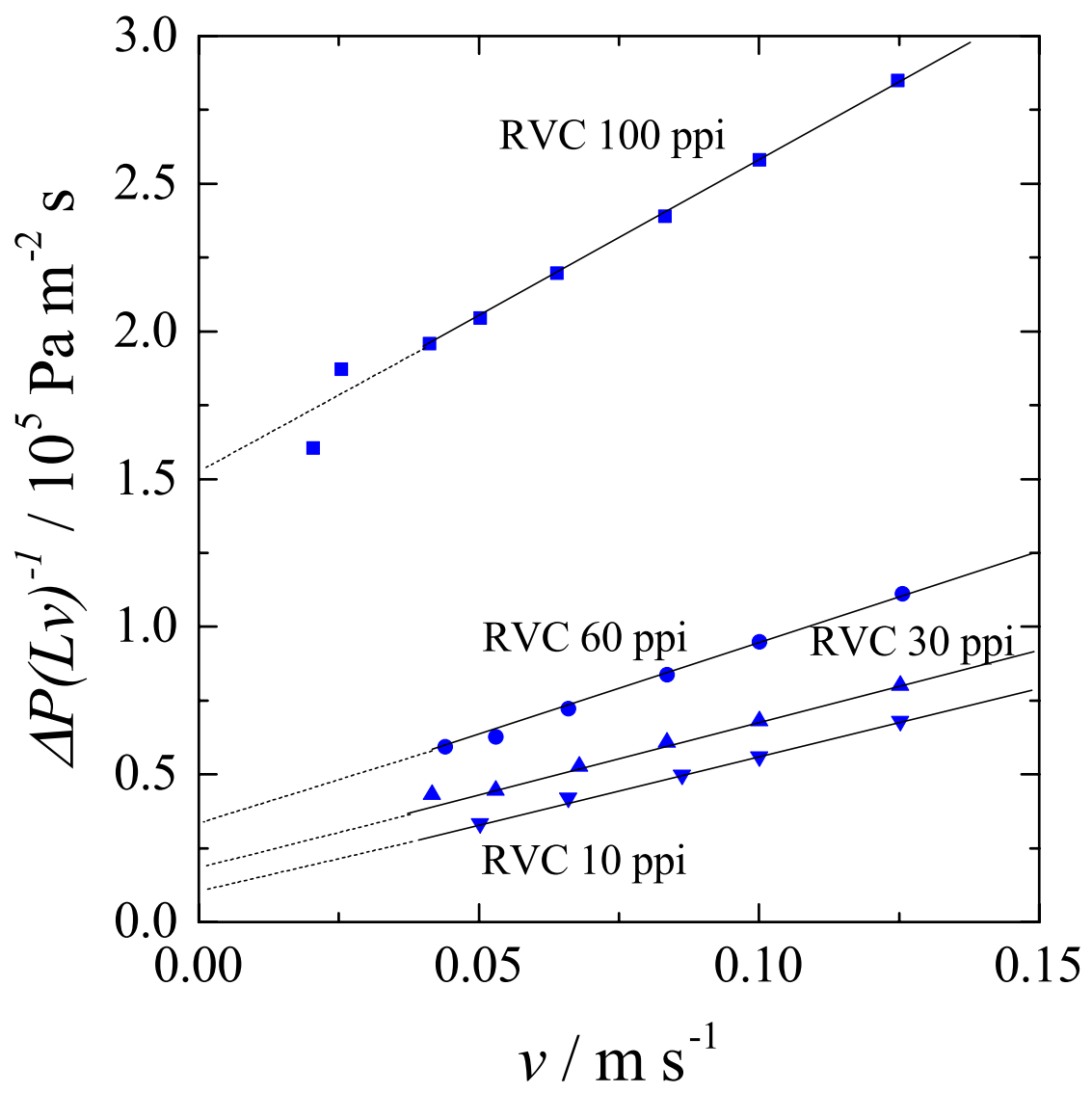

Figure 10c). 


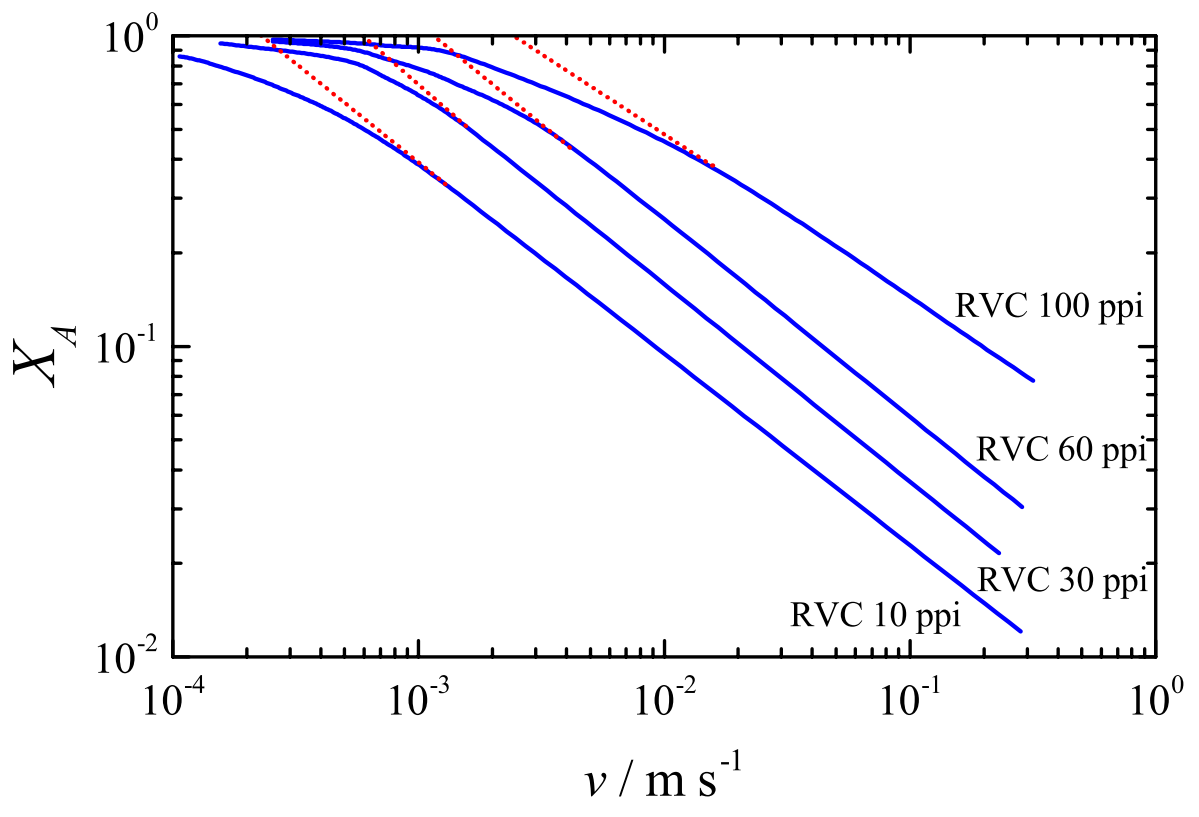

Figure 11. 


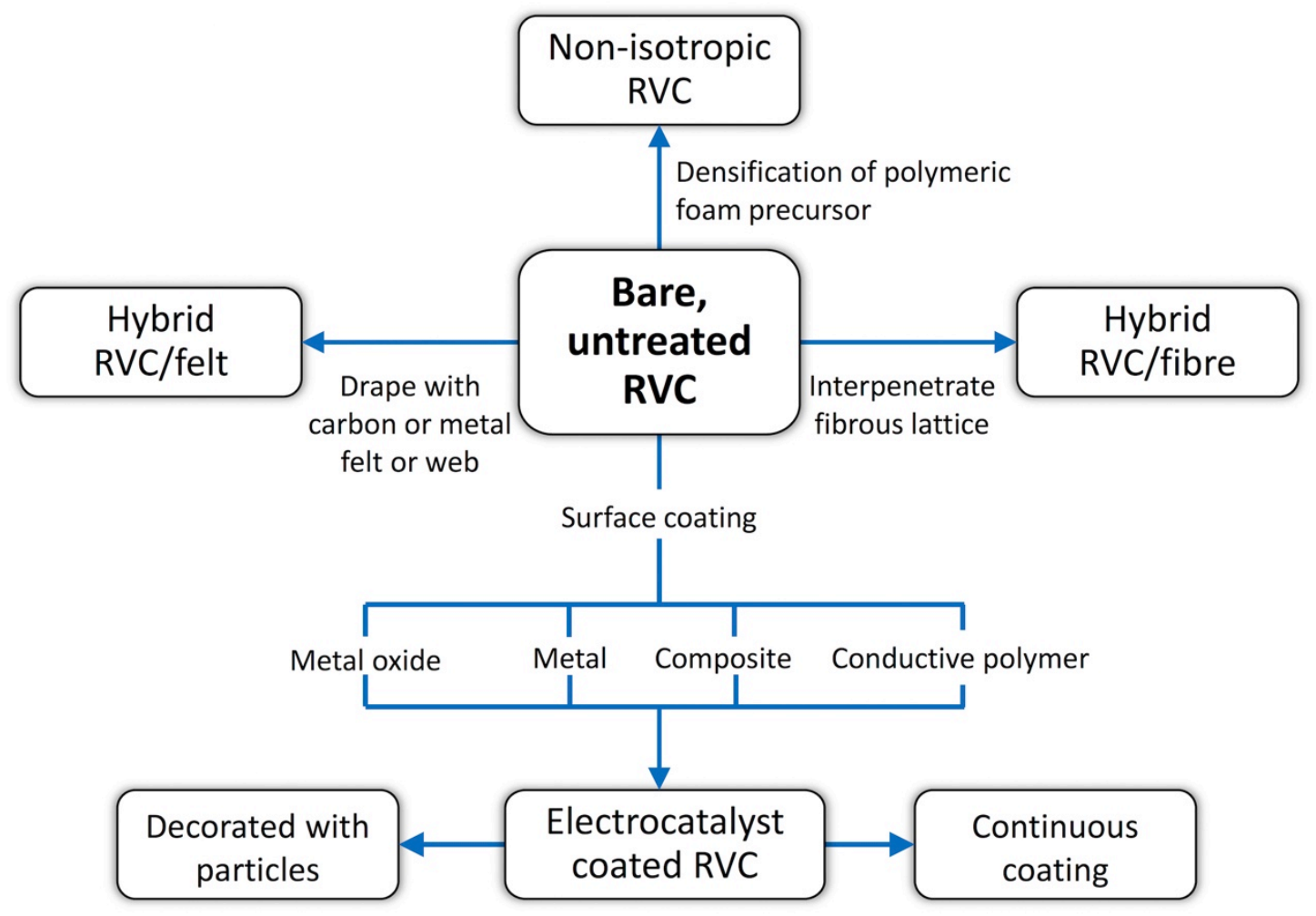

Figure 12. 


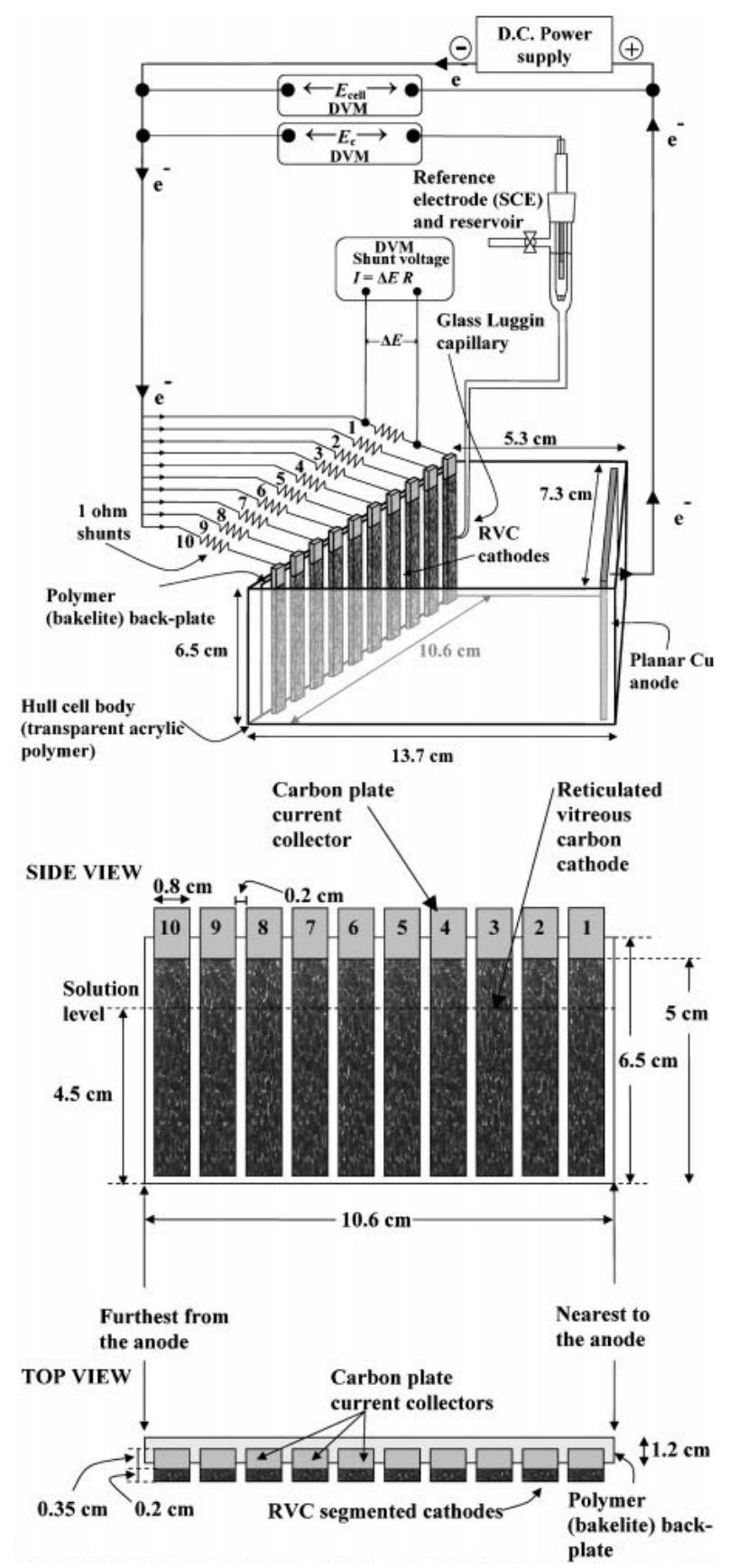

Figure 13. 


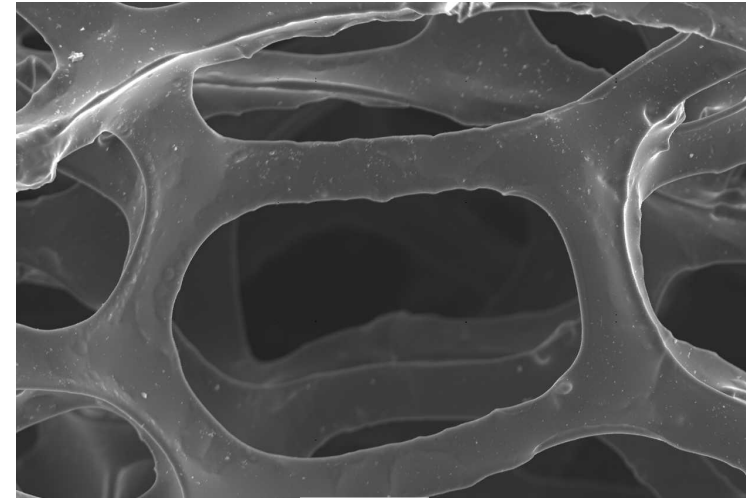

(a)

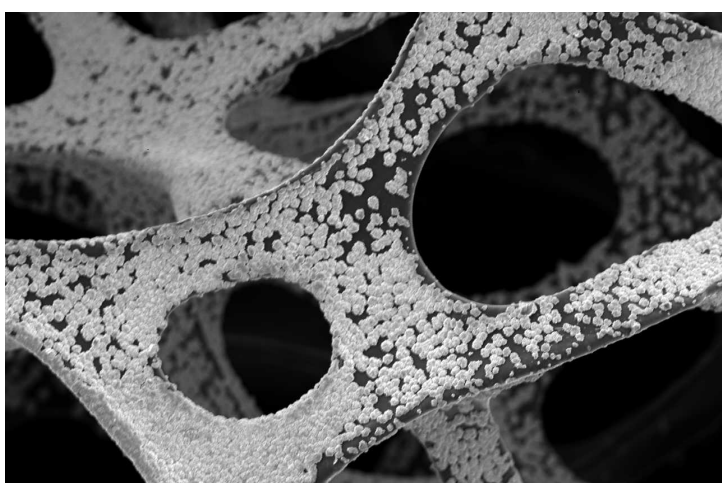

(b)
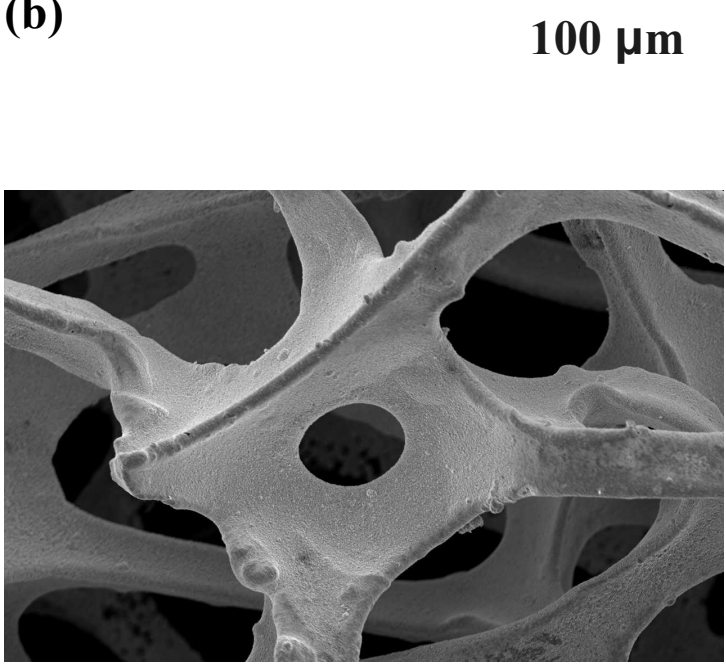

(c)

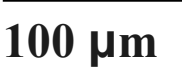

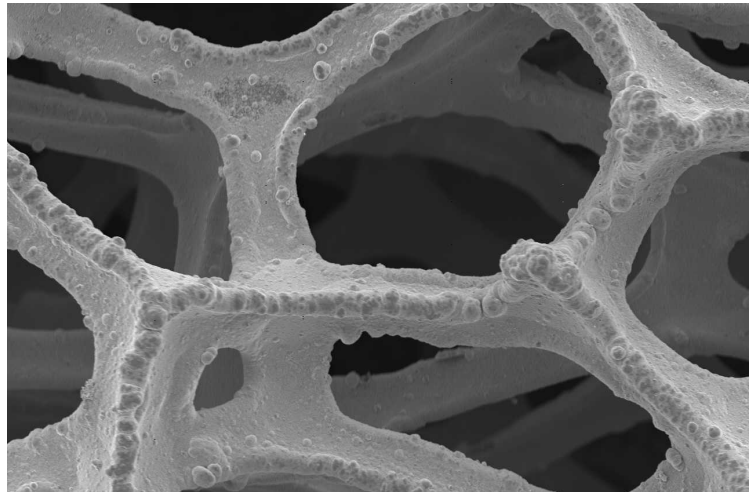

(d)

$100 \mu \mathrm{m}$

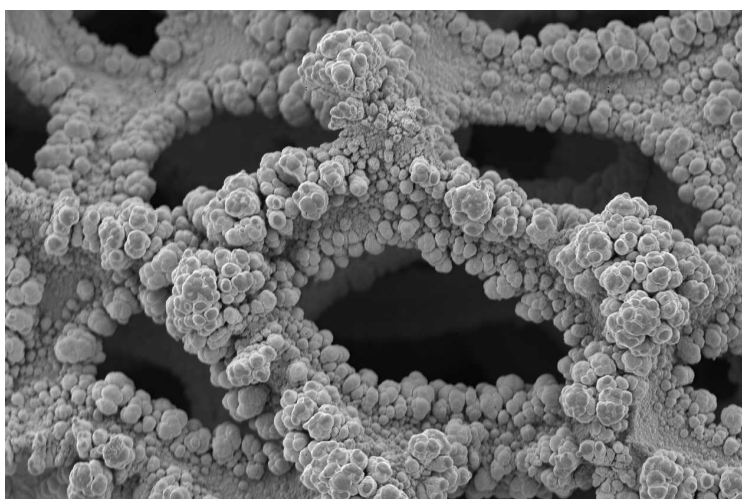

(e)

$$
100 \mu \mathrm{m}
$$

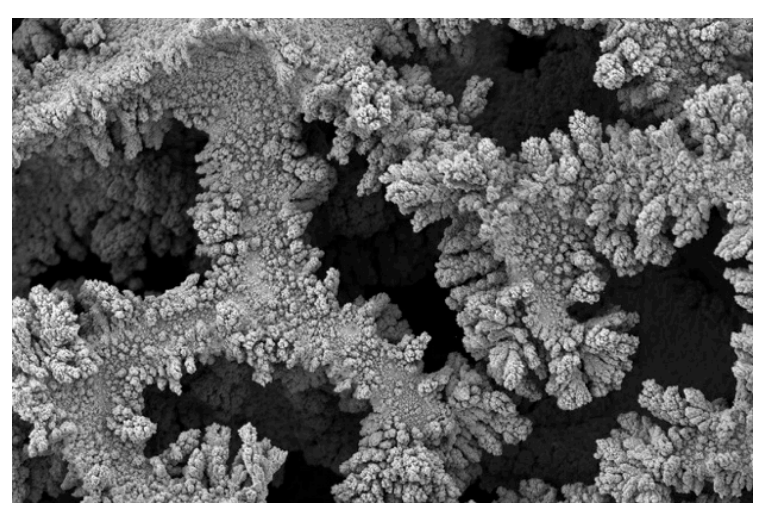

(f)

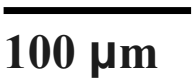

Figure 14. 

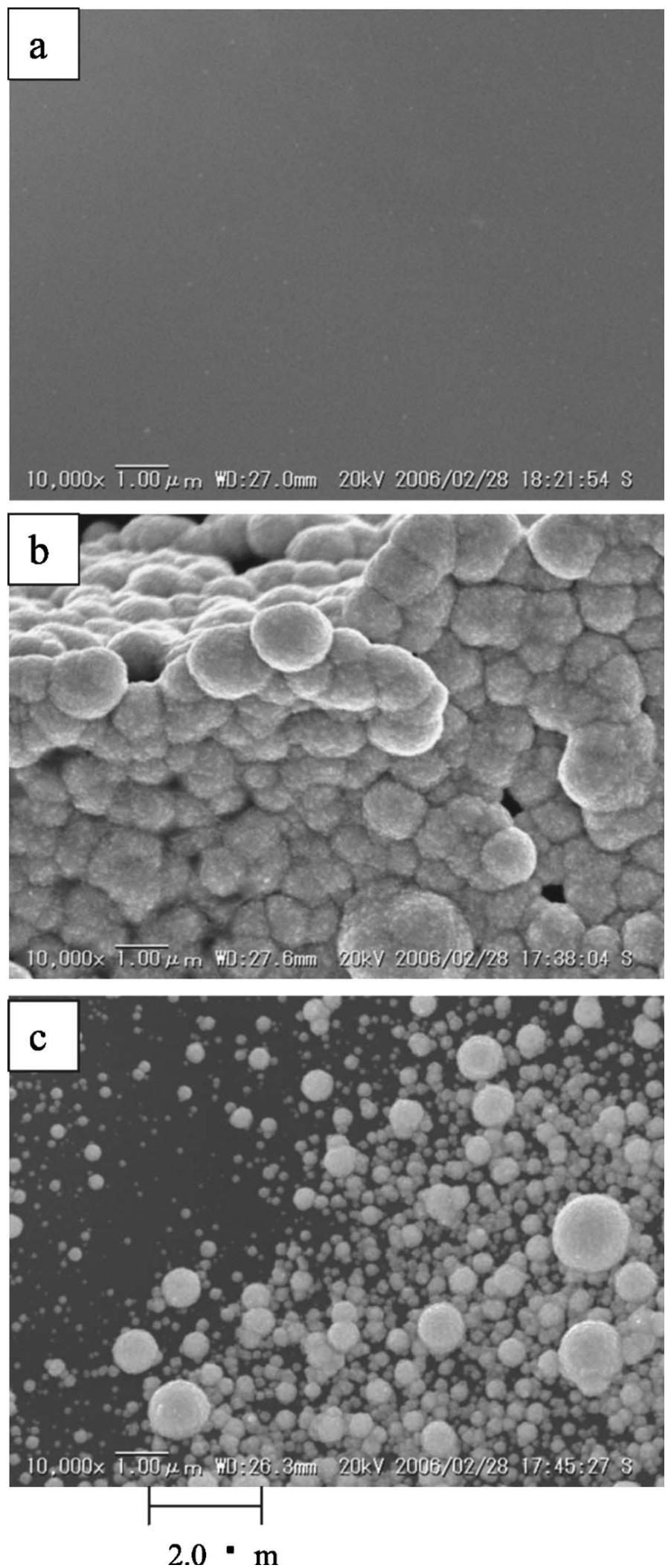

Figure 15. 


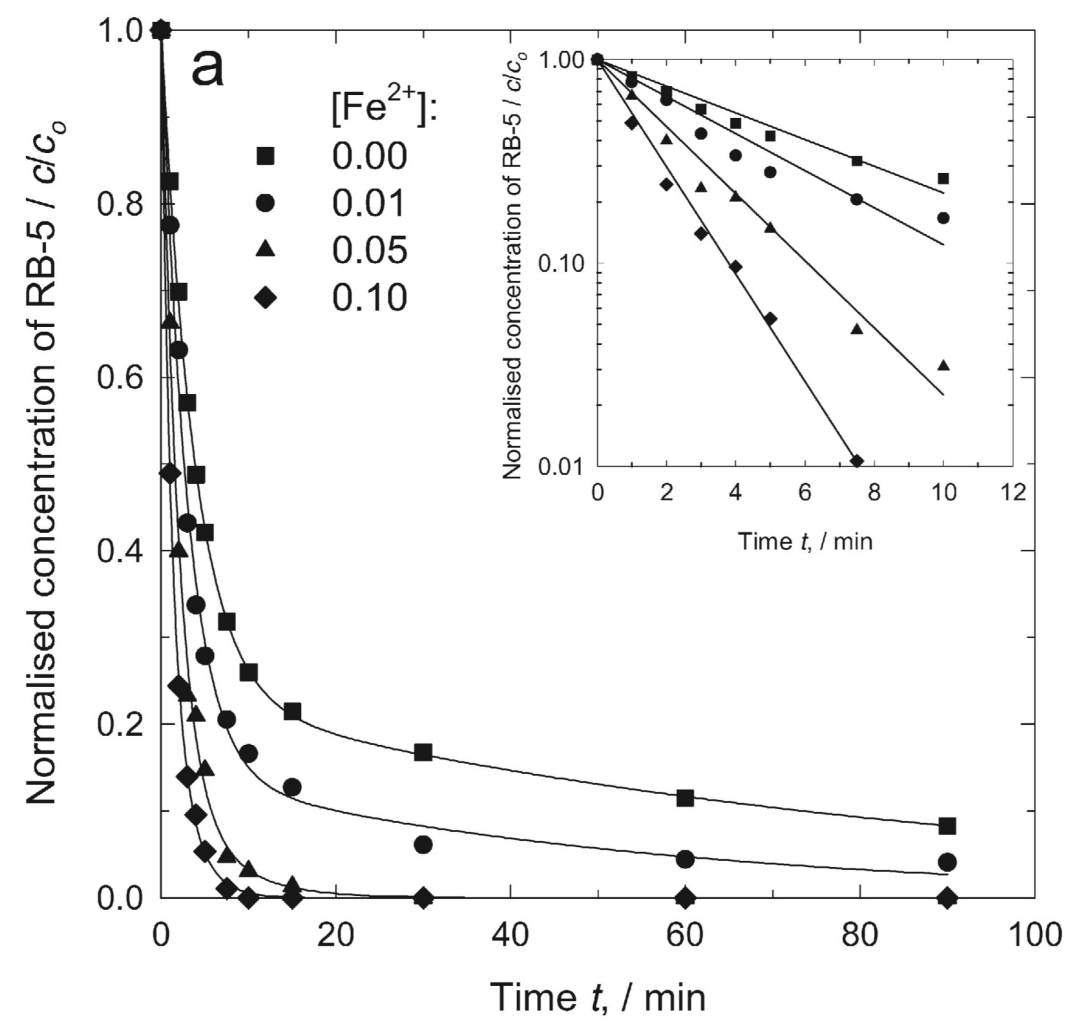

Figure 16. 

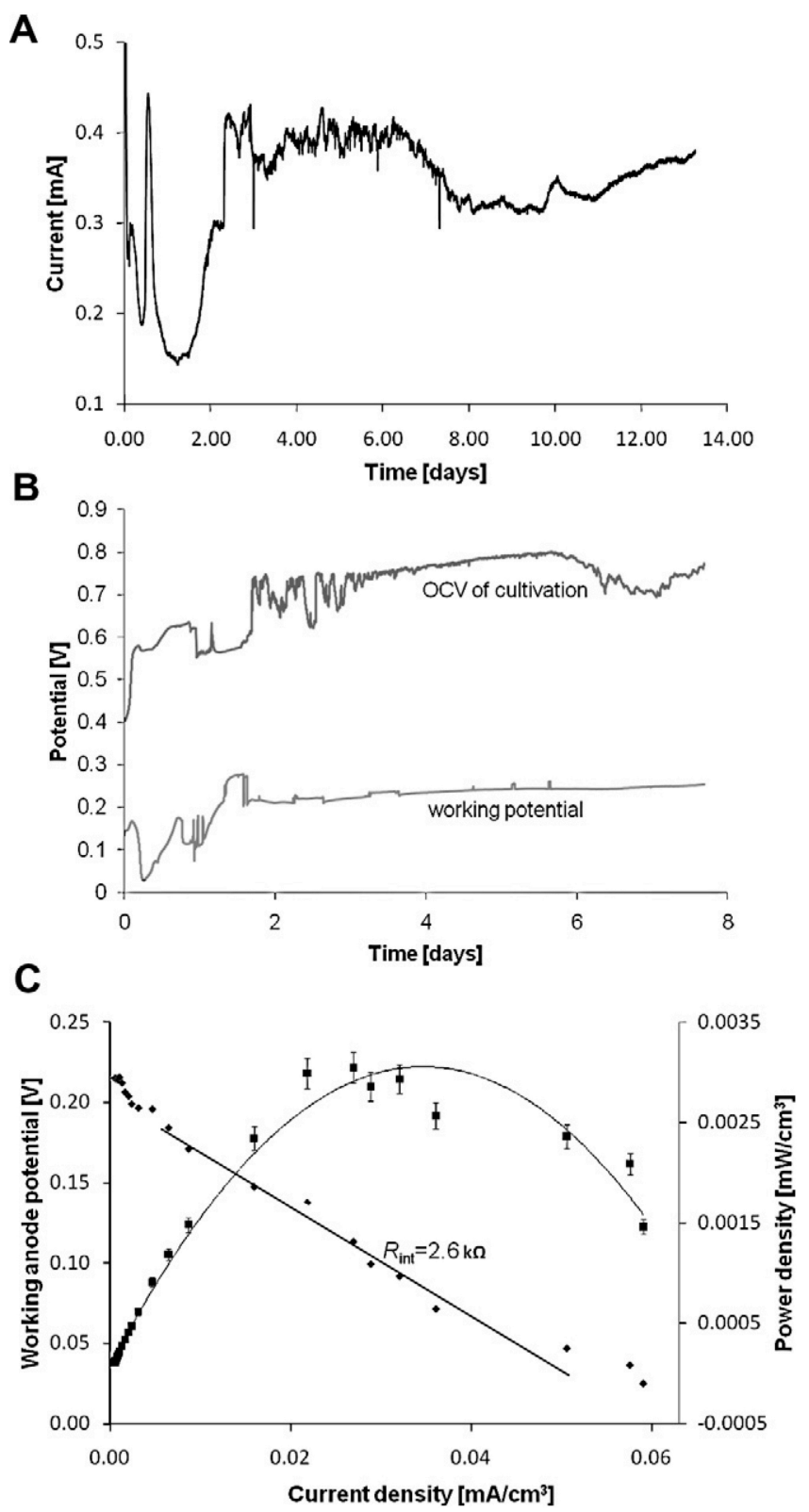

Figure 17. 


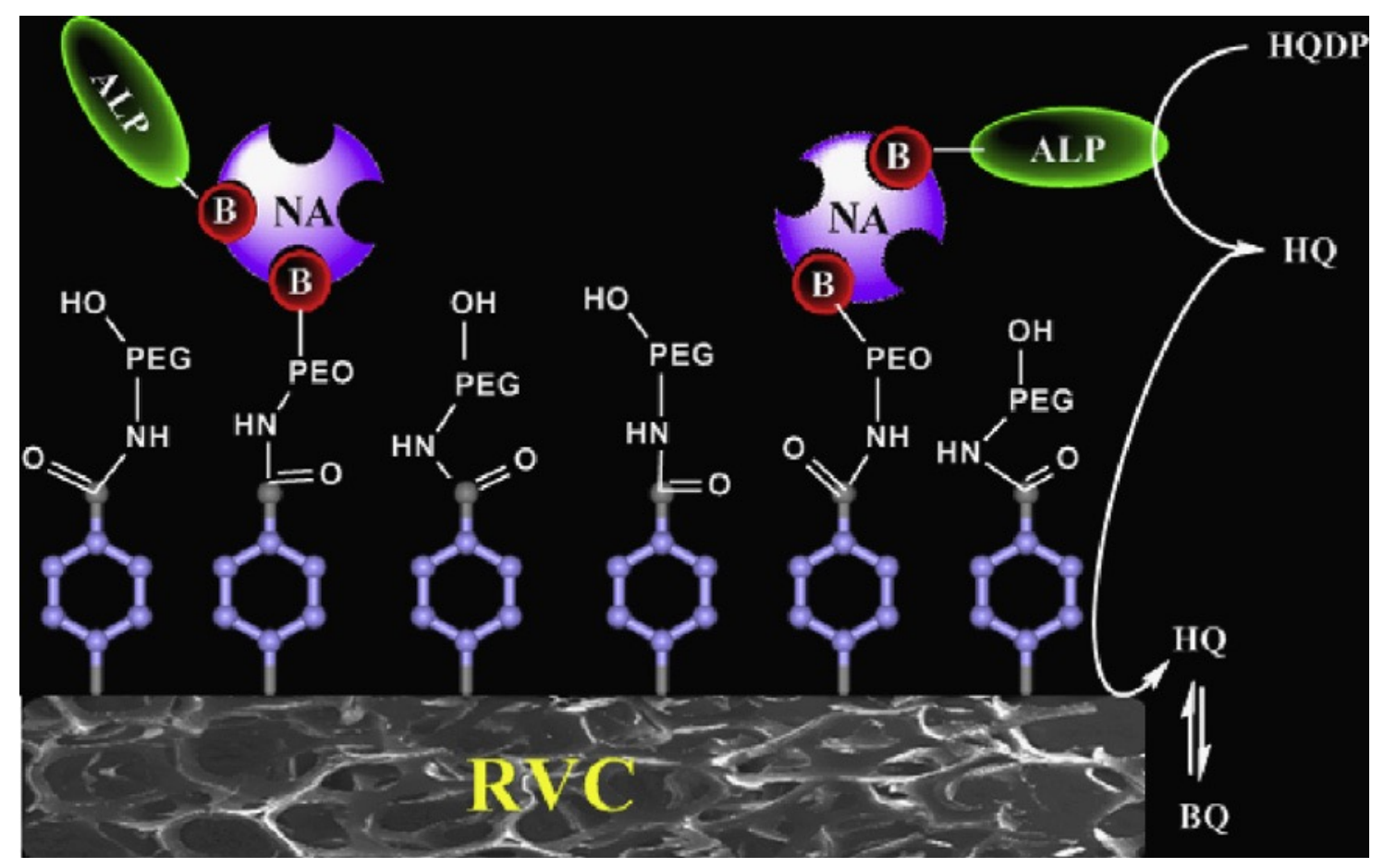

Figure 18. 

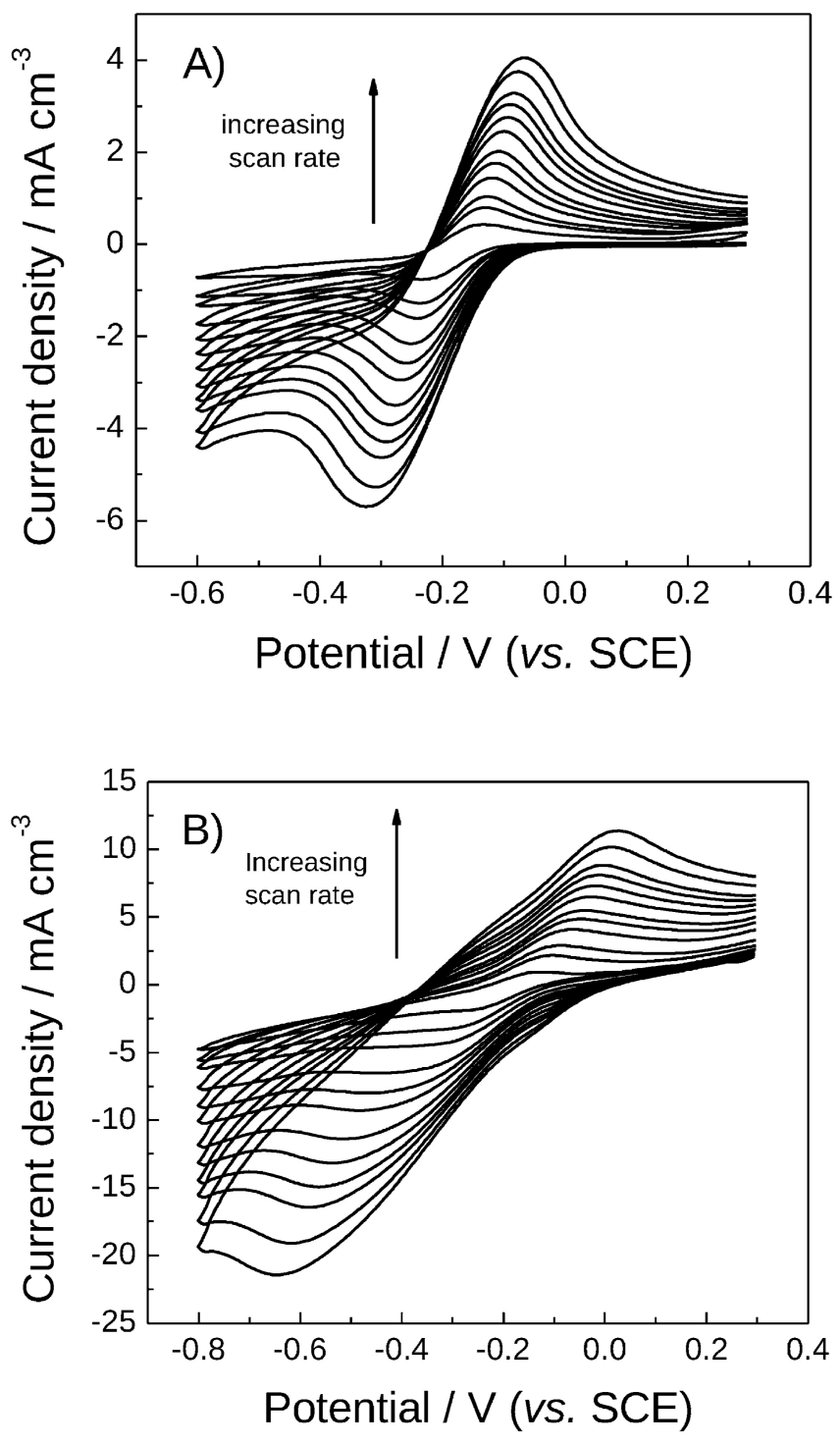

Figure 19. 


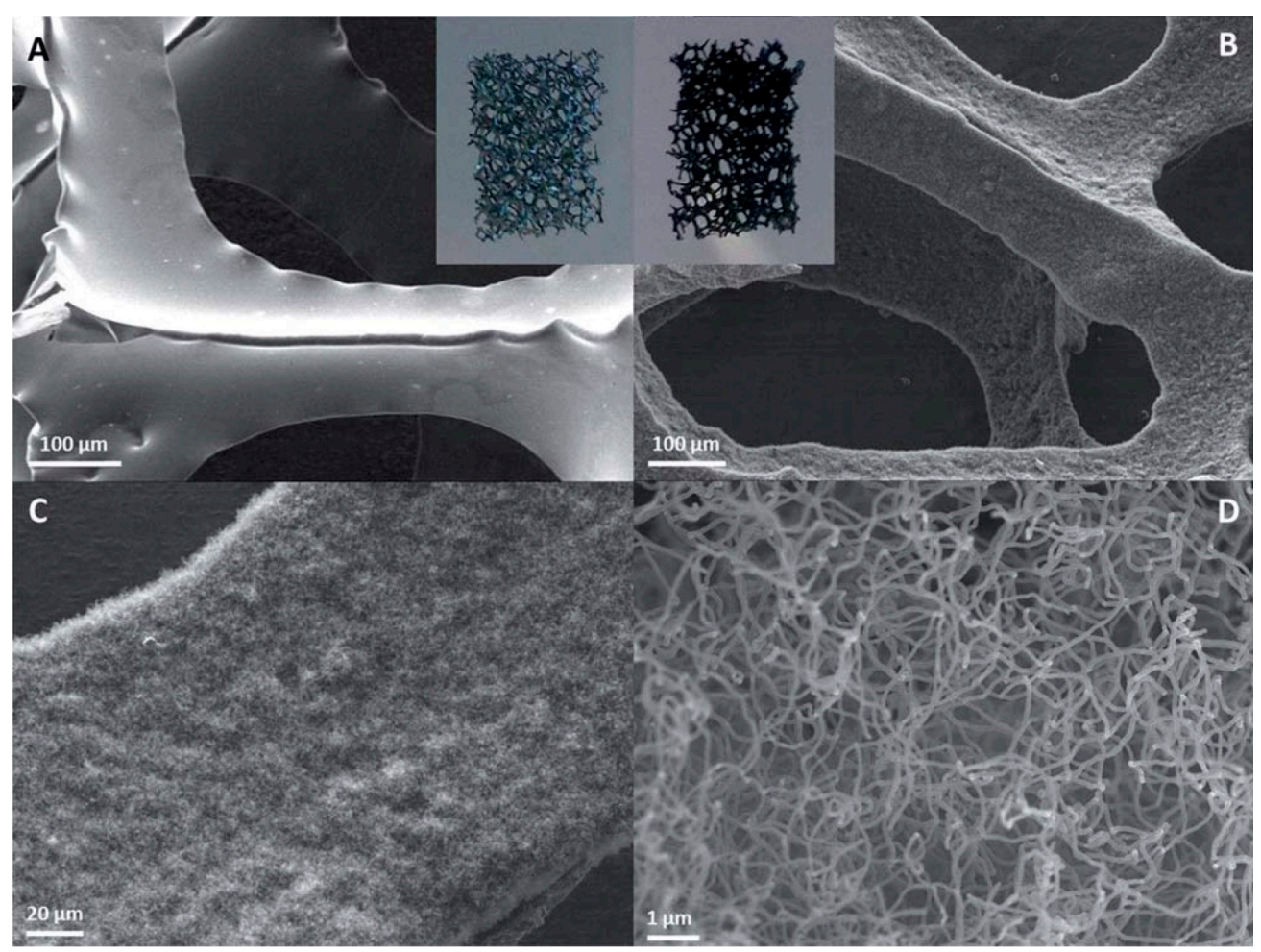

Figure 20. 